Anotação de imagens radiológicas usando a web semântica para colaboração científica e clínica 



\title{
Anotação de imagens radiológicas usando a web semântica para colaboração científica e clínica
}

\author{
Kleberson Junio do Amaral Serique
}

Orientador: Prof. Dr. Dilvan de Abreu Moreira

Dissertação apresentada ao Instituto de Ciências Matemáticas e de Computação - ICMC-USP, como parte dos requisitos para obtenção do título de Mestre em Ciências - Ciências de Computação e Matemática Computacional. VERSÃO REVISADA 
Ficha catalográfica elaborada pela Biblioteca Prof. Achille Bassi e Seção Técnica de Informática, ICMC/USP, com os dados fornecidos pelo(a) autor(a)

Amaral Serique, Kleberson Junio

A485a Anotação de imagens radiológicas usando a web Semântica para colaboração científica e clínica / Kleberson Junio Amaral Serique; orientador Dilvan de Abreu Moreira -- São Carlos, 2012.

$92 \mathrm{p}$.

Dissertação (Mestrado - Programa de Pós-Graduação em Ciências de Computação e Matemática Computacional) -Instituto de Ciências Matemáticas e de Computação, Universidade de São Paulo, 2012.

1. Sistemas Web Interativos. 2. Informática Biomédica. 3. Ontologia. 4. Radiologia. 5. Web Semântica. I. de Abreu Moreira, Dilvan, orient. II. Título. 
Dedico este trabalho

aos meus pais, pelo seus exemplos e dedicação. 



\section{Agradecimentos}

Agradeço aos meus pais, pois sem os ensinamentos e exemplos que me deram durante minha criação eu não poderia chegar a lugar algum. O apoio e motivação que meus pais me deram eu não poderia ter terminado e nem sequer começado este trabalho, Dirce Maria do Amaral Serique e Carlos de Almeida Serique sou eternamente grato por tudo e amo muito vocês. Agradeço também a minha irmã, Karla Katriny do Amaral Serique, por me ajudar nos momentos difíceis e poder sempre contar com ela. Aos todos os demais familiares pelo apoio e forças que me deram durante minha caminhada.

Dedico um agradecimento especial ao Dr. José Laurindo Campos dos Santos que me deu a oportunidade de melhorar meus estudos, a cada conselho e motivação que me deu eu não teria conseguido chegar onde estou, serei eternamente grato por tudo. Deixo também um agradecimento ao meu orientador Prof. Dr. Dilvan de Abreu Moreira, pelo trabalho de orientação deste mestrado e obrigado pela o oportunidade de trabalhar em sua equipe e de todas as dicas e ensinamentos que me passou durante esses anos aqui no ICMC, serão de muita valia para minha careira e para minha vida. Agradeço ao Prof. Dr. Daniel L. Rubin pelo apoio no desenvolvimento deste trabalho e oportunidade de participar nos projetos desenvolvidos na Stanford University, sem esta oportunidade não poderia concluir este trabalho.

Aos todos meus amigos do INPA e ICMC, especialmente ao João Paulo Orlando que me ajudou no desenvolvimento deste mestrado. Um agradecimento em especial ao casal de amigos, Lucas Portilho Camargos Gomes e Cintia Blaskovsky, pela força e incentivo que me deram durante o mestrado.

Agradeço também a Coordenação de Aperfeiçoamento de Pessoal de Nível Superior (CAPES) pelo apoio financeiro, ao Instituto de Ciências Matemáticas e de Computação e à Universidade de São Paulo pela estrutura disponibilizada para realização deste projeto. 

"A menos que modifiquemos a nossa maneira de pensar, não seremos capazes de resolver os problemas causados pela forma como nos acostumamos a ver o mundo"

(Albert Einstein) 



\section{Resumo}

Este trabalho faz parte de um projeto maior, o Annotation and Image Markup Project, que tem o objetivo de criar uma base de conhecimento médico sobre imagens radiológicas para identificação, acompanhamento e reasoning acerca de lesões tumorais em pesquisas sobre câncer e consultórios médicos. Esse projeto está sendo desenvolvido em conjunto com o Radiological Sciences Laboratory da Stanford University. O problema específico, que será abordado nesse trabalho, é que a maior parte das informações semânticas sobre imagens radiológicas não são capturados e relacionados às mesmas usando termos de ontologias biomédicas e padrões, como o RadLex e DICOM, o que impossibilita a sua avaliação automática por computadores, busca em arquivos médicos em hospitais, etc. Para tratar isso, os radiologistas precisam de uma solução computacional fácil, intuitiva e acessível para adicionar essas informações. Nesse trabalho foi desenvolvida uma solução Web para inclusão dessas anotações, o sistema ePAD. O aplicativo permite a recuperação de imagens médicas, como as imagens disponíveis em sistemas de informação hospitalares (PACS), o delineamento dos contornos de lesões tumorais, a associação de termos ontológicos a esses contornos e o armazenamento desses termos em uma base de conhecimento. Os principais desafios desse trabalho envolveram a aplicação de interfaces intuitivas baseadas em Rich Internet Applications e sua operação a partir de um navegador Web padrão. O primeiro protótipo funcional do ePAD atingiu seus objetivos ao demonstrar sua viabilidade técnica, sendo capaz de executar o mesmo trabalho básico de anotação de aplicações Desktop, como o OsiriX-iPad, sem o mesmo overhead. Também mostrou a sua utilidade a comunidade médica o que gerou o interesse de usuários potenciais.

Palavras-chaves: Sistemas Web Interativos; Informática Biomédica; Ontologia; Radiologia; Web Semântica. 



\section{Abstract}

This work is a part of a larger project, the Annotation and Markup Project, which aims to create a medical knowledge base about radiological images to identify, monitor and reason about tumors in cancer research and medical practices. This project is being developed in conjunction with the Laboratory of Image Informatics at Stanford University. The specific problem that will be addressed in this work is that most of the semantic information about radiological images are not captured and related to them using terms of biomedical ontologies and standards, such as RadLex or DICOM, what makes it impossible to automatic evaluate them by computers, to search for them in hospital databases using semantic criteria, etc. To address this issue, radiologists need an easy, intuitive and affordable computational solution to add this semantic information. In this work, a web solution for adding the information was developed, the ePAD system. It allows the retrieval of medical images, such as images available in hospital information systems (PACS), the creation of contours around tumor lesions, the association of ontological terms to these contours, and the storage of this terms in a knowledge base. The main challenges of this work involved the creation of intuitive interfaces using Rich Internet Applications technology and the operation from a standard Web Browser. The first functional prototype of ePAD reached its goal of proving its technical feasibility. It was able to do the same basic annotation job of desktop applications, such as OsiriX-iPad, without the same overhead. It also showed to the medical community that it was a useful tool and that generated interest of potential early users.

Keywords: Interactive Web Applications; Biomedical Informatics; Ontology; Radiology; Semantic Web; HTML5. 



\section{Lista de Figuras}

Figura 1 - Fluxos de dados e os principais componentes de um PACS (Bui e Morioka, 2010) 32

Figura 2 - Hierarquia de objetos do padrão DICOM (Bui e Morioka, 2010) ...........................35

Figura 3 - Arquitetura "Bolo de Noiva" da Web Semântica (Pollock, 2009)......................... 39

Figura 4 - Representação da Tripla RDF - Fonte: W3C. .................................................... 40

Figura 5 - Conjunto de triplas RDF e seu diagrama representativo....................................... 41

Figura 6 - Anotação Semântica e marcação de imagem no AIM ClearCanvas....................... 51

Figura 7 - Arquitetura com os componentes do OsiriX (Rosset et al., 2006). ........................52

Figura 8 - Anotação semântica marcada com o AIM iPAD ................................................... 54

Figura 9 - Arquitetura de funcionamento do BIMM (Korenblum et al., 2010)......................55

Figura 10 - Web 2.0, camadas de tecnologias (Shah, 2008) ................................................5

Figura 11 - Uma visão geral da abordagem do GWT (Cooper e Collins, 2008) .....................58

Figura 12 - O padrão de projeto MVC, surgido na década de 80 (Kereki, 2011)...................59

Figura 13 - O padrão de projeto MVP, com menor nível de acoplamento (Kereki, 2011) .....60

Figura 14 - Tela de visualização de imagens DICOM do protótipo........................................ 66

Figura 15 - Tela com pop-up de criação de anotação do protótipo. ........................................ 68

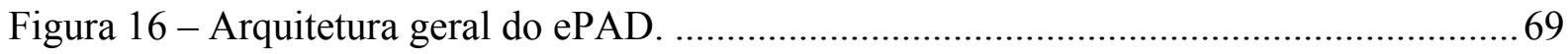

Figura 17 - Arquitetura do servidor Proxy Server do ePAD. ............................................. 70

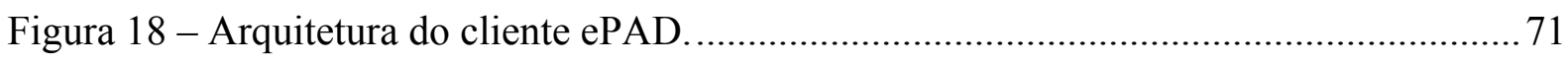

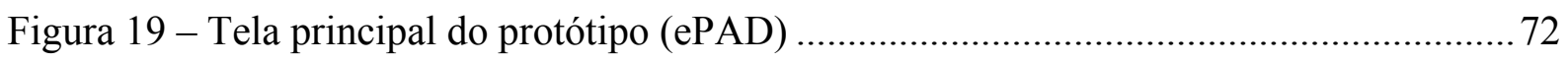

Figura 20 - Barra superior de menu e pesquisa .............................................................. 72

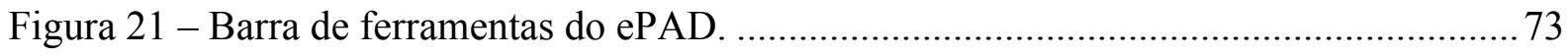

Figura 22 - Tela com Widget de resultado de busca do ePAD ............................................... 74

Figura 23 - Tela com o Widget de visualização de imagem do ePAD .................................. 75

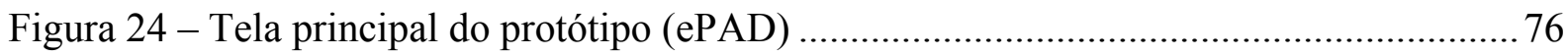




\section{Lista de Tabelas}

Tabela 1 - Partes do padrão DICOM 3.1 (Parte 9 e 13 foram retiradas) ................................. 35

Tabela 2 - Ferramentas AIM disponíveis no AIM ClearCanvas Workstation ........................ 50

Tabela 3 - Lista de funcionalidades da barra de ferramentas ............................................... 73 



\section{Lista de Siglas e Abreviaturas}

\begin{tabular}{|c|c|}
\hline ACR & American College of Radiology \\
\hline ACR-NEMA & American College of Radiology - National Electrical Manufacturers Association \\
\hline ACRIN & American College of Radiology Image Network \\
\hline AIM & Annotation and Image Markup \\
\hline Ajax & Asynchronous JavaScript And XML \\
\hline API & Application Programming Interface \\
\hline BIMM & Biomedical Image Metadata Manager \\
\hline caBIG & cancer Biomedical Informatics Grid \\
\hline Chebi & Chemical Entities of Biological Interest \\
\hline $\mathrm{CR}$ & Radiografia Computadorizada \\
\hline CT & Computed Tomography \\
\hline DICOM & Digital Imaging and Communication in Medicine \\
\hline DICOM SR & DICOM Structured Reporting \\
\hline DICOM UID & DICOM Unique IDentifiers \\
\hline EMR & Electronic Medical Record \\
\hline ER & Entidade Relacionamento \\
\hline EUA & United States of America \\
\hline FMA & Foundational Model of Anatomy \\
\hline GIF & Graphics Interchange Format \\
\hline GO & Gene Ontology \\
\hline GWT & Google Web Toolkit \\
\hline $\mathrm{HCI}$ & Human Computer Interaction \\
\hline HIS & Hospital Information System \\
\hline HL7 CDA & Health Level Seven CDA \\
\hline HTML 5 & HyperText Markup Language 5 \\
\hline HTTP & Hypertext Transfer Protocol \\
\hline IOM & Institute Of Medicine \\
\hline ISO & International Standardization Organization \\
\hline ITK & The Insight Segmentation and Registration Toolkit \\
\hline JPEG & Joint Photographic Experts Group \\
\hline JRE & The Java Runtime Environment \\
\hline LII & Lab. of Imaging Informatics \\
\hline LIS & Laboratory Information System \\
\hline MIR & Magnetic Resonance Imaging \\
\hline MPEG & Moving Picture Experts Group \\
\hline MVC & Model-view-controller \\
\hline MVP & Model-view-presenter \\
\hline NAS & Network-Attached Storage \\
\hline
\end{tabular}




\begin{tabular}{|l|l|}
\hline NCBO & National Center for Biomedical Ontology \\
\hline NCI & National Cancer Institute \\
\hline OBO & Open Biomedical Ontologies \\
\hline PACS & Web Ontology Language \\
\hline PATO & Picture Archiving and Communication System \\
\hline PET & Phenotypic Quality Ontology \\
\hline PRO & Tomografia por emissão de Pósitrons \\
\hline RDF & Protein Ontology \\
\hline RECIST & Resource Description Framework \\
\hline RIA & Response Evaluation Criteria in Solid Tumors \\
\hline RIS & Rich Internet Applications \\
\hline RM & Radiology Information System \\
\hline ROI & Ressonância Magnética \\
\hline RSNA & Regiões de Interesse \\
\hline SAN & Radiological Society of North America \\
\hline TI & Storage Area Network \\
\hline TIFF & Tecnologia da Informação \\
\hline UML & Tagged Image File Format \\
\hline URI & Unified Modeling Language \\
\hline VTK & Uniform Resource Identifier \\
\hline W3C & The Visualization Toolkit \\
\hline WADO & World Wide Web Consortium \\
\hline WWW & Web Access to DICOM Persistent Objects \\
\hline XAO & Word Wide Web \\
\hline XML & Xenopus Anatomy Ontology \\
\hline ZFA & ZXtensible Markup Language \\
\hline
\end{tabular}





\section{Sumário}

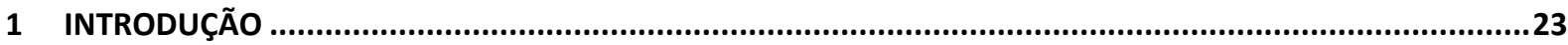

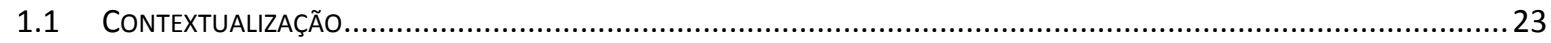

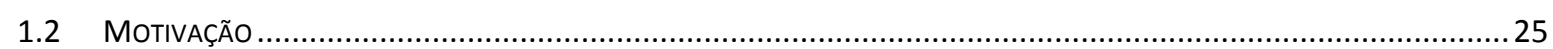

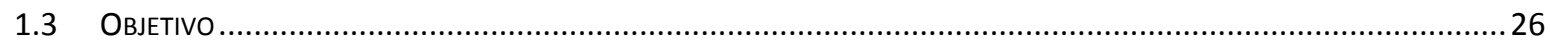

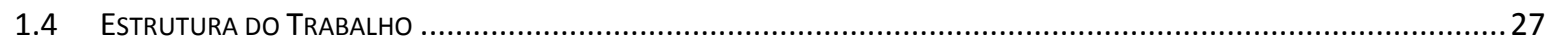

2 INFORMÁTICA BIOMÉDICA .............................................................................................................29

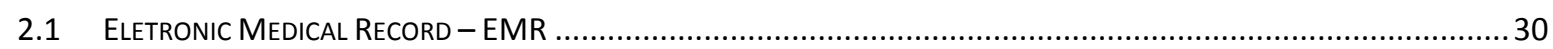

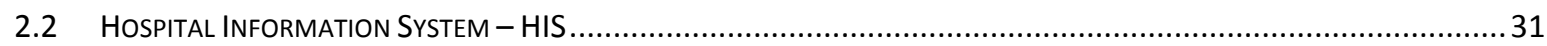

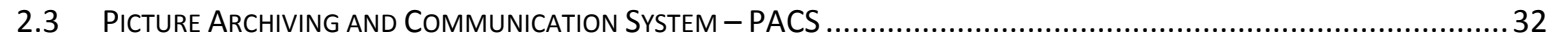

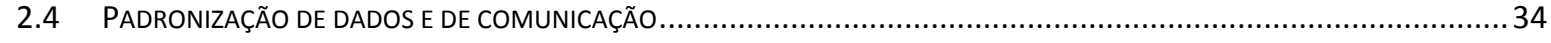

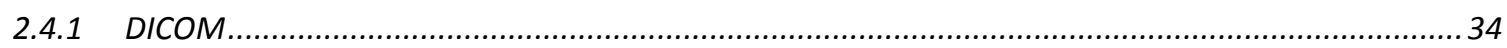

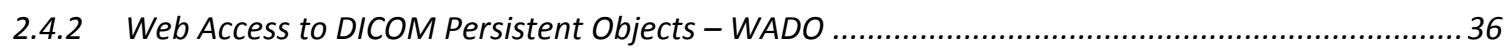

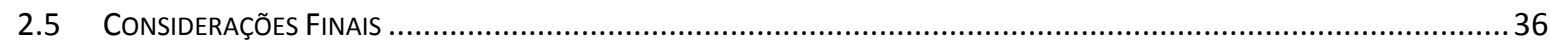

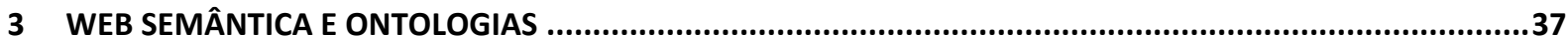

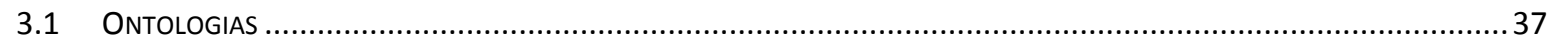

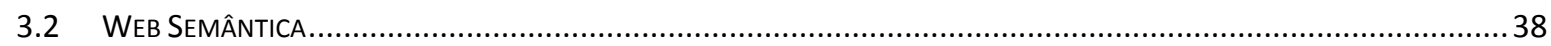

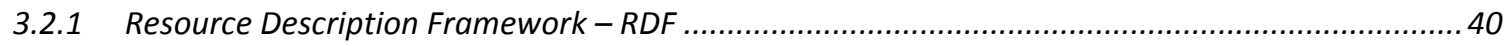

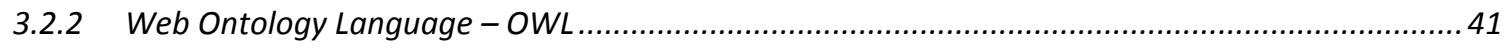

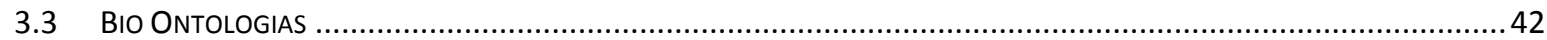

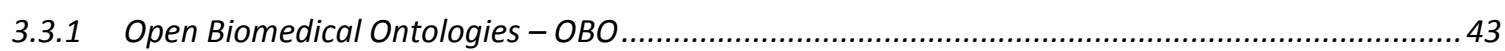

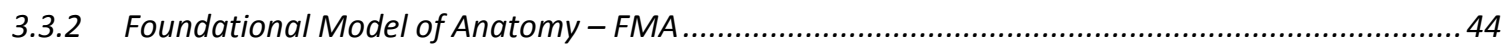

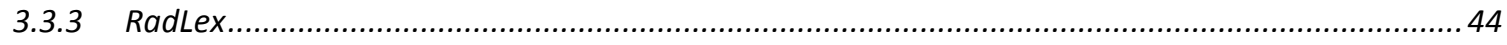

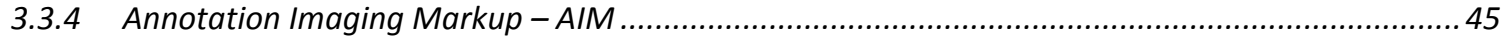

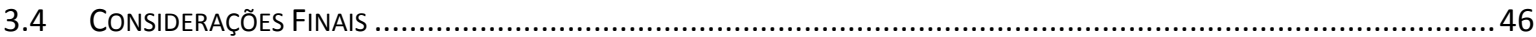

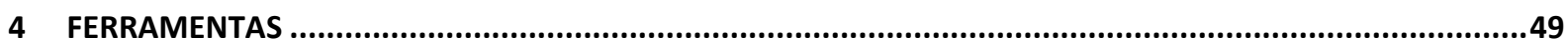

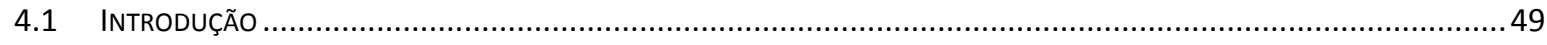

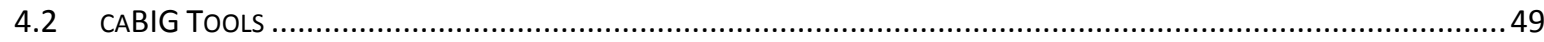

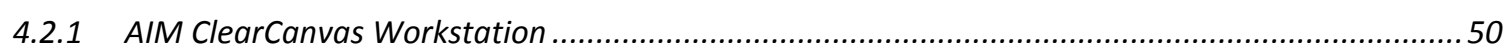

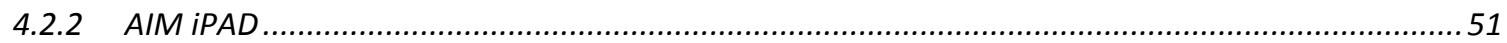

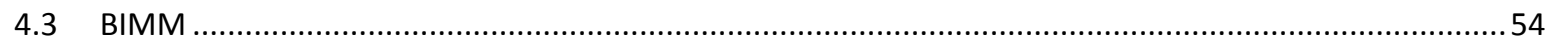




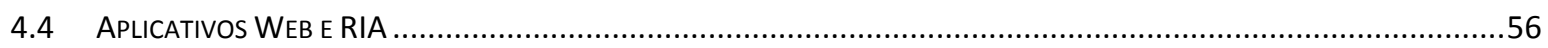

4.4.1 GWT

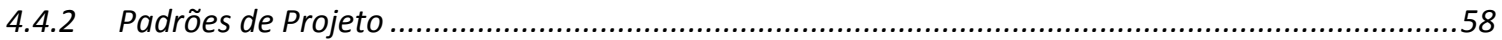

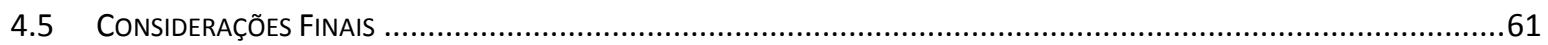

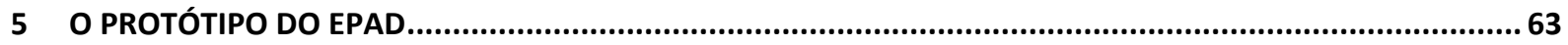

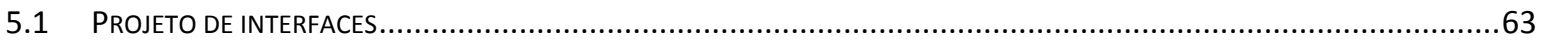

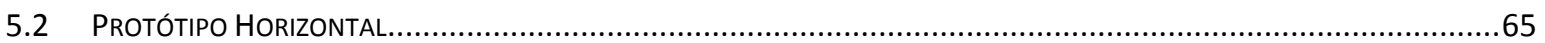

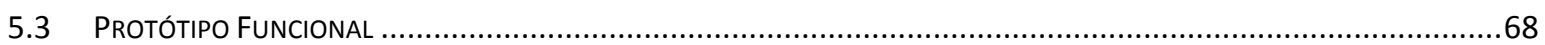

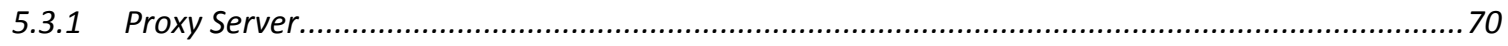

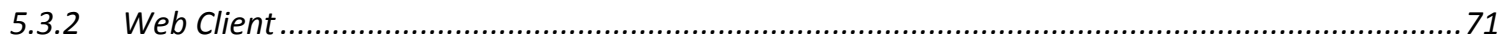

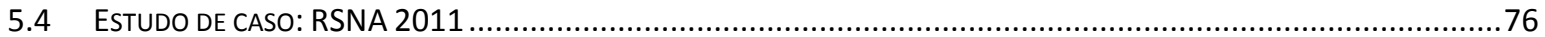

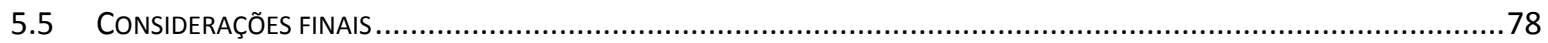

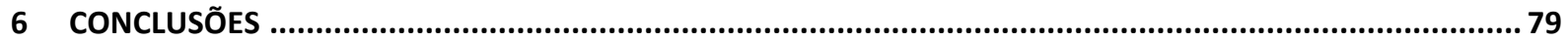

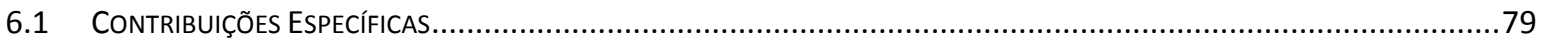

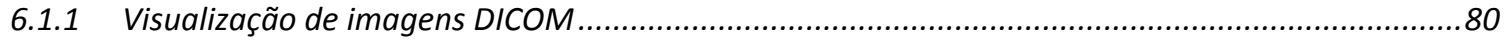

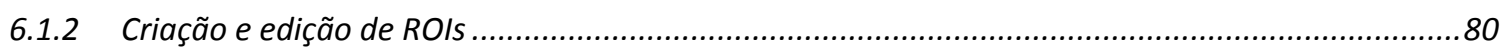

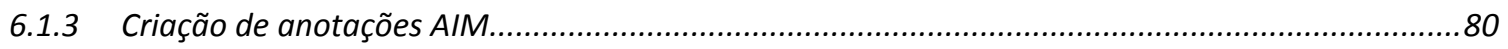

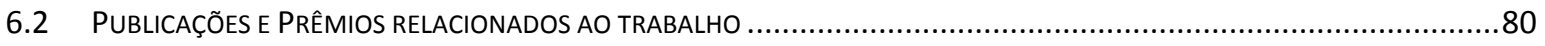

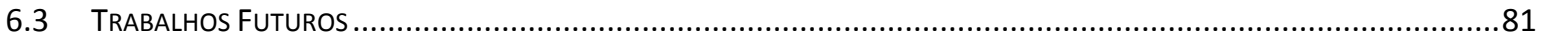

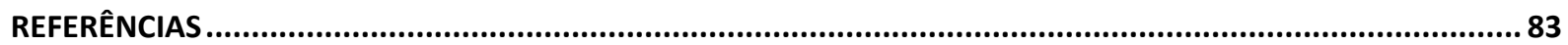

APÊNDICE A - QUESTIONÁRIO APLICADO COM USUÁRIOS ..............................................................89

APÊNDICE B - RESULTADOS DO QUESTIONÁRIO APLICADO COM USUÁRIOS ..........................................90 


\section{Introdução}

Imagens medicas digitais contêm uma grande riqueza de informações (em áreas como anatomia e patologia) que muitas vezes não são explicitadas e computacionalmente acessíveis. Imagens radiológicas são consideradas como um tipo de dado crítico em biomedicina, pois fornecem ricas informações visuais sobre doenças, como o câncer. Enquanto apenas a imagem radiológica pode ser útil, algumas aplicações necessitam realizar o processamento das informações contidas nessas imagens, porém, boa parte dos conteúdos semânticos críticos dessas imagens não estão explicitados e não podem ser compreendidos por computadores, o que dificulta a descoberta de novos conjuntos de dados em grandes volumes de imagens digitais.

De modo geral, um usuário de um sistema de informação médico requer um acesso rápido e confiável a relatórios e imagens médicas. Aplicativos visualizadores de imagens no formato DICOM (Digital Imaging and Communication in Medicine), que anteriormente eram encontrados apenas nos departamentos de radiologia e com alto custo, agora estão começando a estar disponíveis como Aplicativos Web e a ficar mais integrados aos serviços de registros eletrônicos de pacientes. Com esses avanços é possível que vários usuários possam visualizar, debater e coordenar estudos colaborativamente através da Web em clinical trails, ou ensaios médicos. Clinical trials são conjuntos de testes em pesquisa médica e desenvolvimento de drogas que geram dados sobre segurança e eficácia de drogas, dispositivos médicos, terapias ou outras intervenções em saúde.

\subsection{Contextualização}

Apesar da Informática Biomédica ter realizado grandes avanços nos estudos e compreensão das imagens médicas nas últimas décadas, lacunas ainda podem ser encontradas, por exemplo, no workflow de trabalho entre os radiologistas e oncologistas.

Em clinical trials, os oncologistas solicitam exames de imagens médicas para avaliar lesões tumorais e também para o acompanhamento e avaliação da evolução do tratamento nos pacientes. Já os radiologistas criam relatórios reportando os seus achados nas imagens médicas,. Essas imagens (geralmente no padrão DICOM) são adquiridas de acordo com a modalidade solicitada pelo oncologista, por exemplo Tomografia Computadorizada, 
Ressonância Magnética, Radiografia, Ultrassonografia, etc. O fluxo deste workflow segue os seguintes passos principais:

- Os oncologistas criam requisições de exames radiológicos, em papel ou eletronicamente, onde informam a indicação do tempo, a modalidade e a parte do corpo a ser avaliada pelo estudo solicitado.

- Depois que as imagens são adquiridas, os radiologistas analisam as imagens e criam um relatório radiológico mostrando suas descobertas.

- Os oncologistas recebem e analisam os relatórios e as imagens para terem subsídios para suas decisões de diagnóstico e tratamento.

A execução do workflow é repetida durante todo o tratamento do paciente e, em cada ciclo, um radiologista diferente pode estar executando a analise e relatório radiológico das imagens médicas. O oncologista tem que ter certeza que os radiologistas têm informações suficientes sobre o paciente e acesso a imagens antigas para preparar relatórios precisos. Além do mais, dados quantitativos e qualitativos sobre as imagens médicas são componentes vitais de um laudo radiológico. No entanto, os métodos tradicionais para registrar esses dados são ineficientes e sujeitos a erros.

Esse workflow tem várias limitações. A pesquisa de Jaffe et al. (2010) mostra que foi encontrada uma discordância significativa entre as práticas e observações radiológicas e as opiniões e expectativas dos oncologistas sobre os tipos de resultados que deveriam ser relatados.

Além de falhas de comunicação e coleta de dados quantitativos incompletos, existem várias limitações para a avaliação quantitativa da resposta do tumor em ensaios clínicos. Em outro estudo, apenas $26 \%$ dos laudos radiológicos de pacientes envolvidos em clinical trails tinham informações suficientes para aplicar o Response Evaluation Criteria in Solid Tumors (RECIST) (Eisenhauer et al., 2008).

A chave do problema em todo esse processo é o fato de que relatórios de radiologia serem feitos em formatos não-estruturados em textos livres. Relatórios radiológicos em texto livre são muito difíceis de manipular e realizar cálculos, mesmo simples, sobre as alterações nas dimensões das lesão tumorais. Além disso, esses relatórios tornam nada trivial a realização de analises agregadas em uma grande quantidade de relatórios (Levy e Rubin, 2011).

Modelos de informação estão sendo desenvolvidos para descrever o conteúdo semântico das imagens, porém esses modelos podem ser complicados para operacionalização, pois há poucas ferramentas que permitem que usuários capturem facilmente informações semânticas estruturadas como parte do seu fluxo de trabalho de investigação de rotina. Mais 
recentemente, o Annotation and Image Markup Project (AIM) do cancer Biomedical Informatics Grid (caBIG) (iniciativa do National Cancer Institute - NCI) desenvolveu um modelo de informação que descreve o conteúdo semântico das imagens (Rubin et al. 2008 a). O AIM fornece um esquema XML que descreve a estrutura anatômica e a observação visual das imagens utilizando a ontologia RadLex (Kundu et al., 2009). As anotações sobre as informações da imagem são gravadas no AIM como XML compatível com o AIM schema, permitindo uma consistente representação, armazenamento e transferência de significados semânticos de imagens, bem como suas marcações e delineamentos das regiões relatadas nas anotações. Ferramentas estão sendo desenvolvidas para coletar anotações sobre imagens em formato AIM, como por exemplo, o AIM iPAD (Rubin et al. 2008 b) e o AIM ClearCanvas, que são ferramentas de código aberto que permitem aos pesquisadores e clínicos criarem anotações semânticas em imagens radiológicas. O AIM iPAD esconde a complexidade do modelo de informação das anotações dos usuários e lhes permite descrever as imagens e regiões dessas imagens usando uma interface gráfica que mapeia, de forma semi-automática, as suas descrições para ontologias estruturadas.

Ferramentas, como o AIM iPAD e AIM ClearCanvas, podem ajudar a reduzir o esforço de se recolher informação semântica estruturada sobre imagens e finalmente permitir que pesquisadores e médicos possam explorar grandes volumes de imagens usando as relações biológicas e fisiológicas entre os conteúdos dessas imagens.

\subsection{Motivação}

Embora sistemas, como AIM iPad e AIM ClearCanvas, facilitem a criação de anotações no formato AIM, eles são de arquitetura stand-alone, ou seja necessitam de um executável instalado na maquina cliente. Por isso, eles possuem limitações de compatibilidade de plataformas e tem a necessidade de instalação de aplicativos e plugins nas máquinas de seus usuários. Um fato importante é que apenas o AIM ClearCanvas suporta a utilização de templates AIM para auxiliar na criação das anotações, o AIM iPAD permite apenas o uso de alguns templates que foram implementados em seu código (hard coded). Outro fato importante é que os arquivos no formato AIM, criados a partir desses sistemas, em conjunto com as imagens de referência no formato DICOM (ou outro formato de imagem) são depositados e indexados (manualmente por usuários) em repositórios de dados, como o BIMM (Biomedical Image Metadata Manager), que permitem a consulta para estudo de outros pesquisadores clínicos. A integração entre essas ferramentas e os repositórios de dados 
em AIM ainda é considerada uma limitação devido a intervenção manual do usuário, que pode gerar erros e outros problemas.

Podemos ver então que existe uma carência por ferramentas Web de criação de anotações semânticas integradas a repositórios de imagens (PACS) e de anotações semânticas em AIM. Sendo assim, a principal motivação deste trabalho é a possibilidade de desenvolver uma ferramenta desse tipo e que também possa realizar a os requisitos atendidos pelos atuais sistemas de anotação de imagens desktop, como AIM iPAD e AIM ClearCanvas,.

\subsection{Objetivo}

O objetivo desse trabalho é desenvolver e explorar tecnologias Web interativas para criação de anotações semânticas em imagens médicas numa ferramenta simples e integrada com os sistemas de gerenciamento de imagens médicas (PACS - Picture Archiving and Communication System). Essa ferramenta deve ser capaz de se integrar no workflow de trabalho de oncologistas e radiologistas. Acreditamos que com as recentes tecnologias que tornaram os navegadores mais interativos, como o HTML 5, uma aplicação RIA seja capaz de dar suporte, de forma satisfatória, à essas atividades de anotação.

Para atingir esse objetivo, é necessário a criação de interfaces intuitivas e interativas, sua implementação em navegadores Web usando tecnologias Web para comunicação de dados (como Web Services), num ambiente que permita a colaboração entre pesquisadores, estudantes e profissionais da área de radiologia e oncologia. Para isso será criado um paradigma de interação baseado na Web. Este aplicativo usará:

- Modelos e protótipos de interfaces baseado em ferramentas existentes, como o sistema AIM iPad e AIM ClearCanvas;

- Tecnologias baseadas em RIA, como Ajax e GWT, para o desenvolvimento das funcionalidades das interfaces do lado do cliente, que rodam no navegador Web;

- Backends para a criação e processamento da informação semântica adicionada às imagens e acessíveis através de Web Services.

Esse aplicativo está sendo desenvolvido de maneira colaborativa com o Laboratory of Imaging Informatics (LII - Stanford University) coordenado pelo professor Daniel L. Rubin ${ }^{1}$ e parte do Radiological Sciences Laboratory ${ }^{2}$ da Stanford University ${ }^{3}$.

\footnotetext{
${ }^{1} \mathrm{http}: / /$ stanford.edu/ rubin/

${ }^{2}$ http://rsl.stanford.edu/
} 


\subsection{Estrutura do Trabalho}

Além da introdução, este trabalho está estruturado da seguinte forma: no capítulo 2 a Informática Biomédica é discutida, são abordadas tecnologias de TI usadas nessa área que são a intra-estrutura necessária para os trabalhos na área medica e de pesquisa médica. No capítulo 3, a Web Semântica e Ontologias são investigadas este capítulo dá ênfase as principais tecnologias e discute sobre as Bio Ontologias, OBO, FMA e RadLex e do projeto AIM. No capítulo 4 são apresentadas ferramentas relacionadas a proposta deste trabalho, destacando-se o sistema de visualização e anotação semântica de imagens médicas e as tecnologias de criação de interfaces interativas na Web, como RIA e o GWT. No capítulo 5 são apresentadas as implementação dos protótipos do ePAD e os resultados dos trabalhos já realizados, como os protótipos de interface, o questionário com usuários e o protótipo funcional. Por fim, no capítulo 6 (Conclusão) são apresentadas as considerações finais desse trabalho, juntamente com as contribuições alcançadas e sugestões para trabalhos futuros.

\footnotetext{
${ }^{3}$ http://www.stanford.edu/
} 


\section{Informática Biomédica}

A Informática Biomédica tem sido, ao longo das últimas décadas, um campo emergente. No entanto, ainda não existe uma definição universal para "Informática" nos campos da medicina, saúde ou biomédicina. Sumarizando estas discussões, a Informática Biomédica pode ser considerada como a Ciência da Informação aplicada no estudo do contexto da biomedicina (Bernstam et al., 2009).

De fato, os computadores têm mudado a maneira como as pessoas interagem, processam, armazenam e recuperam informações na área de saúde. A área da Informática Biomédica surgiu para atender as aplicações da TI (Tecnologia da Informação) na área da saúde (Bui e Taira, 2010).

Mais recentemente, a adoção de Registros Médicos Eletrônicos (Eletronic Medical Record - EMR) tornou as informações dos pacientes mais rapidamente acessíveis aos médicos com a adoção de sistemas de informação para resolverem problemas específicos de cada setor, como os Sistemas de Informações Hospitalares (Hospital Information System - HIS), Sistemas de Arquivamento de Imagens e Comunicação (Picture Archiving and Communication System PACS) e Sistemas de Informação Radiológica (Radiology Information System - RIS).

Por sua vez, a Informática Radiológica (sub-área da informática biomédica) é uma área da Radiologia responsável pela melhoria da eficiência, precisão e confiabilidade dos serviços radiológicos dentro da área médica (Branstetter IV, 2007) (Huang, 2010). Embora os serviços de arquivamento e sistemas de comunicação sejam o foco principal da Informática Radiológica, existem outras maneiras pelas as quais a tecnologia pode melhorar a eficiência do trabalho do Radiologista e até de todo departamento de radiologia, como os sistemas de documentação dos cuidados dos paciente (utilizados pelas enfermeiras) e os sistemas de agendamento e coordenação entre os médicos e os radiologista. As ramificações da informática podem ser sentidas em todo o departamento de radiologia.

Neste capítulo são apresentados conceitos relacionados aos EMR e a Informática Radiológica. Na Seção 2.1 são apresentados os conceitos gerais referentes aos EMRs. Em seguida, na Seção 2.2, são apresentados os HISs. Na seção 2.3, são discutidos os PACSs. Por fim, na seção 2.4, será abordada a padronização de dados e de comunicação na área da Informática Radiológica. 


\subsection{Eletronic Medical Record - EMR}

O desenvolvimento de sistemas de EMR vem sendo realizado há muito tempo pela comunidade de Informática Médica. A justificativa desse esforço de trabalho é de permitir a gestão e o acesso informatizado das informações dos pacientes (Bui e Taira, 2010). Os principais componentes dos registros médicos, que compreendem um prontuário eletrônico, são os históricos médicos individuais do paciente, como, por exemplo, os resultados laboratoriais, sinais vitais, dados demográficos, relatórios de medicamentos e de resultados de exames de radiologia.

O relatório do Institute Of Medicine (IOM) divulgado em 2003, apresentou potenciais benefícios dos EMR, que foram categorizados em três (Bui e Morioka, 2010):

1. Melhorias da qualidade dos cuidados de saúde. Os EMR acrescentam melhorias no atendimento através de funcionalidades como: agendamento automático de lembretes de vacinas, avaliação médica (baseada em evidencias e desempenho médico) por meio de ferramentas de apoio a decisão, diagnóstico auxiliado por computador (para melhorar o diagnostico de doenças) e padronização da avaliação e dos cuidados médicos.

2. Melhorias da eficiência. Em tese, a disponibilidade imediata dos resultados e a capacidade de localizar rapidamente informações críticas nos registros dos pacientes geram economia de tempo para os médicos. Eficiências são conseguidas com a diminuição do consumo de recursos, como a diminuição da redundância de exames. Outro ponto é que um EMR deve conter uma interface favorável a disponibilização dos dados (escondendo tudo que pode ser desnecessário) que deve atender as expectativas dos profissionais de saúde.

3. Redução de erros. Há uma preocupação do IOM, desde 1999, em reduzir o número de mortes decorrentes de erros médicos e de melhorar a segurança geral dos pacientes. Para isso, é necessário minimizar incertezas usando a avaliação e prescrição eletrônicas para reduzir erros, como, por exemplo, a ilegibilidade da caligrafia médica, e também para detectar eventos adversos, como alergias e efeitos colaterais de medicamentos.

Os sistemas de EMR foram inicialmente desenvolvidos a partir de necessidades específicas, de acordo com fluxos de trabalhos de campos mais especializados da medicina. A seguir, falaremos dos subconjuntos dos EMR, os HISs que lidam com bases de dados 
demográficos, resultados laboratoriais, receitas farmacêuticas, informações administrativas, etc., e dos PACSs, que lidam com o armazenamento e comunicação de imagens médicas.

\subsection{Hospital Information System - HIS}

Inicialmente os HISs surgiram por volta da década de 60 para atender a necessidades financeiras das instituições médicas (Institute of Medicine, 2003). Além disso, os HISs têm agregado várias funcionalidades principais dos EMRs, como: atendimento clínico, protocolos clínicos, lembretes e alertas, gestão administrativa, ensino e pesquisa, neste caso possibilitando a exploração e mineração de dados e assim descobrir tendências em uma população.

No entanto, outros sistemas de informação relacionados a informações médicas são mais específicos, lidando com particularidades de um determinado departamento clínico. Dessa forma, esses sistemas atuam como subconjuntos das funcionalidades de um HIS, como exemplos destes sistemas temos o Laboratory Information System (LIS) e o RIS.

Os LISs trabalham com o fluxo de trabalho dos serviços laboratoriais e de patologia, oferecendo interfaces de comunicação com os diversos dispositivos utilizados para a realização das avaliações químicas e de imunologia, microbiologia, genética e marcadores hispatológicos. Os LISs são vistos como um modelo de monitoramento, validação de resultados e divulgação eletrônica dos mesmos aos médicos solicitantes.

Os RISs atentem o fluxo de trabalho de um departamento de radiologia, eles são uma interface dos PACSs, onde são atribuídas funcionalidades de agendamento de pacientes, gerenciamento de imagens de estudos e de relatórios, que podem ser revisões de resultados de estudos anteriores. Os RISs se destacam dos PACSs por normalmente serem sistemas restritos aos dados das imagens, enquanto os PACSs estão preocupados com os aspectos de armazenamento e manipulação dos dados das imagens. Como os dados de imagens se tornaram parte integrante dos processos de cuidados da saúde, é inevitável a preocupação com a integração dos HISs e RISs por possibilitar, ao radiologista, um abrangente histórico do paciente (facilitando assim uma interpretação adequada) e por garantir que o resultado radiológico seja rapidamente disseminado entre os médicos. 


\subsection{Picture Archiving and Communication System - PACS}

Um PACS é um conjunto formado por dispositivos de captura de imagem, unidades de armazenamento, processamento computacional e banco de dados de imagens médicas integrados em rede (Huang, 2004). PACSs são muito úteis na área de saúde por diminuir o uso de papel e filme radiológico, permitindo constantes revisões, compartilhamento de imagens entre diferentes dispositivos e a melhoraria da precisão e do tempo dos diagnósticos, além de permitir a visualização entre diferentes profissionais de saúde. PACSs também permitem o aumento global da produtividade, diminuição de custos operacionais e geram oportunidades para ambientes de trabalho em telemedicina e trabalho colaborativo auxiliado por ferramentas computacionais (Silva et al., 2011) (Gao et al., 2011).

Desenvolver um sistema PACS envolve diversos desafios, como, por exemplo, a natureza e o tamanho dos estudos das imagens adquiridas, podendo variar de 2 até mais de $800 \mathrm{MB}$ (Bui e Taira, 2010). De fato, imagens medicas digitais vem crescendo em volumetria de dados devido a grande quantidade de fatias de imagens de alta resolução que os novos equipamentos permitem (Philbin et al., 2011). Podemos citar três pontos importantes no desenvolvimento dos PACSs, que são: o armazenamento de longo prazo, a recuperação e difusão rápidas em rede das imagens (para analise e visualização) e a indexação de dados das mesmas.

Uma infra-estrutura para o uso de PACSs consiste em um ambiente de sistemas com diversos componentes de hardware implantados, a saber: Dispositivo para o intercâmbio de imagens, dispositivos de armazenamento, servidores, redes de comunicação e visualizadores (Huang, 2004).

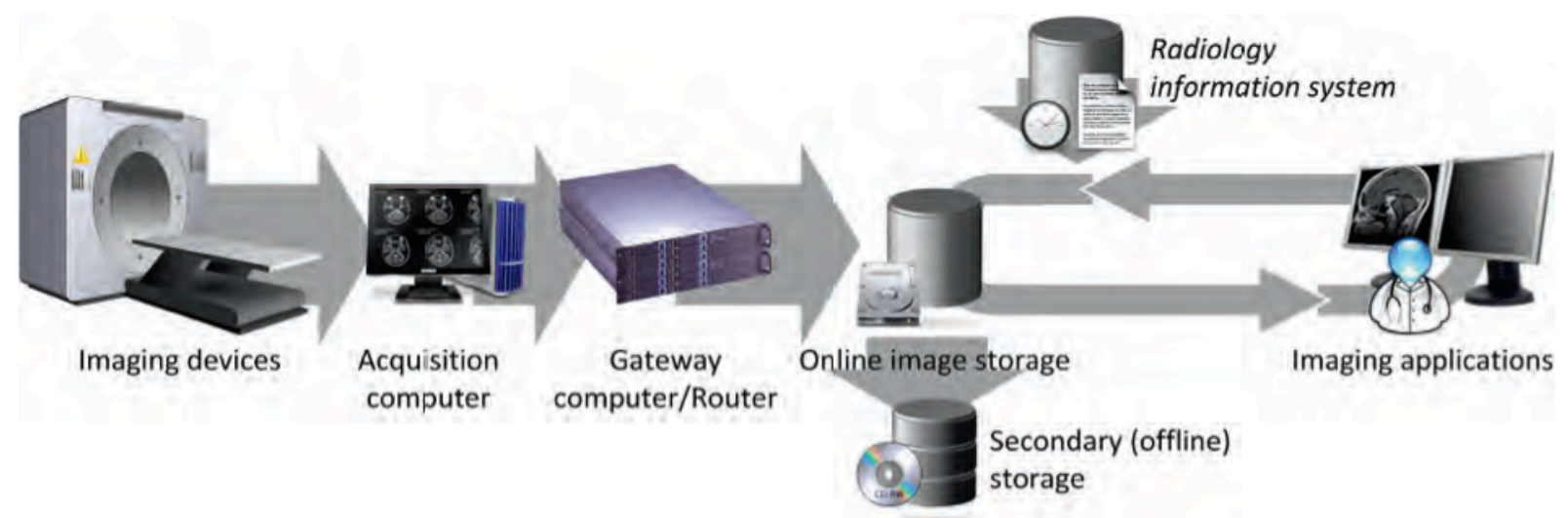

Figura 1 - Fluxos de dados e os principais componentes de um PACS (Bui e Morioka, 2010)

A Figura 1 apresenta os componentes principais de um PACS e o fluxo de dados entre eles:

1. Dispositivos de imagem e computadores de aquisição: Com a criação dos PACSs, esses dispositivos foram substituindo os filmes por aquisição digital de imagem. 
Exemplos desses dispositivos digitais são: tomografia computadorizada (CT), ressonância magnética (RM), radiografia computadorizada (CR), tomografia por emissão de pósitrons (PET), raios-X digital, mamografia e ultrassom. Em muitos casos, os dispositivos de imagens são interligados a computadores de aquisição, pois os dispositivos de imagens fornecem apenas sinais brutos que precisam ser fatiados ou volumetrizados. Os computadores de aquisição armazenam uma pequena quantidade de dados localmente e depois enviam esses estudos (imagens) para os PACSs, através de um gateway, para o armazenamento definitivo de longo prazo.

2. O computador gateway ou roteador: é responsável por auxiliar as tarefas de receber as imagens do computador de aquisição e encaminhar essas imagens a um dispositivo de armazenamento em rede (storage) ou estação de trabalho.

3. Armazenamento on-line de imagens e armazenamento secundário: $\mathrm{O}$ armazenamento on-line consiste em um banco de dados de imagens contento as meta-informações das imagens armazenadas. Os arquivos, contendo as imagens propriamente ditas, são disponibilizados por unidades de armazenamento rápidas em rede, como os Network-Attached Storage (NAS) e Storage Area Network (SAN). O armazenamento secundário é a forma como as imagens são armazenadas de forma permanente, porém utilizando dispositivos mais baratos e de acesso mais lento, como, por exemplo, matizes de disco óticos. Conjuntos de regras fazem com que as imagens sejam disponibilizadas da forma on-line ou off-line, ou seja, na forma de armazenamento primário e secundário respectivamente. Este recurso é uma forma de garantir a disponibilidade mais eficiente de imagens, mais utilizadas ou mais recentes.

4. Aplicações de imagem: é a última parte do PACS e são aplicativos clientes que realizam requisições de imagens. Em Radiologia, geralmente são aplicações de visualização de imagens que utilizam dispositivos de alta definição de imagem para análise e diagnóstico. Atualmente, o desenvolvimento de novas tecnologias baseadas na Web (HTML5 e WebGL) vem tornando navegadores Web capazes de realizar a visualização das imagens (Bui e Taira, 2010), outros serviços de processamento de imagens, como simulação e desenho em 3D, também estão incluídos nessa camada cliente do PACS. 


\subsection{Padronização de dados e de comunicação}

Em sistemas de informação, em nosso caso o EMR, a heterogeneidade da informação é considerada um problema crítico, logo, fica difícil integrar a diversidade de bases de dados e manter as informações dos pacientes devido a heterogeneidade e complexidade destas informações. Normas foram criadas nas últimas décadas para a comunicação dos diferentes componentes do EMR.

\subsubsection{DICOM}

Em principio, PACSs podem exportar e trabalhar com imagens em diversos formatos de arquivos, como JPEG, TIFF, entre outros formatos de imagens. Na prática, um departamento de radiologia tem que trocar imagens com outros departamentos e, nesse caso, um padrão é necessário. Partindo desse principio, foi desenvolvido o padrão DICOM, que é o padrão para representação e compartilhamento de dados e imagens médicas (Gao et al., 2011). Ele foi iniciado em 1993 a partir de um padrão anterior, o ACR-NEMA, formalmente conhecido como American College of Radiology e o National Electrical Manufacturers Association, e evoluiu pelo esforço em fornecer interoperabilidade de comunicação entre os componentes e fabricantes de dispositivos que compõem um PACS (Bui e Morioka, 2010).

O padrão DICOM é, inegavelmente, o padrão de imagens biomédicas (Gibaud, 2011). Ele se tornou predominante nas áreas de radiologia, cardiologia, medicina nuclear, radioterapia e medicina dentária. O seu desenvolvimento continua a crescer, atingindo os campos da oftalmologia, endoscopia, patologia, bem como a cirurgia e medicina veterinária.

O padrão DICOM especifica: 1) o conjunto de protocolos de rede para serem seguidos pelos dispositivos em conformidade com o padrão; 2) uma sintaxe e semântica dos comandos e informações associados que são trocados por esses protocolos; 3) um conjunto de meios de armazenamento, para serem seguidos pelos dispositivos padronizados, que compreende desde o formato de arquivo, estrutura de diretórios (para facilitar o acesso das imagens), dos dados e informações relacionadas (Bui e Morioka, 2010).

O padrão completo do DICOM está disponível on-line (DICOM, 2009), ele é constantemente atualizado e adaptado para acompanhar as mudanças nas tecnologias usadas no processamento de imagens médicas digitais. 
O padrão atual do DICOM, versão 3.1 de 2008, específica 18 partes relacionadas, mas independentes, que seguem as recomendações da International Standardization Organization - ISO (Bui e Taira, 2010), (Gibaud, 2011) e (Huang, 2010).

Tabela 1 - Partes do padrão DICOM 3.1 (Parte 9 e 13 foram retiradas)

\begin{tabular}{|c|l|}
\hline Parte & \\
\hline 1 & Introdução e Visão Geral. \\
\hline 2 & Conformidade \\
\hline 3 & Definição de Informação \\
\hline 4 & Especificação de Classe de Sebjetivo \\
\hline 5 & Estrutura de dados e Codificação \\
\hline 6 & Dicionário de Dados \\
\hline 7 & Troca de mensagens \\
\hline 8 & Rede de apoio a comunicação \\
\hline 10 & Armazenamento de Mídia e meios físicos \\
\hline 11 & Aplicação de Perfis de Mídia de Armazenamento \\
\hline 12 & Formato de Mídia e meios físicos \\
\hline 14 & Padrões de tons de cinza \\
\hline 15 & Segurança e Perfis do Sistema de Gestão \\
\hline 16 & Mapa de recursos e conteúdo \\
\hline 17 & Informações explicativas \\
\hline 18 & Acesso Web para objetos persistentes DICOM \\
\hline
\end{tabular}

O núcleo do modelo de dados do DICOM utiliza uma estrutura de Entidades de Relacionamento (ER) e conceitos de orientação a objetos como fundamento para classes de objetos (partes 5 e 6 da Tabela 1).

Esse modelo é divido em duas idéias principais:

1. Classes de objetos: os dados são representados na forma de classes de objetos. Cada tipo de elemento, como dados do paciente e de imagens, é mapeado em uma classe de objetos.

2. Classe de serviços: são classes que se referem aos processos onde os dados são gerados, operados ou comunicados. Como os serviços de armazenamento, pesquisa e recuperação de imagens.

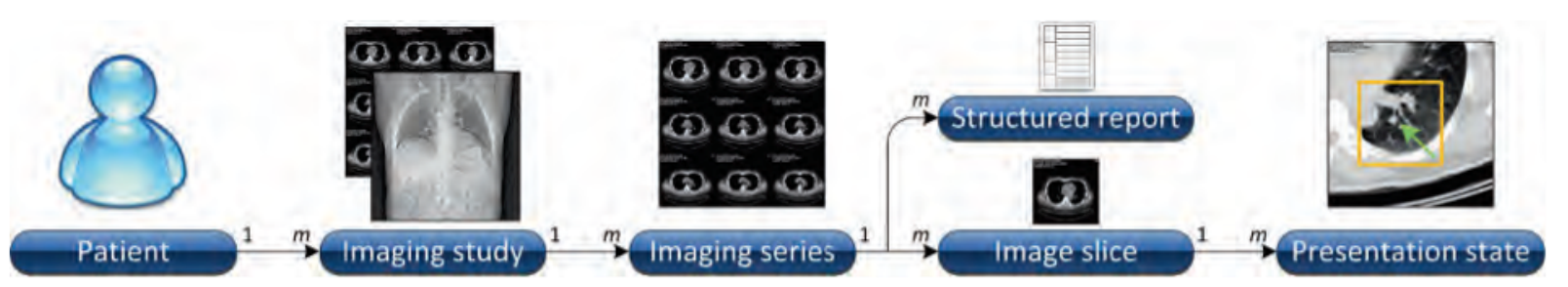

Figura 2 - Hierarquia de objetos do padrão DICOM (Bui e Morioka, 2010) 
A Figura 2 mostra a hierarquia de objetos do DICOM, onde o paciente é o objeto do topo da hierarquia, podendo ter uma coleção de estudos de imagens. Cada estudo poderá ter um conjunto de series de imagens. Por sua vez, cada serie pode possuir conjuntos de relatórios e de fatias de imagens. Por fim, cada uma destas fatias pode conter uma marcação específica ou delineador.

\subsubsection{Web Access to DICOM Persistent Objects - WADO}

O Acesso Web a Objetos DICOM Persistentes, ou Web Access to DICOM Persistent Objects (WADO), não é um novo protocolo de comunicação, mas uma visão Web do DICOM: um serviço para acessar e apresentar objetos DICOM persistentes e um mecanismo simples para visualizar e processar esses objetos, através de requisições em Hypertext Transfer Protocol (HTTP) (Koutelakis e Lymperopoulos 2006).

Os documentos são recuperados através do protocolo HTTP utilizando um DICOM UID (Unique Identifiers). Os dados podem ser recuperados, conforme especificado pelo solicitante, em um formato pronto para apresentação, como o JPEG, GIF ou DICOM nativo (Huang, 2010).

Servidores PACS DICOM, que provêm o serviço WADO, podem ser utilizados para a integração de diversos sistemas na área médica, por exemplo, no compartilhamento de imagens médicas e prontuários de pacientes. O padrão WADO provê uma maneira eficiente e simples para o compartilhamento de imagens de diversos centros médicos e, quando necessário, para manter a privacidade dos dados do paciente (Almeida et al., 2008).

\subsection{Considerações Finais}

A Informática Biomédica surgiu para atender as aplicações de TI na área médica. Como as informações médicas são, em geral, de natureza heterogênia, integrar dados e sistemas tornase uma atividade nada trivial. No decorrer das últimas décadas, muitas discussões sobre o desenvolvimento de sistemas de informação e de como eles deveriam interoperar dados trouxeram como resultado o surgimento de tecnologias como os EMRs, HISs e PACSs. Além delas, padrões de interoperabilidade entre os sistemas de informação e dispositivos médicos, como o DICOM, foram desenvolvidos e constantemente atualizados.

Este capítulo forneceu uma base teórica para compreensão de como a TI tem auxiliado e contribuído para os avanços na gestão de dados sobre pacientes. 


\section{Web Semântica e Ontologias}

As ciências da vida, bem como a Informática Biomédica, vem tirando proveito das tecnologias da Web Semântica para obter melhores resultados. A Web semântica surge nesse contexto como uma plataforma robusta, com tecnologias amplamente utilizadas e atualizadas. As ontologias são muito utilizadas nas ciências da vida para interoperabilidade de dados.

Neste capitulo são apresentados conceitos relacionado com a Web Semântica e ontologias. As Bio ontologias são discutidas por serem a base da estruturação dos conteúdos semânticos, podendo interagir e se relacionar com terminologias médicas, como o RadLex e AIM.

Este capítulo está organizado da seguinte maneira, na Seção 3.1 serão expostos conceitos referentes à Ontologias. Na seção 3.2, a Web Semântica será discutida. Já na seção 3.2.1 apresentaremos conceitos relacionados ao Resource Description Framework (RDF). A Web Ontology Language (OWL) é exposta na seção 3.2.2. Em seguida, na seção 3.3 apresentaremos as Bio Ontologias e as principais ontologias e termologias envolvidas nas pesquisas deste trabalho.

\subsection{Ontologias}

Etimologicamente, o termo "ontologia" significa o estudo da existência (Guizzardi, 2008). Segundo Smith (2004), a Ontologia é um ramo da filosofia que é a ciência “do que é”, dos tipos e estruturas dos objetos, propriedades, eventos processos e relações em todas as áreas da realidade. $\mathrm{Na}$ área das ciências de computação e informação, o termo ontologia vem se tornando muito popular, principalmente nas áreas de engenharia do conhecimento, processamento de linguagem natural, sistemas de informação cooperativos, integração inteligente da informação e gerencia do conhecimento (Smith, 2004).

Gruber (1993) define o termo ontologia como uma especificação formal e explicita de uma conceitualização compartilhada de um domínio de interesse e de informações de como os indivíduos são agrupados e se encaixam em um determinado domínio. Noy e McGuinness (2001) afirmam que as ontologias surgiram como artefatos para representar, organizar e compartilhar conhecimento em um determinado domínio. 
De forma geral, uma ontologia é especificada por meio de componentes básicos que são as classes, relações, axiomas e instâncias, além de ser expressa por meio de uma linguagem de construção (Almeida e Bax, 2003). Os componentes básicos de uma ontologia são definidos por meio de uma linguagem de representação. Diferentes linguagens para ontologias proporcionam diferentes facilidades (Horridge et al., 2004).

$\mathrm{Na}$ Web Semântica, o papel das ontologias é de explicitar o vocabulário utilizado e de servir como padrão para o compartilhamento de informação de modo significativo entre agentes, softwares e aplicações (Breitman, 2005). Já Maedche e Staab (2001) definem ontologias como esquemas de metadados, fornecendo um vocabulário controlado e conceitos, cada um com semântica explicitamente definida e com semântica processável por maquinas.

\subsection{Web Semântica}

A Web atual, definida por muitos como a Web Sintática, é composta por páginas Web, que trabalham apenas com a apresentação e formatação da informação, e não com a estruturação, significado e interoperabilidade dos dados apresentados, deixando a cargo dos usuários dessas páginas o papel de compreender e entender o conhecimento ali publicado.

Em 2001 foi publicada, na revista Scientific America, o artigo "The Web Semantic: a new form of Web content that is meaningful to computers will unleash a revolution of new possibilities" (Berners-Lee et al., 2001). Nesse artigo, os autores comentaram a respeito do futuro, onde a Web Semântica iria ter um papel fundamental na realização das tarefas do cotidiano das pessoas.

Em face do crescimento exponencial do volume de dados digitais, as soluções de software existentes não fornecem qualquer significado ou entendimento desses dados. Hoje, muitos desenvolvedores da Web Semântica, arquitetos e visionários estão trabalhando para dar sentido a um mundo confuso de dados digitais (Pollock, 2009).

A Web Semântica, uma extensão da Web atual, é uma representação capaz de associar significados explícitos aos conteúdos dos documentos disponíveis na Internet, sendo que, sua principal meta, é possibilitar que programas processem e interpretem automaticamente esses documentos (Berners-Lee et al., 2001).

O sucesso da Web atual se deve a liberdade como as pessoas publicam seus conteúdos. Essa liberdade é também apoiada pela Web Semântica. Ao invés de impor a cada usuário ou instituição da Web um modelo único de organização, irá surgir um conjunto de modelos em paralelo de organização, podendo ou não estar relacionados entre si. 
Em 2000, durante uma conferência sobre XML, Tim Berners Lee propôs um modelo de camadas para a arquitetura da Web Semântica, conhecida como "bolo de noiva" (Breitman, 2005) (Pollock, 2009). A arquitetura lógica é apresentada na Figura 3. Ela demonstra, em camadas, como as principais tecnologias da Web semânticas devem se encaixar. Também são separadas, através dos contornos tracejados, as tecnologias pelo grau de maturidade.

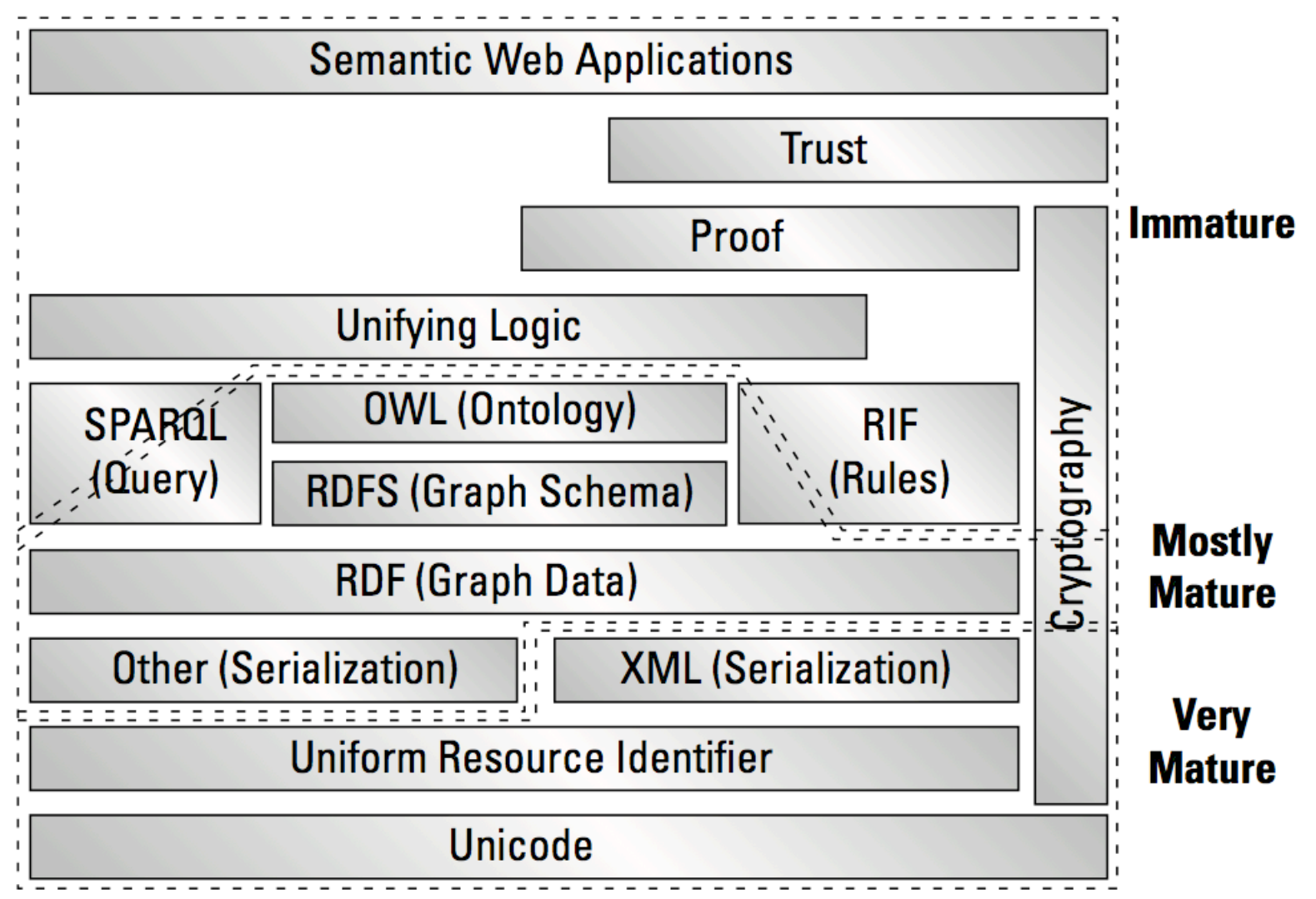

Figura 3 - Arquitetura "Bolo de Noiva" da Web Semântica (Pollock, 2009).

A idéia central desse modelo de camadas (Figura 3) é de adicionar gradativamente cada nova camada para trazer novas funcionalidades paulatinamente, como o aumento de expressividade, possibilidade de realizar inferência e autenticação. Essa arquitetura consiste em construir algo novo em cima do que já existe e não reinventar tudo de novo (Breitman, 2005). A justificativa para isso é que, na Internet, é fácil obter consenso sobre pequenas modificações, enquanto é muito difícil conseguir apoio a mudanças radicais.

Na Figura 3, a camada Unicode, um padrão da ISO, corresponde a forma utilizada para a codificação de textos, que é compatível com várias línguas. Isso é importante para o transporte e troca de informações através do mundo, codificando diversos caracteres alfanuméricos e outros caracteres que as pessoas necessitam para se comunicar. 
O Uniform Resource Identifier (URI) é considerado a fundação da Word Wide Web (WWW). Ele provê o endereço para localizar qualquer tipo de recurso na Web. Através das URIs as páginas da Web podem ser visualizadas e também ligadas através de objetos RDF.

O eXtensible Markup Language (XML) é uma linguagem para marcação de documentos e mensagens que utiliza tags que podem ser facilmente analisadas por máquinas. Essa linguagem descreve a gramática e a sintaxe para criação das tags, bem como as regras de como as tags serão analisadas.

Analisando a Figura 3, tanto o RDF como o OWL podem ser considerados como os fundamentos da Web Semântica, desde de que esses padrões foram recomendados em 2004, tem demonstrado ser muito estáveis, mesmo desde as suas primeiras versões.

O RDF e OWL são detalhados com mais atenção nas seções 3.2.1 e 3.2.2, respectivamente, por estarem envolvidas nas camadas da Web Semântica, ilustradas na Figura 3.

\subsubsection{Resource Description Framework - RDF}

O RDF, uma recomendação do World Wide Web Consortium (W3C) de fevereiro de 2004, é uma linguagem baseada em XML com o propósito geral de representar informação na Web (W3C, 2004). Como descrito na Figura 3, ele é a base da arquitetura de camadas da Web Semântica.

O RDF contém uma estrutura básica de sentenças baseadas em triplas de termos, o sujeito, predicado e objeto, que juntos e nesta ordem representam uma declaração em RDF, veja na Figura 4.

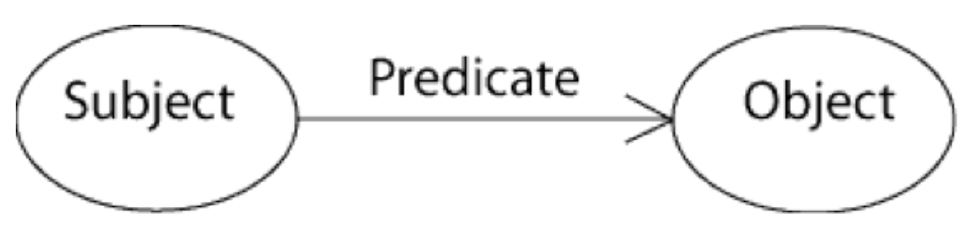

Figura 4 - Representação da Tripla RDF - Fonte: W3C.

O sujeito é algo que está sendo descrito numa expressão RDF, ele pode ser uma página Web, parte de uma página, uma palavra contida em uma página, o site inteiro ou até mesmo um objeto do mundo real, por exemplo, um livro. O recurso é identificado por um URI que é usado como o nome do recurso.

O Predicado é utilizado como um nome para uma propriedade, ou seja, ele pode ser usado para descrever algum aspecto específico, atributo, característica ou relação a um determinado recurso.

O objeto é o valor do metadado, podendo ser um tipo estabelecido ou um valor literal. 
Um Grafo RDF é um conjunto de declarações em RDF. Uma declaração é uma tripla RDF. A Figura 5 mostra linhas de código RDF (em XML) e seu respectivo diagrama.

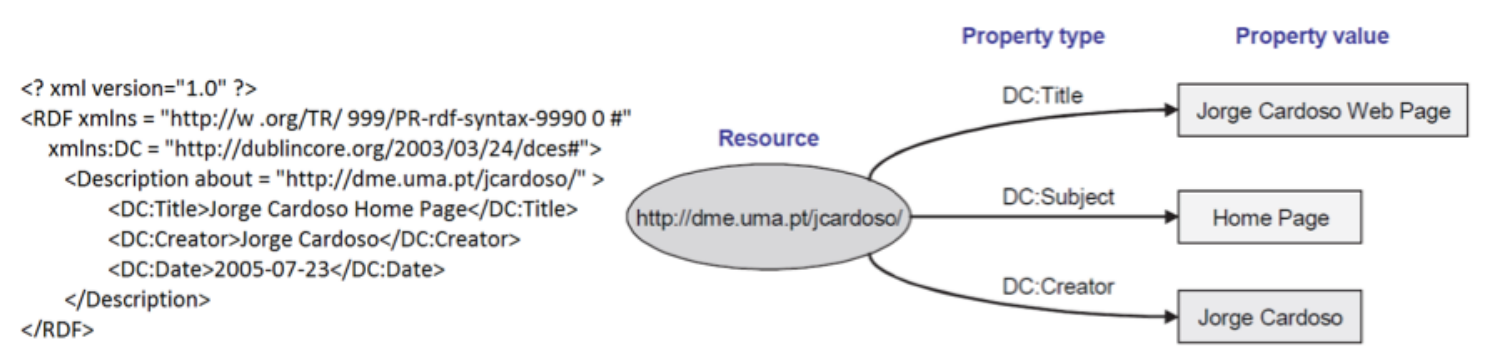

Figura 5 - Conjunto de triplas RDF e seu diagrama representativo.

\subsubsection{Web Ontology Language - OWL}

Embora a proposta inicial da Web Semântica fosse utilizar o RDF, essa linguagem demonstrou limitações em poder de expressividade (Horrocks et al., 2003). O W3C lançou em 2004 a linguagem OWL, como resultado da formação do Web Ontology Working Group. A linguagem OWL se divide em três variantes que tem graus crescentes de expressividade: OWL Lite, OWL DL e OWL Full (Patel-Schneider et al., 2004)

Ontologias em OWL foram desenvolvidas em várias áreas, como e-Science, medicina, biologia, geografia, astronomia, defesa e nas indústrias automobilística e aeronáutica (Grau et al., 2008). Apesar do sucesso da OWL foram encontradas algumas deficiências na linguagem. Em resposta aos comentários e requisições dos usuários da OWL, surgiram a OWL 1.1, uma revisão incremental da linguagem e, depois de extensivas discussões, a OWL 2 (abril de 2008). A OWL 2 foi considerada um passo substancial para a evolução da linguagem (Grau et al., 2008).

A linguagem OWL 2 criou três novos perfis: OWL 2 EL, OWL 2 QL e OWL RL, cada um oferece um poder de expressividade diferente e para diferentes cenários de aplicação.

\subsubsection{O perfil OWL $2 \mathrm{EL}$}

Esse perfil foi baseado na família EL++ de lógica descritiva, com raciocínio eficiente mesmo com terminologias grandes (Motik et al., 2009). OWL 2 EL utiliza um padrão comum utilizado em ontologias para conceitos e planejamento, ou seja a combinação de conjunção e qualidades existenciais. Muitas ontologias em grande escala podem ser capturadas com este perfil, um exemplo disso é a ontologia médica SNOMED CT. 


\subsubsection{O perfil OWL $2 \mathrm{QL}$}

O perfil OWL 2 QL foi baseado na família de DL-Lite, um subconjunto da linguagem description logic (Motik et al., 2009). Este perfil foi projetado para permitir o raciocínio (reasoning) eficiente com grandes quantidades de dados estruturados de acordo com esquemas relativamente simples.

O perfil fornece a maioria dos recursos necessários para capturar os modelos conceituais, tais como diagramas de classe UML, diagramas de Entidade Relacionamento, e esquemas de banco de dados. No entanto, OWL 2 QL proíbe o uso de restrições de disjunção e AllValuesFrom, bem como algumas outras características que exigem avaliação de consulta recursiva.

\subsubsection{O perfil OWL 2 RL}

A OWL 2 perfil RL é voltada para aplicações que exigem raciocínio escalável em troca de alguma restrição de poder expressivo. Ela define um subconjunto sintático de OWL 2 que favorece à implementação utilizando tecnologias baseadas em regras (Motik et al., 2009).

O perfil OWL 2 RL pode ser utilizado na maioria das construções OWL 2, no entanto, para permitir implementações baseadas em regras de raciocínio, a forma como essas construções podem ser usadas em axiomas foi restringida.

A especificação OWL 2 RL também fornece um conjunto de implicações de primeira ordem que podem ser diretamente aplicados a um grafo RDF, a fim de retirar as respectivas conseqüências.

\subsection{Bio Ontologias}

Grandes volumes de dados digitais sobre conhecimento médico e biológico sobrecarregam os pesquisadores dessas áreas. Eles têm a difícil tarefa de gerenciar terabytes de informação, com conteúdos semânticos, em grandes repositórios de dados que usam tecnologias de gerenciamento cada vez mais sofisticadas. Pesquisadores da área biomédica podem trabalhar com uma enorme quantidade de dados, que não se pode ser interpretada sem o auxílio de computadores (Shah e Musen, 2007). 
Os pesquisadores também devem agregar e integrar toda estas informação. Para tanto, eles precisam de ferramentas que permitam a descoberta de conhecimento nesse paradigma rico em dados. Portanto, eles começaram a utilizar ontologias para descrever a estrutura de seus domínios complexos e relacionar com os seus dados para o compartilhamento e interoperabilidade das informações Biomédicas (Rubin 2008c).

Muitas ciências, a exemplo da Informática Biomédica, estão utilizando as tecnologias semânticas para promover o entendimento de dados, interoperabilidade e controle da entropia através do uso e desenvolvimento de novas ferramentas semânticas, capazes de recuperar e organizar, semanticamente, dados distribuídos através de análises colaborativas e apoiadas, em sua grande parte, por Aplicações Web.

\subsubsection{Open Biomedical Ontologies - OBO}

A plataforma OBO, criada em 2003 pelo Open Biomedical Ontologies (OBO, 2008), se desenvolveu como um repositório de ontologias biomédicas online, de domínio público. A partir disso, a iniciativa $O B O$ Foundry desenvolveu um conjunto de princípios compartilhados que regulam o desenvolvimento de ontologias biomédicas (Smith 2007). O alcance do $O B O$ Foundry compreende diversas ontologias biológicas, incluindo a Gene Ontology (GO) (discutida na seção 3.4.2), a Foundational Model of Anatomy (FMA) (discutida na seção 3.4.3), e outras ontologias, como a Chemical Entities of Biological Interest (ChEBI), Phenotypic Quality Ontology (PATO), Protein Ontology (PRO), Xenopus Anatomy Ontology (XAO) e Zebrafish Anatomy Ontology (ZFA).

A OBO também conta com um formato de representação de ontologia, que utiliza uma sintaxe textual simples e foi projetado para ser compacto, legível por seres humanos, extensível, de fácil analise e com pouca redundância (Moreira et al, 2007). Porém, ela necessita de mais definições formais para realizar o processamento computacional como, por exemplo, para o uso de reasoners que facilitem a manutenção e desenvolvimento de uma ontologia (Moreira et al, 2007).

Existem grandes esforços para se migrar e adaptar este formato para o uso em conjunto com tecnologias da Web Semântica (Moreira et al, 2007), (Golbreich et al, 2007). Para tanto, o National Center for Biomedical Ontology (NCBO) desenvolveu um mapeamento entre os formatos OWL e OBO em um software para conversão entre eles. O objetivo é permitir o compartilhamento de ferramentas, ontologias e dados associados entre a comunidade $\mathrm{OBO}$ e a comunidade de Web Semântica (Moreira et al, 2009). 


\subsubsection{Foundational Model of Anatomy - FMA}

Outra Bio Ontologia importante no escopo deste estudo é a FMA. De modo geral, a anatomia é o estudo das estruturas físicas dos organismos biológicos. Descrever e capturar de forma computável as termologias e ontologias que envolvem entidades anatômicas é uma tarefa não trivial. A falta de uma representação generalizada da anatomia leva os desenvolvedores de terminologias e ontologias, tanto da área de medicina clinica quanto de biologia, a representar a anatomia a partir dos seus próprios pontos de vista. Isso gera um obstáculo para correlacionar os termos anatômicos entre si, devido a heterogeneidade das representações anatômicas.

A FMA vem sendo desenvolvida para oferecer uma ontologia de referencia, destinada ao uso por qualquer ferramenta computacional que necessite de informações anatômicas. A estrutura ontológica da FMA fornece uma maquina de inferência, permitindo que ferramentas computacionais possam inferir sobre dados biomédicos (Rosse e Mejino, 2007).

Com sua natureza fundacional, a FMA fornece uma base, não só para a evolução de aplicações, como também para outras ontologias de referência em áreas da ciência como fisiologia, patologia, biologia e neurociência. Especificamente, a FMA representa um corpo coerente de conhecimentos declarativos sobre a anatomia humana (Mejino et al.,2008) (Gu et al., 2009). No entanto, seu quadro ontológico pode ser aplicado e estendido para outras espécies. A FMA tem sido desenvolvida e mantida pelo Structural Informatics Group da University of Washington (Gu et al., 2009).

A FMA é de código aberto e está disponível para download no formato OWL (http://www.bioontology.org/wiki/index.php/FMAInOwl) e em outros formatos (http://sig.biostr.washington.edu/projects/fma/release/index.html).

\subsubsection{RadLex}

O RadLex é a mais importante Bio Ontologia do escopo deste trabalho. Ela surgiu da necessidade de disseminar o conhecimento radiológico entre os radiologistas. De forma geral, os radiologistas utilizam constantemente imagens médicas, relatórios de imagens e registros médicos, que se encontram on-line. Para tanto, eles necessitam de uma linguagem unificada para organizar e recuperar estes dados. 
Por muitas décadas, o American College of Radiology (ACR) desenvolveu o Index for Radiological Diagnoses, conhecido como o Índice ACR. Ele tem características atraentes para indexação de imagens. Para tanto, utiliza um sistema de dois códigos numéricos, separados por pontos. O primeiro é para a localização da anatomia e o segundo para a entidade patológica: Por exemplo, o código ACR 642.3212 significa 642 = "adenocarcinoma primário" e 3212 = "língula" (Langlotz, 2006).

Como o Índice ACR possui apenas milhares de índices, fica fácil para as pessoas se lembrarem, todavia, comparado as novas terminologias e ontologias, como o SNOMED-CT e FMA, fica evidente que ele oferece poucos termos específicos.

Para facilitar o gerenciamento digital de imagens, a Radiology Society of North America (RSNA) desenvolveu o Medical Imaging Resouce Center (MIRC): um conjunto de ferramentas para possibilitar que usuários se conectem a arquivos didáticos eletrônicos através da Internet. O MIRC possibilita também a criação de material didático e outras formas de anotação em bibliotecas digitais pessoais.

Com o surgimento do mundo digital, a necessidade de criar sistemas de indexação informatizados levou a RSNA a desenvolver a ontologia RadLex (RNSA, 2012), como resposta as lacunas encontradas em outras terminologias radiológicas, criando assim uma única e completa terminologia. A ontologia RadLex é uma forma unificada de reunir os termos usados em radiologia; ela é projetada para atender as necessidade dos radiologistas (Langlotz, 2006).

A RSNA teve o apoio do ACR, dessa forma, os matérias de ensino poderão conter novos índices em RadLex. Além disso, houve apoio do College of American Pathologists na utilização de um subconjunto de termos estendidos do SNOMED-CT, como um ponto de partida para criação do RadLex. Outras cooperações com outras normas tornaram o RadLex mais abrangível, como a norma DICOM e IHE. Ele também tem o apoio de uma vasta gama de profissionais da área da radiologia (Langlotz, 2006). O RadLex está disponível para download no National Center for Biomedical Computing's Bioportal (http://bioportal.bioontology.org/ontologies/40885).

\subsubsection{Annotation Imaging Markup - AIM}

As modernas imagens médicas contêm uma vasta quantidade de informação no formato padrão DICOM. No entanto, essas informações são relacionadas apenas a metadados sobre as imagens. As informações mais importantes relacionadas as imagens ficam codificadas nos 
seus pixels. Elas contêm um rico conteúdo que, porém, não está explícito ou acessível às máquinas. Essas informações são interpretadas por observadores humanos, como os radiologistas, e não são capturadas ou relacionadas às imagens de uma forma estruturada (Rubin et al., 2008a).

O projeto AIM, que atualmente encontra-se em sua segunda versão, trata de um modelo de informação que oferece uma infra-estrutura de apoio para a criação de uma coleção de anotações médicas de imagens (que podem ser lidas por máquinas). Ele é resultado do cumprimento de novas exigências da comunidade de imagens médicas e vem conseguindo atingir os requisitos estabelecidos pela caBIG In Vivo Imaging Workspace (Rubin et al., 2008a). O projeto é centrado no modelo AIM de anotação e marcação de imagens DICOM. As anotações e marcações de imagens são consideradas como um objeto de informação da imagem, porém não estão ligadas fisicamente as mesmas. Esse modelo de informação, no entanto, é compatível com outros formatos de imagens além do DICOM.

O modelo AIM de informação, ou AIM schema, é descrito em (Rubin et al., 2008a) usando um diagrama de classe UML. O modelo é usado para expressar a captura de informações contidas nas imagens médicas através de anotações e marcações de informações relevantes. Uma anotação pode ser explicativa ou uma descrição de informação, gerada por seres humanos ou por máquinas, que se relaciona diretamente com o conteúdo de uma imagem ou várias imagens de referência. As anotações tornam-se uma coleção de descrições de conteúdo que podem ser usadas para fins de mineração de dados semânticos. Uma marcação de imagem é composta de símbolos gráficos ou descrições textuais associados a uma imagem.

Marcações podem ser usadas para descrever uma informação textual e as regiões de interesse visual. Informações nas anotações e marcações são usadas para preencher o schema AIM, através de funções da biblioteca de software AIM, com a finalidade de geração de objetos DICOM SR, documentos XML AIM e documentos no formato HL7 CDA.

\subsection{Considerações Finais}

Padrões médicos de interoperabilidade vem melhorando a forma de trabalho na área de saúde. Eles utilizam as tecnologias da Web Semântica para auxiliar as pesquisas médicas e encontrar soluções através do auxilio de computadores, como por exemplo, o uso dos formatos RDF, OWL para realização de reasoners.

O AIM, um padrão de anotação, vem sendo desenvolvido e elaborado, tanto para ajudar na estruturação dos relatórios radiológicos, como também para ser entendido por maquinas. 
Esses avanços vem contribuído no entendimento, interoperabilidade e compartilhamento do conhecimento biomédico radiológico como um todo. 


\section{Ferramentas}

\subsection{Introdução}

Neste capítulo abordaremos as ferramentas utilizadas pelos radiologistas para visualização de imagens médicas, criação semântica de anotações sobre essas imagens, o gerenciamento semântico de anotações e a pesquisa semântica sobre essas anotações. Iremos também abordar as tecnologias Web envolvidas no desenvolvimento da solução proposta.

As ferramentas aqui discutidas estão relacionadas a atividade de anotação de dados. Elas são utilizas pelo The Cancer Bioinformatics Grid (CaBIG) para anotação semântica de imagens médicas. O Biomedical Image Metadata Manager (BIMM) é um repositório de dados de anotações semânticas de imagens médicas no formato AIM, ele realiza buscas semânticas em imagens com base nessas anotações.

Na Seção 4.2 são discutidas as ferramentas AIM ClearCanvas e AIM iPAD. A seção 4.3 é destinada a apresentação do BIMM e de sua arquitetura de funcionamento. Finalmente na seção 4.4 são discutidas as ferramentas, APIs e as Tecnologias utilizadas para o desenvolvimento de interfaces Web interativas que foram utilizadas neste trabalho.

\section{2 caBIG Tools}

O caBIG é um programa que foi criado em 2004 pelo National Cancer Institute (NCI) com a intenção de facilitar o compartilhamento de infra-estrutura de TI, dados e aplicações ao longo dos mais de 50 centros de câncer nos EUA (Prior et al., 2007). Em 2005, o CaBIG, criou o In Vivo Imaging Workspace para promover o uso de imagens médicas no estudo do Câncer. O principal objetivo do In Vivo Imaging Workspace é de promover avanços no campo da Informática Radiológica através do desenvolvimento, otimização e validação de ferramentas computacionais para extrair conhecimentos a partir de imagens médicas in vivo e melhorar, dessa forma, os resultados dos pacientes com Câncer (Prior et al., 2007).

Recentemente, o caBIG apoia dois projetos de ferramentas para anotação semântica de imagens médicas no formato AIM: o AIM ClearCanvas Workstation e o AIM iPAD (renomeado posteriormente para AIM ePAD). 


\subsubsection{AIM ClearCanvas Workstation}

O ClearCanvas é um pacote de soluções em código aberto que incluem um servidor de imagens (PACS), um RIS e um programa cliente Workstation, para visualizar imagens médicas, compatível com a plataforma Windows (Barra et al., 2010). O projeto AIM ClearCanvas foi desenvolvido baseado no sistema ClearCanvas Workspace. Esta ferramenta possibilita a pesquisa de imagens e estudos médicos no National Biomedical Imaging $\operatorname{Archive}^{4}$, que é um serviço aberto que provê a usuários, de forma segura, o armazenamento, pesquisa e identificação de imagens. O AIM ClearCanvas adiciona um conjunto de funcionalidades de anotação AIM que são descritos na Tabela 2.

Tabela 2 - Ferramentas AIM disponíveis no AIM ClearCanvas Workstation

\begin{tabular}{|l|l|}
\hline Ferramenta & \multicolumn{1}{c|}{ Descrição } \\
\hline & $\begin{array}{l}\text { AIM TCGA template tool, permite que anotações baseadas em questões e respostas } \\
\text { sejam capturaras a partir de um template. }\end{array}$ \\
\hline & $\begin{array}{l}\text { AIM object locator, permite que o usuário liste todos os objetos AIM do estudo, } \\
\text { sem a necessidade de percorrer as imagens da série. }\end{array}$ \\
\hline $\begin{array}{l}\text { AIM Details tool, permite a visualização detalhada das informações de entidades } \\
\text { anatômicas e de observação da imagem quando o usuário seleciona uma marcação } \\
\text { gráfica de uma anotação já existente. }\end{array}$ \\
\hline $\begin{array}{l}\text { Line measurement tool, permite que o usuário crie duas linhas retas para medir o } \\
\text { maior diâmetro e comprimento perpendicular. }\end{array}$ \\
\hline
\end{tabular}

A Figura 6 apresenta o formulário de anotação baseado na AIM TCGA template tool. O rótulo 1 indica a localização do botão para ativação da ferramenta dentro do AIM ClearCanvas, já o número 2 faz com que o pop-up de anotação fique fixado na interface do AIM ClearCanvas e o rótulo 3 mostra o formulário carregado a partir de um AIM TCGA template.

\footnotetext{
${ }^{4}$ https://cabig.nci.nih.gov/community/tools/NCIA
} 


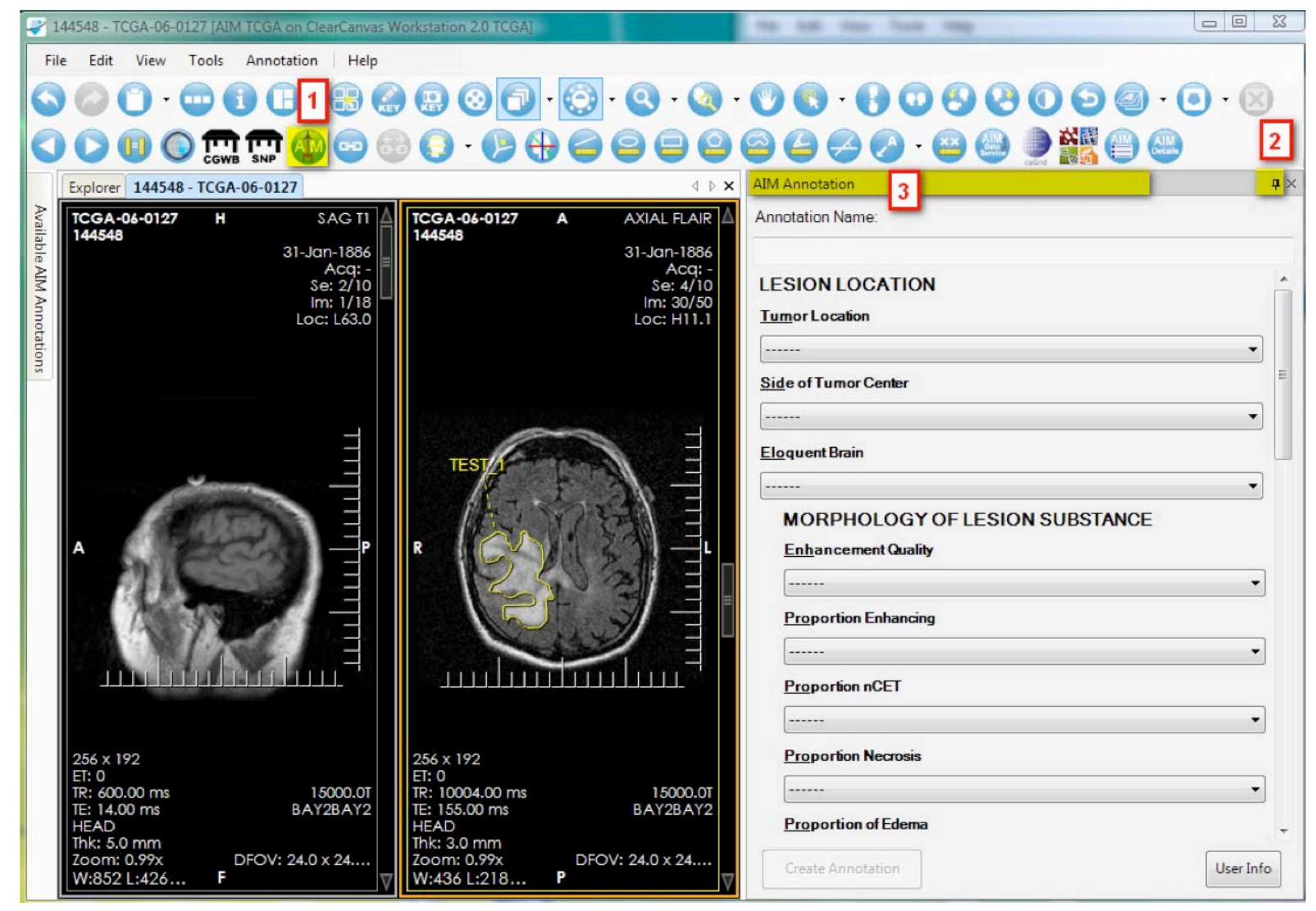

Figura 6 - Anotação Semântica e marcação de imagem no AIM ClearCanvas

Quando o usuário finaliza o preenchimento de suas anotações, o sistema permite que ele as salve no formato AIM em XML em um diretório local. A imagem anotada permanece com a mesma estrutura, porém os arquivos de anotação mantém um conjunto de referencias para as imagens que foram marcadas com os dados de ROI (Regions Of Interest), que são desenhos geométricos feitos pelos usuários para delimitar a região anotada nas imagens.

\subsubsection{AIM IPAD}

O AIM iPAD é um plug-in do OsiriX, que, por sua vez, trata-se de um software livre de código aberto capaz de navegar e visualizar imagens médicas com a capacidade de explorar grandes conjuntos de dados de modalidades multidimensionais (Rosset et al., 2004). O OsiriX é um aplicativo stand-alone para o sistema operacional MacOS X. Ele também inclui um banco de dados de imagens. O OsiriX foi desenvolvido sobre uma arquitetura de componentes de código aberto, mostrada na Figura 7. 


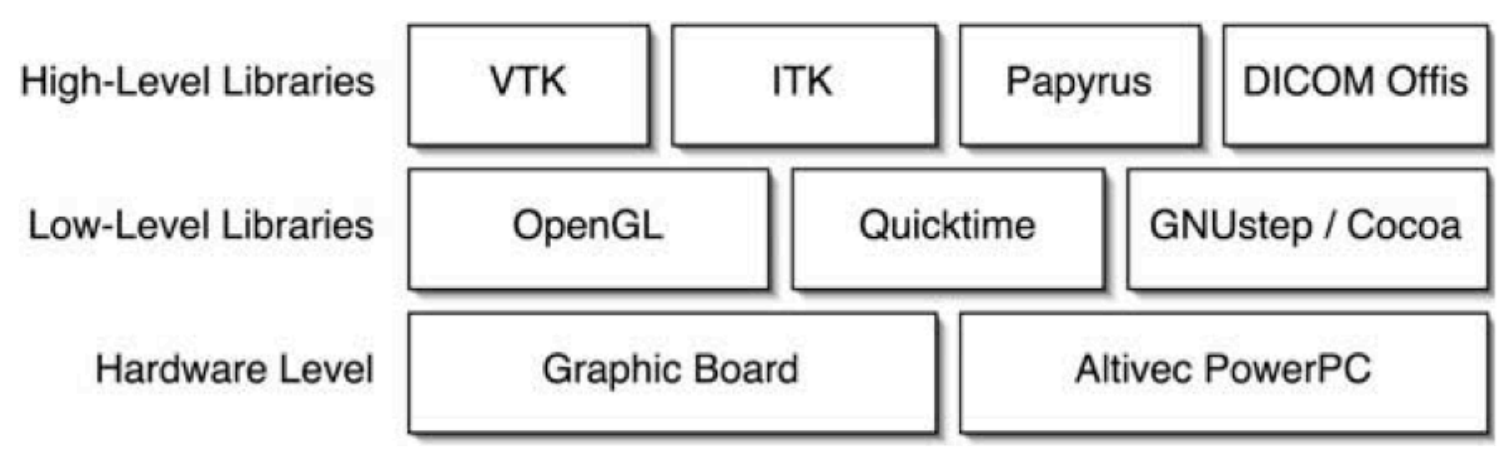

Figura 7 - Arquitetura com os componentes do OsiriX (Rosset et al., 2006).

Os componentes principais da arquitetura do OsiriX (Figura 7) são:

GNUstep / Cocoa: trata-se de um framework orientado a objetos para o desenvolvimento de interfaces de usuário complexas, o Cocoa é o nome dado pela Apple Computer ao ambiente gráfico do MacOS X e utiliza a linguagem Objective-C.

OpenGL: é um padrão gráfico industrial para imagens em 3D.

The Visualization Toolkit (VTK): é uma biblioteca de processamento e visualização de imagens 3D que é grandemente adotada pela comunidade cientifica.

The Insigth Segmentation and Registration Toolkit (ITK): é um conjunto de extensão de bibliotecas específicas para imagens médicas com um completo conjunto de processamento de algoritmos $2 \mathrm{D}$ e $3 \mathrm{D}$ adaptados para estas tarefas.

Papyrus toolkit: trata-se de um toolkit para gerenciamento de arquivos DICOM, provendo funcionalidades de leitura e escrita deste formato incluindo todos os metadados.

DICOM Offis: é uma biblioteca para funcionalidades de rede do padrão DICOM, suporta os protocolos DICOM de comunicação.

Altivec of PowerPC: é uma função de baixo nível da plataforma PowerPC que possibilita a aceleração do processamento de funções de sinais digitais, possibilitando um alto desempenho em tempo real de interação.

Quicktime: é uma biblioteca para trocas de formatos de imagem. Ela possibilita exportar imagens nos formatos TIFF, Photoshop, JPEG, JPEG2000 e BMP. Ela também exporta a seqüência de slides de imagens em formatos de vídeo, como AVI, MPEG e MPEG4.

Essa arquitetura modular do OsiriX facilita o desenvolvimento de plug-ins. Por isso, ele foi usado como base para o desenvolvimento do AIM iPAD, um tab-plugin de código aberto do software OsiriX (Rubin et al., 2008).

O AIM iPAD permite que pesquisadores e clínicos criem anotações semânticas em imagens radiológicas. Ele fornece também uma interface simples para adicionar informação semântica estruturada (observações radiológicas) a imagens ou a regiões de imagens. Ele 
também fornece uma orientação visual para os usuários enquanto estes gravam essas informações, dando feedback quanto ao conteúdo exigido por cada tipo de anotação semântica. Quando o usuário insere informações, o AIM iPAD sugere termos das ontologias RadLex e FMA a medida que o usuário digita o texto. Ele também fornece pistas visuais sobre a integralidade das descrições radiológicas.

A aplicação AIM iPAD compreende três componentes:

1. Um modelo de informação para anotações semânticas de imagens;

2. Uma interface de usuário para coletar as anotações dos usuários;

3. Um back-end de armazenamento para salvar as anotações como XML e para serializar os dados para outros formatos padrões.

A tela do aplicativo AIM iPAD é mostrada na Figura 8. O usuário seleciona uma imagem a ser anotada e entra uma descrição usando uma sintaxe e gramática que é semelhante ao Inglês (por exemplo, "an enhancing, irregular mass in the right lobe of the liver"). Dessa forma o AIM iPAD simultaneamente fornece um feedback para o usuário com a validação do texto. Uma vez que o conteúdo da anotação seja válido, o AIM iPAD armazena as anotações em um arquivo XML, posteriormente serializado para uma variedade de padrões de formatos, como o DICOM-SR ou HL7-CDA. A imagem em si continua separada da anotação, embora a anotação esteja ligada à ela através de um identificador exclusivo. 


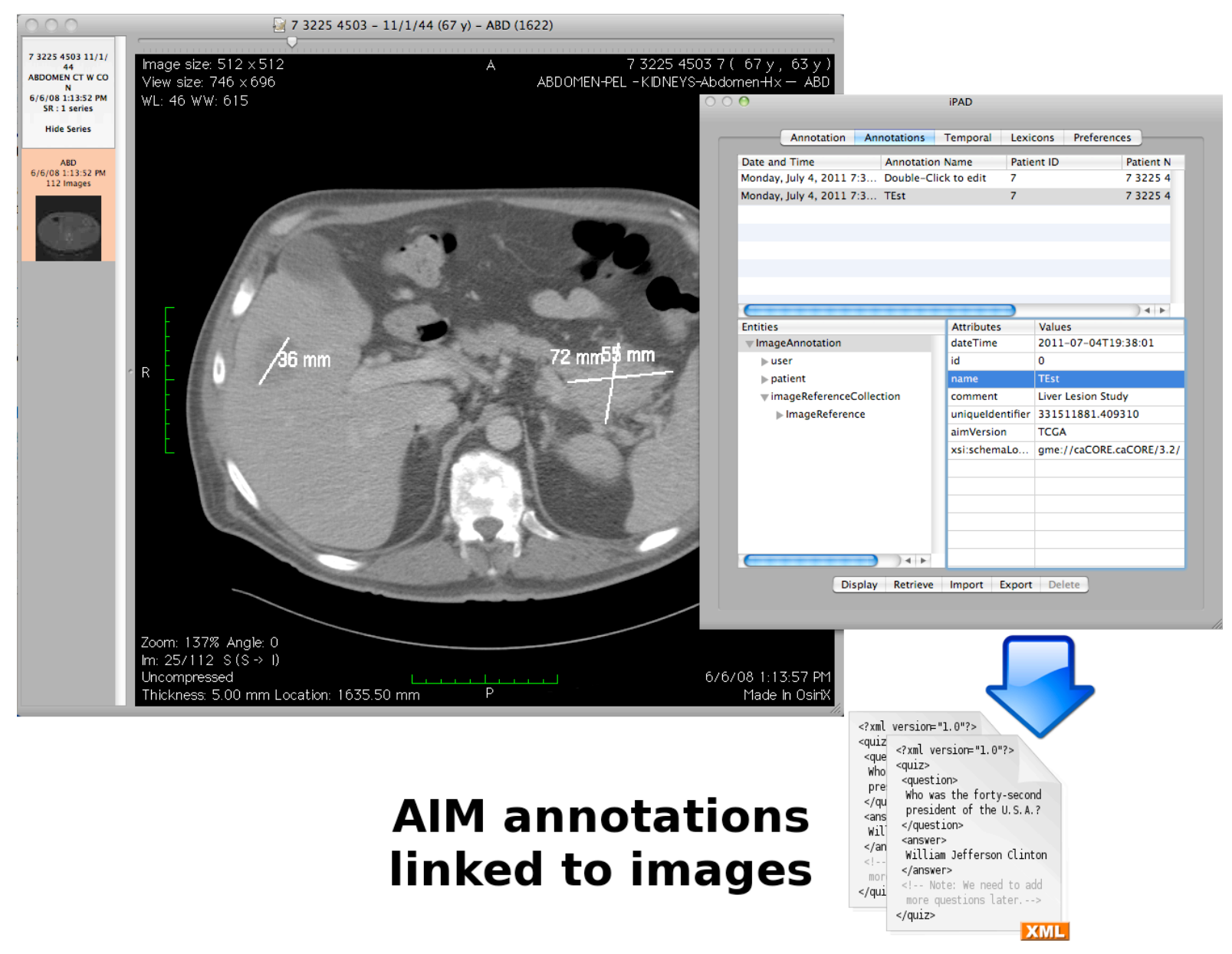

Figura 8 - Anotação semântica marcada com o AIM iPAD

Quando o usuário completa suas anotações, o sistema AIM iPAD salva as informações em um arquivo XML, como uma instância do AIM schema. A imagem recém anotada continua a mesma, sem modificações, embora seus metadados anotados em AIM estejam "linkados" a ela por meio de um DICOM UID.

\subsection{BIMM}

Com o crescimento explosivo no número de imagens médicas obtidas em radiologia se tornou necessário o desenvolvimento de ferramentas que administrem os dados e informações coletados a respeito dessas imagens. Os metadados das imagens médicas são capturados de forma automática (ex. região do corpo, dados do equipamento, código do estudo, etc.) e armazenados no padrão DICOM, no entanto as Regiões de Interesse (ROI), que lidam com os dados relacionados aos aspectos de anatomia, observação radiológica e anotações relacionados a lesões, são criadas pelos radiologistas. Os PACS possuem facilidades para gerenciar e consultar imagens usando apenas seus metadados do padrão DICOM. Anotações e 
outras informações (como ROIs) referentes às imagens não são aproveitadas na recuperação e gerenciamento das mesmas.

O BIMM é um repositório de dados de anotações AIM de imagens, utilizando traços, contornos e informações semânticas contidos nas anotações. Ele possibilita ao usuário realizar pesquisas com base no conteúdo semântico dessas anotações.

O funcionamento do BIMM pode ser explicado pela arquitetura mostrada na Figura 9.

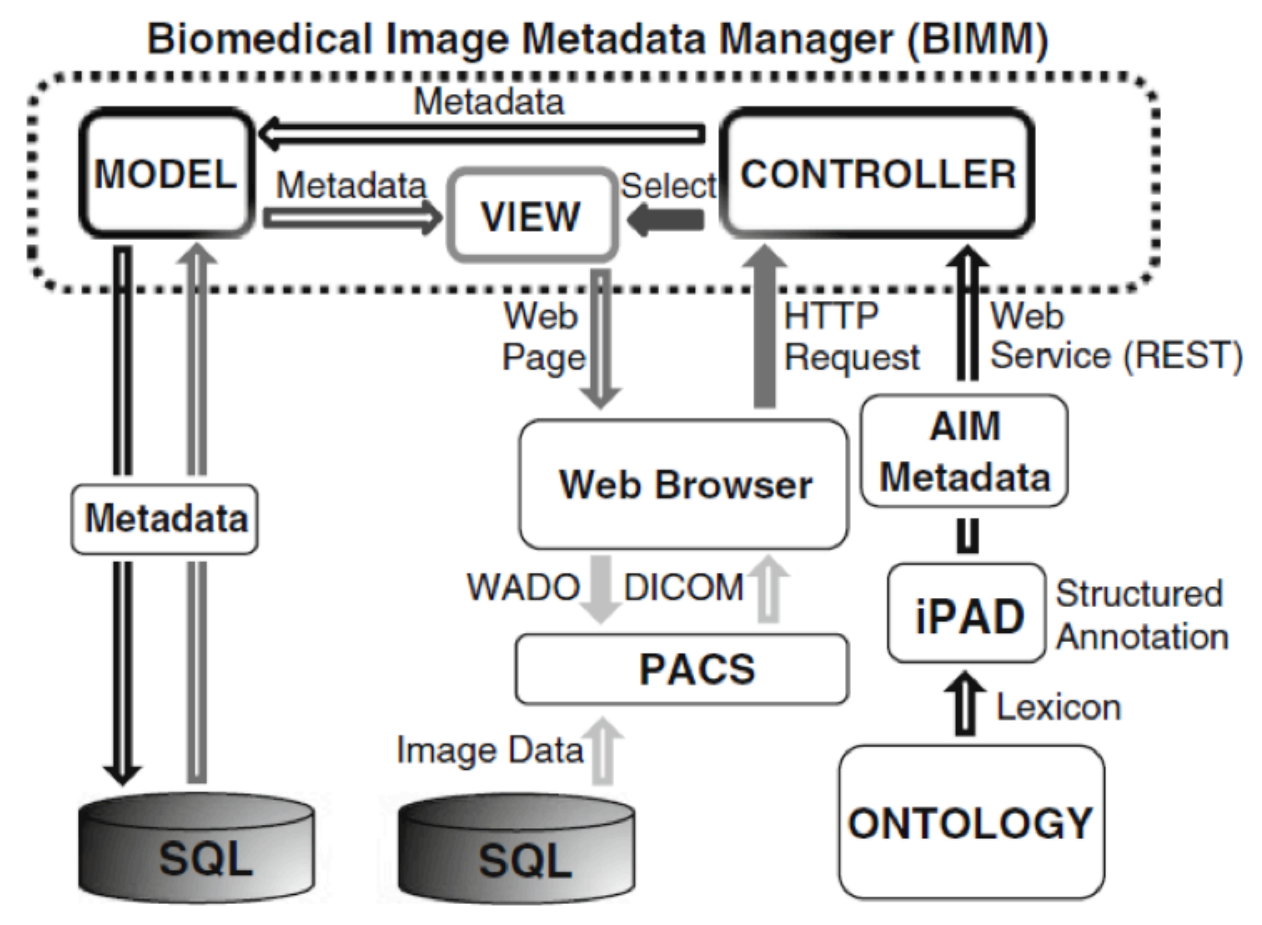

Figura 9 - Arquitetura de funcionamento do BIMM (Korenblum et al., 2010)

As setas pretas representam o processo de envio de metadados para o BIMM.

Inicialmente, é escolhida uma ontologia que especifica um léxico, por exemplo o RadLex. Esse léxico (conjunto de termos) é enviado para o AIM iPAD, que captura as anotações do radiologista sobre a imagem (usando os termos do léxico). O AIM iPAD envia essas anotações (metadados) usando o formato AIM para o controlador apropriado utilizando um serviço Web.

O "CONTROLLER" interage com os modelos para armazenar os metadados em um banco de dados relacional SQL.

O BIMM está sendo desenvolvido pelo LII - Stanford University (pelo professor Daniel Rubin) e será usado para armazenar as informações semânticas criadas com a ferramenta que estamos desenvolvendo nesse trabalho. 


\subsection{Aplicativos Web e RIA}

Um dos objetivos deste trabalho é criar uma ferramenta para a criação de anotações semânticas para imagens médicas. Essa ferramenta deve ser interativa, de fácil uso e estar disponível sem a necessidade de instalação de software na máquina dos usuários, por isso escolhemos implementá-la como uma aplicação Web com Ajax.

O Ajax é uma sigla que significa Asynchronous JavaScript And XML. Trata-se de uma metodologia que emprega o uso de tecnologias de JavaScript e XML (providas por navegadores $\mathrm{Web}$ ) com a finalidade de tornar as páginas Web mais interativas com o usuário, utilizando-se de solicitações assíncronas de informações. O Ajax deu origem ao desenvolvimento de novo tipo de aplicações em Web 2.0, que é uma geração de aplicativos Web com maior interação com os usuários. Embora existam muitas definições para Web 2.0, a maioria parece concordar com a idéia de usar a "Web como plataforma", onde todos os aplicativos são executados em um navegador, em vez de serem pré-instalado no desktop (Kereki, 2011).

A Web 2.0 combina muitas tecnologias. Estas tecnologias residem em diferentes camadas, e são mostradas na Figura 10.

Client Layer: é essencialmente o lado do navegador Web. As tecnologias da Web 2.0 criaram uma revolução nessa camada, utilizando a combinação de várias tecnologias para criar uma experiência interativa para o usuário.

Protocol layer: é onde os novos protocolos, baseados em HTTP, se encontram, e foram criados para suportar as novas tecnologias de cliente e servidor.

Structure layer: é uma camada muito importante, pois contém ingredientes para criação de canais de comunicação. Anteriormente era utilizado apenas o HTML, agora na Web 2.0 são utilizados novos protocolos mais sofisticados nesta camada. 


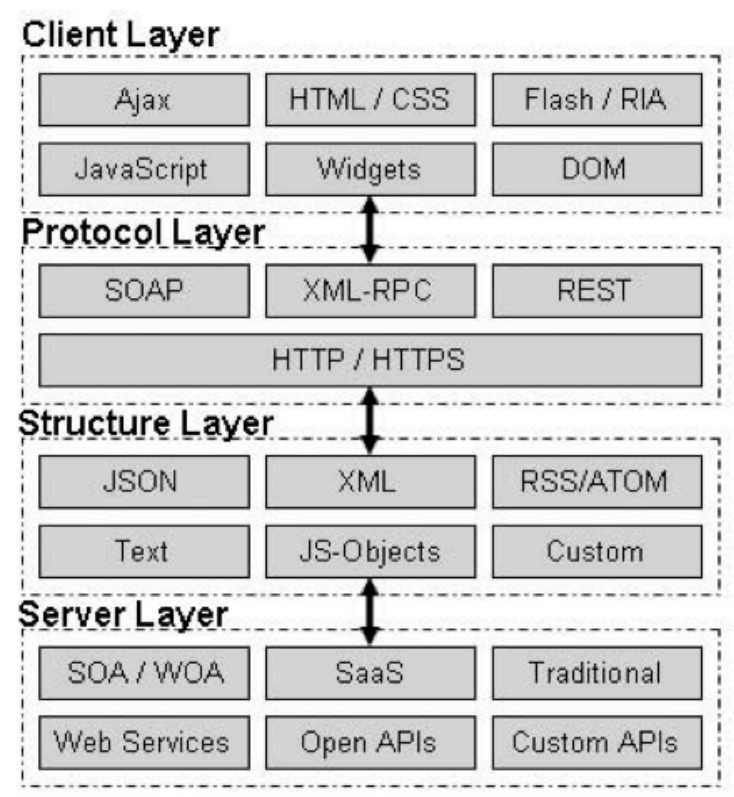

Figura 10 - Web 2.0, camadas de tecnologias (Shah, 2008)

Server Layer: é a camada servidora. A Web 2.0 introduziu novas tecnologias nessa camada para capacitar a rede como uma plataforma e apoiar as troca de informações de uma aplicação para outra.

As aplicações Web 2.0 são denominadas Rich Internet Applications (RIA). Elas são aplicações Web com alto grau de funcionalidade e muito parecidas com as interfaces tradicionais dos programas desktop. Basicamente, é possível construir aplicações Web com RIA que têm a aparência e usabilidade aproximadas de uma aplicação desktop clássica, mas que são carregadas, e não instaladas na máquina cliente, através da Internet. Muitas ferramentas foram criadas com para serem utilizadas para este fim, como Java (através de applets), Adobe Flash e, mais recentemente, o Microsoft Silverlight (Shah, 2008). No entanto, estas plataformas de RIA necessitam de um programa externo ao navegador, como um plugin ou extensão, para funcionarem corretamente e por isso não estão disponíveis em todos os navegadores e Sistemas Operacionais.

\subsubsection{GWT}

Dentre as ferramentas para desenvolvimento de RIA, escolhemos o Google Web Toolkit (GWT) para desenvolver nossa ferramenta de anotações semânticas. O GWT é uma ferramenta que permite aos desenvolvedores Web criarem aplicações Web com níveis de interatividade aproximados de uma aplicação desktop. O desenvolvedor codifica as interfaces trabalhando com a linguagem Java, e posteriormente compila seu código para Javascript, que é executado no navegador Web. O resultado disso é um código final otimizado, em 
Javascript, compatível com as peculiaridades de cada navegador Web, pois o GWT gera um código especifico para cada navegador Web, tirando essa tarefa nada trivial da preocupação de seus desenvolvedores. A Figura 11 demonstra as fases do processo de compilação de um aplicativo em GWT.

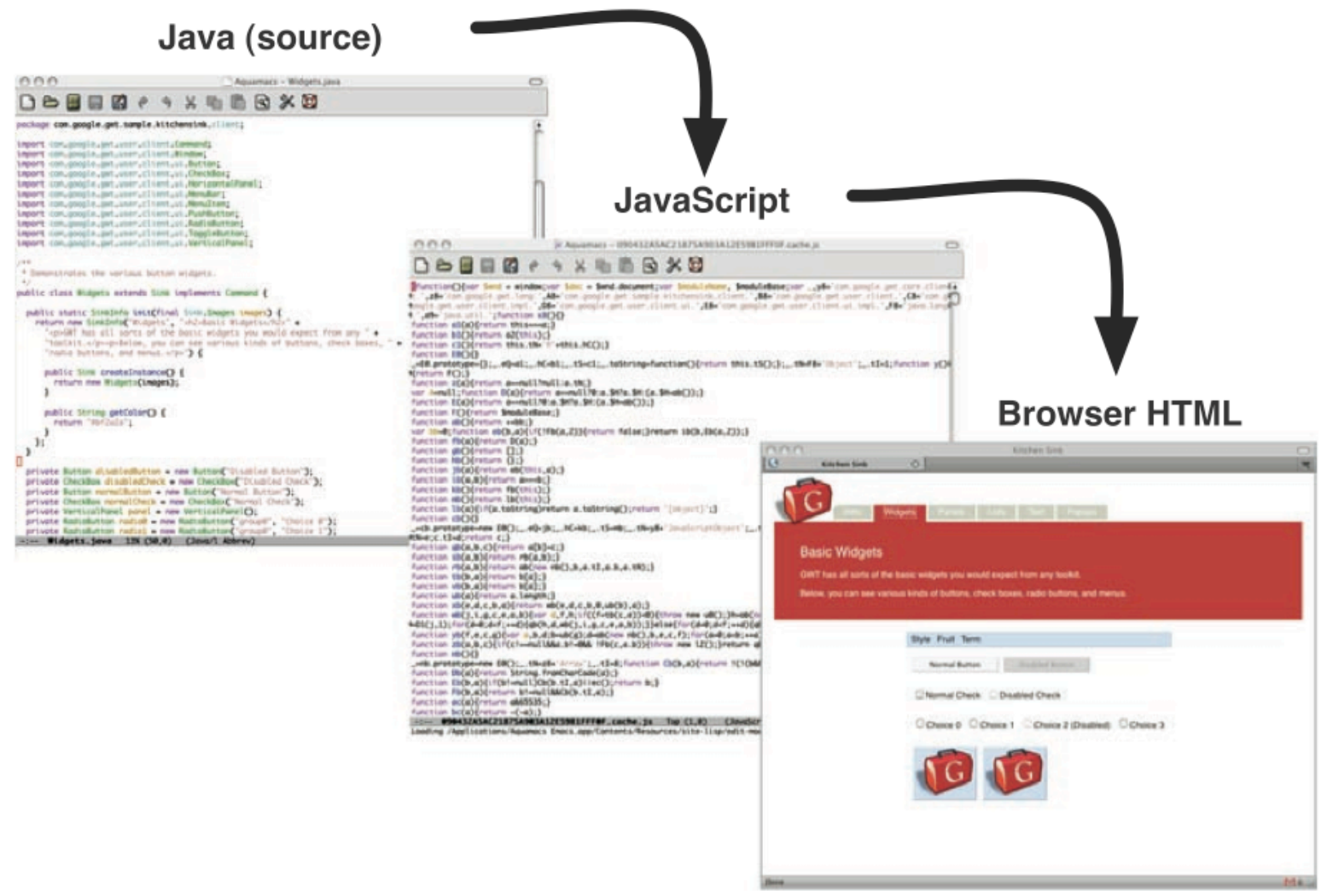

Figura 11 - Uma visão geral da abordagem do GWT (Cooper e Collins, 2008)

A principal vantagem do GWT em relação às demais tecnologias de desenvolvido de RIAs é que o GWT é baseado em Javascript e Ajax e requer apenas um navegador Web padrão para ser executado. Outra vantagem do GWT é que os programas desenvolvidos usando GWT podem ser executados em dispositivos móveis, como tablets e smartphones, e não apenas em computadores padrões. O GWT também facilita a vida dos desenvolvedores escondendo deles as peculiaridades e diferenças entre navegadores Web e tornando o desenvolvimento em Ajax mais simples.

O GWT oferece aos desenvolvedores um conjunto de ferramentas e testadores, incluindo também um debugging shell, que permite a eles testarem e deputarem o código enquanto eles interage com o aplicativo em um navegador Web nativo.

\subsubsection{Padrões de Projeto}

Padrões de projeto no GWT, bem como na maioria dos ambientes de desenvolvimento, fornecem aos programadores um conhecimento de um todo para produzir uma boa arquitetura 
de funcionamento e uma fácil manutenção do código do software. Muitos obstáculos e dificuldades são encontrados quando tentamos construir aplicações de larga escala, no desenvolvimento de aplicações em GWT isso não é uma exceção.

Apesar de existirem diversos padrões de projeto, como Presentation-abstraction-control, Model-view-controle (MVC), Model-view-presenter (MVP) e outras, o MPV é a arquitetura que funciona melhor com o desenvolvimento de aplicações em GWT por duas razões: 1) O modelo MVP desacopla o desenvolvimento de maneira que vários desenvolvedores possam trabalhar simultaneamente no código; 2) o MVP permite que os desenvolvedores testem a maior parte do seu código utilizando apenas o JRE (substituindo as views por mock views) sem necessitar de um navegador (e um software para ativar os botões da interface), o que é mais rápido (GWT, 2012).

O padrão MVP foi desenvolvido originalmente na Taligent na década de 90 e foi implementado primeiramente em C++ e Java (Mike, 1996). Este padrão é baseado no modelo clássico MVC, surgido na década de 80 , onde o controler passa a se chamar presenter e com algumas responsabilidades incorporadas.

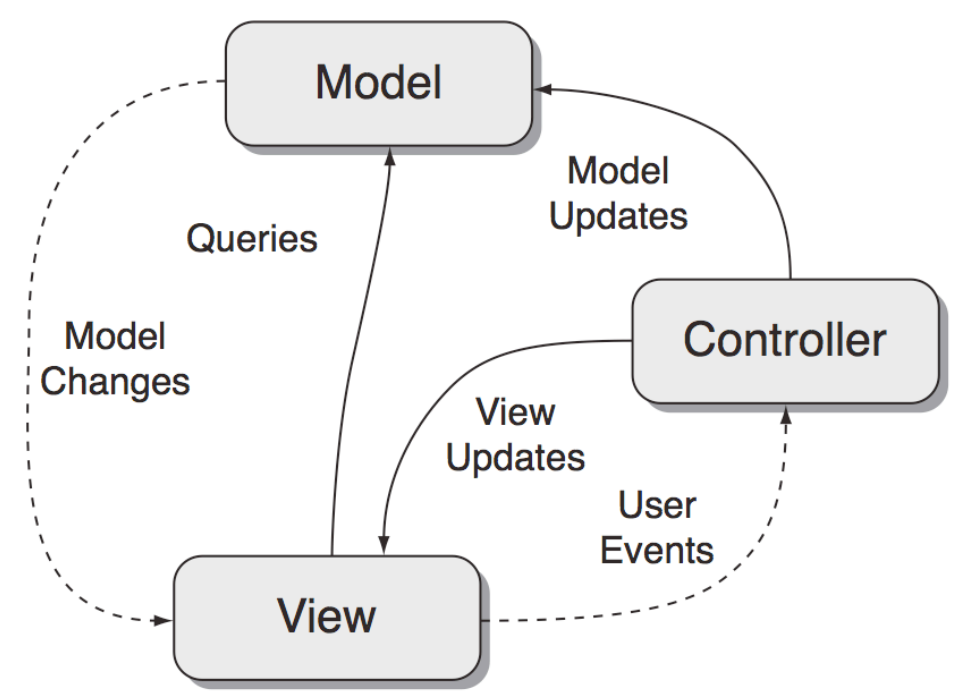

Figura 12 - O padrão de projeto MVC, surgido na década de 80 (Kereki, 2011)

Como apresentado na Figura 12, o padrão MVC basicamente é composto por:

Model: é a camada comprometida com a lógica de negócio, para sistemas Web seria conhecida como servlets, web services, ou outro tipo de implementação residindo do lado do servidor.

View: é a camada onde os widgets de interação com o usuário, em sistemas Web seria conhecido como a implementação que reside do lado do cliente.

Controller: é a camada que recebe as atualizações do usuário que traduz e atualiza o modelo. 


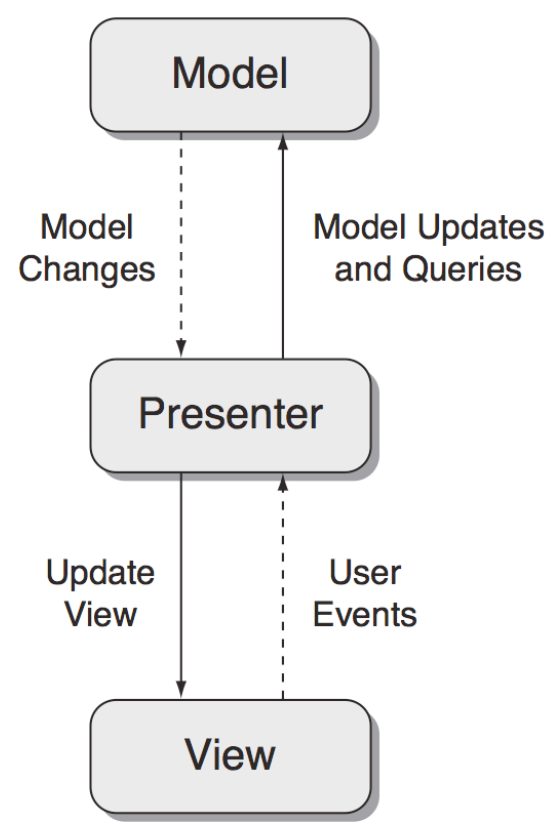

Figura 13 - O padrão de projeto MVP, com menor nível de acoplamento (Kereki, 2011)

A Figura 13, por sua vez, apresenta o padrão MVP, a diferença deste padrão com o MVC é o surgimento da camada Presenter, que seria uma espécie de Controler, em MVC, mas com alguns funcionalidades modificadas.

O MVP é basicamente composto por:

Model: possui as mesmas características como no MVC, porém ela se comunica apenas com a camada Presenter, a qual envia comandos, atualizações e consultas.

View: esta camada possui o mesmo papel em MVC, no entanto a comunicação entre ela e o modelo não acontece. Quando o usuário realiza uma ação, a View informa ao Presenter sobre a ação do usuário, que poderá então atualizar ou não a View.

Presenter: é a camada chave do MVP, como uma ponte entre o Model e a View

Outro fato percebido é o baixo acoplamento da arquitetura, agora a View só irá se comunicar com o Presenter e não pode alterar o Model diretamente, como é possível no padrão MVC.

No desenvolvimento em GWT as interações entre View e Model podem gerar algumas dificuldades, primeiro que a comunicação de mudanças entre o Model e a View é complicada, principalmente pela separação que tem um sistema Web, com um lado cliente e outro servidor. Bem como o fato do envio de consultas entre a View e o Model fazer com que os testes fiquem mais difíceis (por envolverem comunicação via rede.

As views são carregadas estaticamente e cabe a camada presenter modificar os valores contidos nas views por novos e apresentá-las ao usuário. Criar uma nova instancia de uma view, em tempo de execução, é muito custoso para sistemas baseados em GWT. Por isso, o 
GWT recomenda o uso de uma classe estática Factory (aplicando o padrão de projeto Factory ref) para gerar as estâncias para as views.

\subsection{Considerações Finais}

O caBIG tem apoiado o desenvolvimento de ferramentas para captura de informação semântica, como AIM ClearCanvas Workstation e AIM iPAD. Tanto o AIM ClearCanvas Workstation quanto o AIM iPAD são softwares com a finalidade de visualizar imagens medicas e criar anotações de imagens semânticas, com o uso do padrão AIM. No entanto, por se tratarem de aplicações desktops, é necessário instalar e realizar configurações para utilizar o sistema. Outro problema é que o OsiriX só pode ser executado em computadores com sistemas operacionais Mac OS e o ClearCanvas apenas na plataforma Windows, ficando outros potenciais usuários impossibilitados de utilizar e acessar esses sistemas.

Por esta razão, acreditamos que um sistema baseado em tecnologias Web usando tecnologias como RIA e GWT pode solucionar esses problemas de compatibilidade de plataforma e ainda permitir a difusão dessa tecnologia para uma comunidade mais ampla de radiologistas. 


\section{O Protótipo do ePAD}

Neste capítulo são descritos a implementação do protótipo ePAD e os resultados obtidos durante o desenvolvimento deste trabalho. $\mathrm{O}$ ePAD foi desenvolvido para atender as necessidades dos radiologistas dentro de um ambiente clinico padrão. Ele recupera as imagens médicas a partir de servidores PACS dentro de ambiente clinico, no qual deve ser utilizado. Por meio de cliente baseado em RIA, o ePAD é capaz de mostrar e manipular imagens médicas através da interação com os usuários, que precisam usar apenas um navegador Web padrão, sem a necessidade de instalação de softwares e plugins adicionais, para acessar o sistema.

O ePAD suporta AIM Templates para a criação de anotações AIM. Os arquivos de anotação, no formato AIM XML, são armazenados separadamente das imagens médicas. Eles ficam ligados a elas através de identificadores únicos (DICOM UID), que é utilizado para recuperá-las posteriormente.

A partir de uma avaliação com usuários finais, foi possível identificar o que o eles esperaram do sistema. A avaliação serviu também para elaborar o planejamento do desenvolvimento de uma versão completa do ePAD (1.0) que deve ser lançada no mês de junho de 2012.

\subsection{Projeto de interfaces}

A principio, os usuários desse novo sistema de anotação semântica de imagens na Web serão os pesquisadores do Dept. of Radiology - Stanford University. Foi aplicado um questionário (disponível no Anexo A) em alguns destes pesquisadores (futuros usuários do sistema) e o resultado desse questionário é apresentado no Anexo B. O resultado indica que os usuários possuem experiência na atividade de anotação de imagens, boa parte conhece ou já utilizou o AIM iPAD ou o AIM ClearCanvas para realizar suas anotações.

Com base no questionário aplicado avaliamos que:

- A faixa etária da maior parte dos usuário é entorno dos 36 a 40 anos.

- A maior parte são radiologistas e a metade trabalha na área de computação.

- Todos possuem doutorado numa das áreas acima. 
- Todos utilizam o sistema operacional Mac OS.

- Todos acessam Internet pelo trabalho.

- A metade tem apenas menos de uma hora diária para realizar registros radiológicos.

- Todos utilizam muito o padrão AIM.

- A maioria utiliza e conhece bastante a ontologia RadLex.

- Todos utilizam o AIM iPAD para realizar anotações.

Com base na avaliação, acreditamos que com uma interface Web os nossos usuários estarão mais aptos a trabalhar nas pesquisas (clinical trials), desde que o ambiente seja simples e completo, no sentido de oferecer os recursos de interação básicos com as imagens médicas e o padrão AIM, mas sem o overhead do OsiriX (no caso do iPAD) e ClearCanvas (no caso do AIM ClearCanvas).

O sistema deverá realizar a recuperação de imagens médicas (através dos sistemas de informação hospitalares), o delineamento dos contornos das lesões tumorais, a associação de termos ontológicos a esses contornos, e o salvamento dessas informações em uma base de conhecimento. Abaixo a lista dos principais requisitos funcionais do sistema que levantamos, o sistema deve:

- Recuperar imagens médicas a partir de um servidor de imagens DICOM (PACS).

- Controlar se usuários estão cadastrados no sistema (“logados”) para obter todas as funcionalidades.

- Mostrar as imagens por categorias como, pacientes, casos e estudos.

- Exibir as imagens DICOM em uma pilha de imagens.

- Permitir a navegação pela pilha de imagens.

- Permitir a criação de objetos geométricos (regiões de interesse - ROI) sobre as imagens (linhas, pontos, polígonos, etc)

- Permitir que o usuário associe esses desenhos geométricos a anotações criadas no padrão AIM

- Enviar ao repositório de imagens as anotações realizadas pelos usuários

- Permitir que os usuários consultem outras anotações já realizadas nas imagens

Após o levantamento inicial de requisitos, foi realizado a prototipação do sistema, um protótipo horizontal foi desenvolvido e avaliado pelos usuários especialistas do Departamento de Radiologia da Stanford University, iremos abordar este assunto na seção 5.2. Com base no protótipo horizontal iniciamos o desenvolvimento de um protótipo funcional com a implementação de algumas funcionalidades do sistema, ele será apresentado na seção 5.3. O 
protótipo funcional foi desenvolvido em conjunto com uma equipe de desenvolvedores do LII da Stanford University.

Para manter o contato e as trocas de informações sobre o desenvolvimento do protótipo funcional foram realizadas reuniões semanais (por vídeo conferencia) e constantes trocas de e-mails com a equipe do LII. Também foi utilizado uma ferramenta wiki para gerenciamento dos requisitos, da documentação do código, das pautas das reuniões, dos resultados das avaliações com usuários (finais e especialistas) e outras informações importantes.

\subsection{Protótipo Horizontal}

Um protótipo horizontal foi desenvolvido com o objetivo de simular uma navegação horizontal do usuário até as principais funcionalidades do sistema (busca das imagens, visualização de imagens médicas e a edição de anotações semântica das imagens. Dessa maneira, os usuário habituados com as interfaces gráficas comuns (baseadas em desktop) puderam enviar seus primeiros feedback de interações com o novo sistema.

A princípio, o sistema permite a busca em imagens médicas, porém a atividade de anotação só será realizada por usuários cadastrados e autenticados no sistema. Para interagir com o sistema, o usuário deve clicar no botão de login e aparecerá um pop-up com um formulário de login. Caso o usuário erre o seu login, o sistema permite a recuperação de senha, através de um botão "Recuperar Senha" que conduz a um formulário de recuperação de senha.

Após o usuário completar a sua autenticação, será permitido a ele a opção de busca de imagens, visualização das mesmas, edição de polígonos e anotações no padrão AIM. Para anotar uma imagem, o usuário deve primeiramente selecionar uma série de imagens DICOM; abri-las e navegar, no conjunto de imagens, através da interface de visualização de imagens; e criar um ROI (usando polígonos, ou outra forma geométrica). Uma vez que o usuário desenhe uma forma geométrica qualquer, ele poderá associar a esse desenho uma anotação de imagem, para isso é aberta uma janela de pop-up onde irão aparecer duas abas:

- Uma para realizar anotações em modo de texto livre, ou seja, a metáfora exige que o usuário escreva em linguagem natural, porém o sistema sugere termos, relacionamentos e valores enquanto o usuário escreve e quando ele corrige erros sintáticos e semânticos presentes na sua afirmação.

- A outra aba apresenta uma estrutura de árvore para que o usuário pesquise o termo e os relacionamentos para associá-los a uma anotação.

O sistema permite que o usuário troque de abas a qualquer momento sem a perda da anotação que já foi iniciada. 
As duas principais telas do sistema são descritas e apresentadas a seguir:

A tela de visualização de imagens: ao entrar nessa tela, veja a Figura 14, o usuário encontrará uma imagem localizada no centro da área de trabalho e nas áreas laterais:

- Lateral esquerda - a barra de ferramentas, nela o usuário encontra ícones funcionais. Todos são localizados de acordo com a sua proximidade com outros botões de funcionalidades similares ou dependentes entre si. As ferramentas são relacionadas a manipulação de imagens DICOM e manipulação de objetos gráficos como edição de polígonos.

- Lateral direita - a barra que muda a camada (imagem) que o usuário está navegando na coleção de imagens DICOM que compõem uma série.

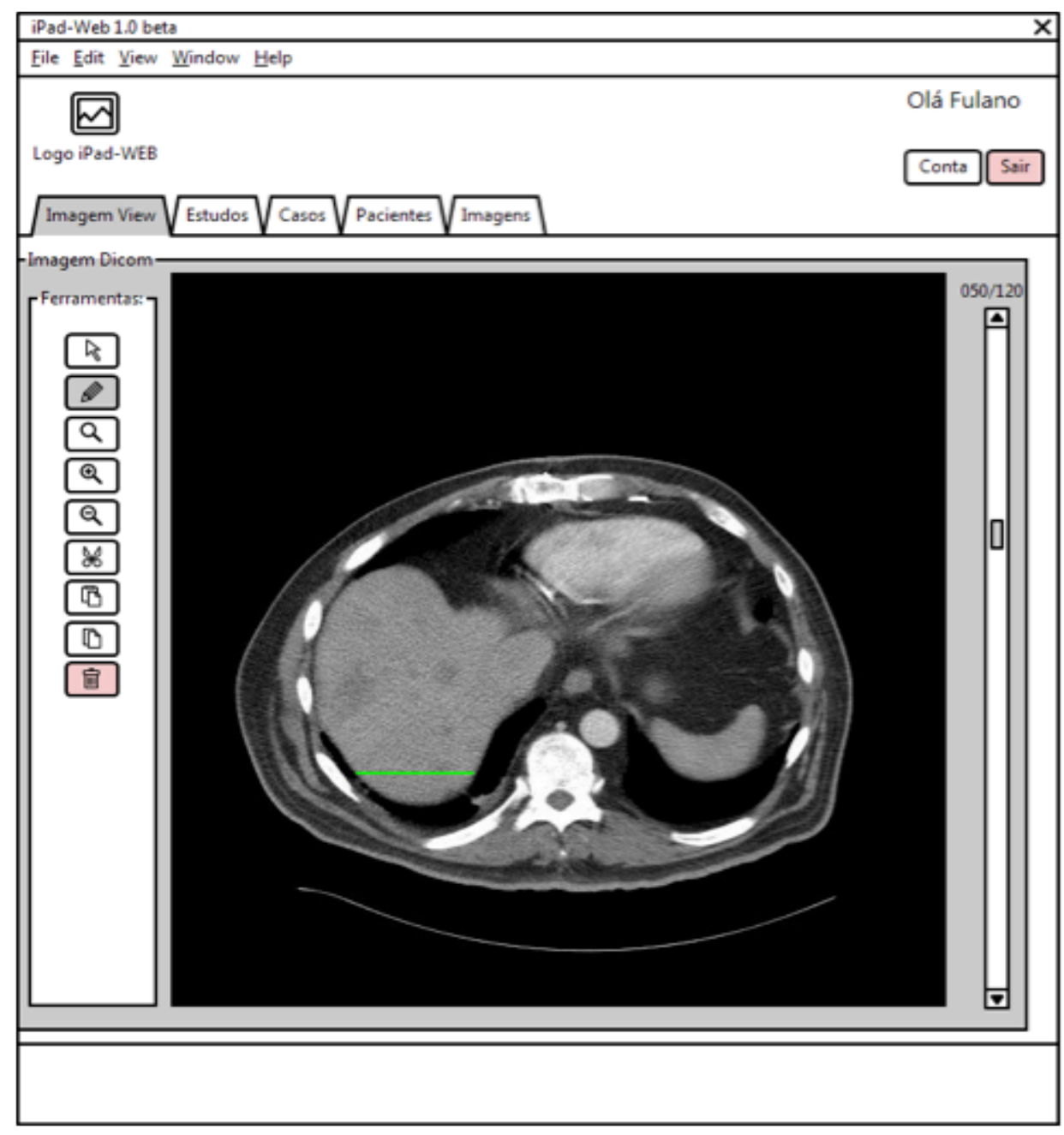

Figura 14 - Tela de visualização de imagens DICOM do protótipo.

Tela de anotação AIM: ao clicar na opção de anotação de dados, o usuário é convidado a inserir dados no formato AIM. Mas esse padrão é um tanto complexo e é necessário que o sistema crie uma metáfora consistente de interação para a criação de anotações. Esta metáfora 
deve ser o mais próximo possível de uma simples anotação em formato de texto, para isso, o formulário de anotação possui duas formas de anotar (Tabs), que podem ser mescladas ou trocas sem perda de dados, veja a Figura 15:

- A primeira Tab é a escrita em texto livre: O sistema tem que acompanhar a digitação do usuário e sugerir, em tempo de escrita, termos e relacionamentos pertencentes à ontologia de anotação (auto-complete). Para tanto, o sistema sugere essas informações em menus pop-ups localizados abaixo do texto que está sendo digitado. O usuário pode clicar em qualquer termo sugerido e o sistema irá completar a digitação automaticamente.

- A segunda Tab usa um campo de escrita em texto livre e uma árvore hierárquica de termos e de relacionamentos para a pesquisa de termos que podem ser utilizados no campo de escrita. Essa Tab é mais indicada para usuários não muito familiarizados com anotações semânticas em imagens ou com os termos da ontologia que está sendo usada.

Ao trocar de Tabs o texto em composição é exportado de uma aba para outra sem perda de informação.

Esse layout foi posteriormente modificado durante o desenvolvimento do protótipo funcional. Inicialmente, a ferramenta de anotação deveria ter a possibilidade de criar anotações em texto livre, no entanto, o workflow de trabalho foi modificado com a introdução da idéia de templates de anotação AIM, ou AIM templates.

Uma AIM template consiste em um modelo XML que orienta a criação do formulário, dos campos que irão formar o arquivo AIM XML final e dos valores que podem ir nesses campos. AIM templates podem ser criadas, antes da realização de um clinical trial, para garantir que os relatórios radiológicos tenham o mesmo padrão, ou podem ser usadas templates padrões como o RECIST (Eisenhauer et al., 2008). Atualmente, apenas o AIM ClearCanvas e o AIM ePAD possuem suporte os AIM templates. Com a utilização dessas templates, os oncologistas e clínicos obtêm todos os termos e valores (quantitativos e qualitativos) que necessitam, ou que acham interessantes, descritos nas anotações. 


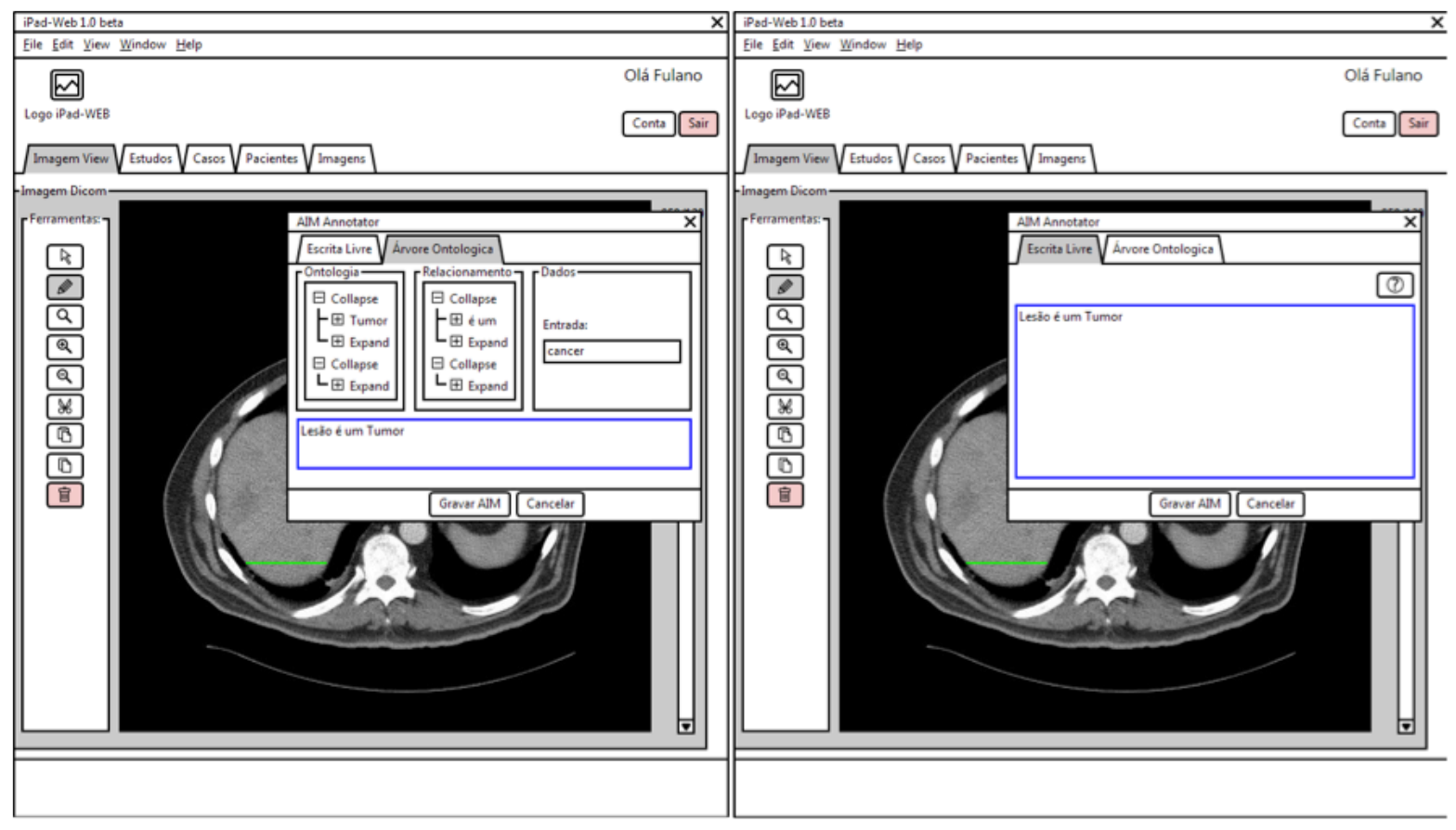

Figura 15 - Tela com pop-up de criação de anotação do protótipo.

\subsection{Protótipo Funcional}

Com base no desenvolvimento e avaliação do protótipo vertical foi iniciada a implementação do protótipo funcional. Ele foi desenvolvido utilizando apenas HTML e Ajax e a maior parte do código foi escrita em GWT. O objetivo principal dessa versão funcional é ser uma prova de conceito das partes principais do software que demonstre a utilidade do sistemas aos usuários finais.

A comunicação entre o ePAD e o servidor PACS ocorre através de um Proxy. O Proxy realiza algumas chamadas especificas, quando necessário, para fazer com que a integração do ePAD com os PACS aconteça. A Figura 16 mostra a arquitetura geral do ePAD. O sistema se conecta aos ambientes clínicos através de servidores PACS (por meio da infra-estrutura de rede local).

O ePAD está dividido em um parte servidora Proxy, uma aplicação Java que roda em um servidor Web, e um lado do cliente, desenvolvido utilizando o GWT que é executado em um navegador Web usando apenas HTML e JavaScript. 


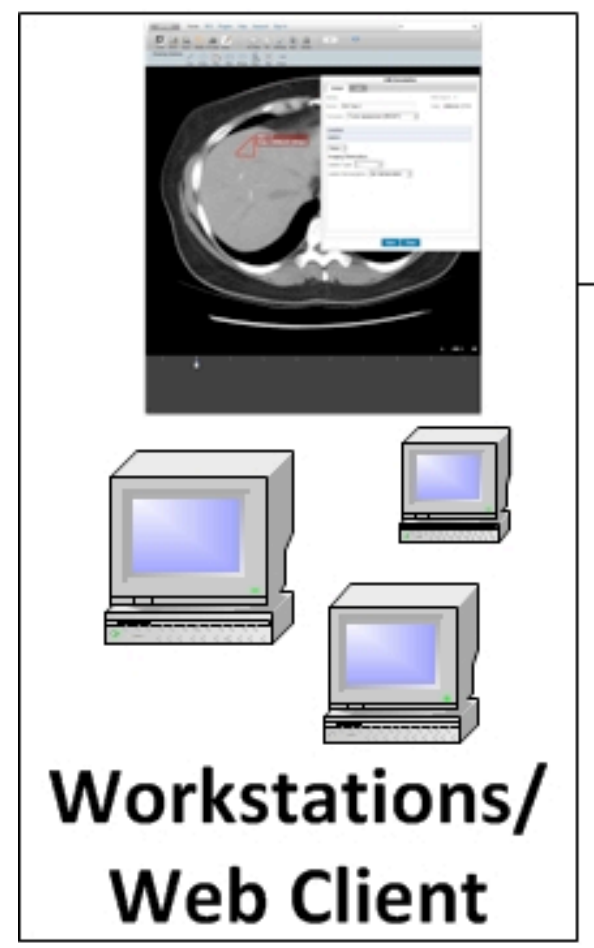

\section{Proxy ePAD \\ Server}

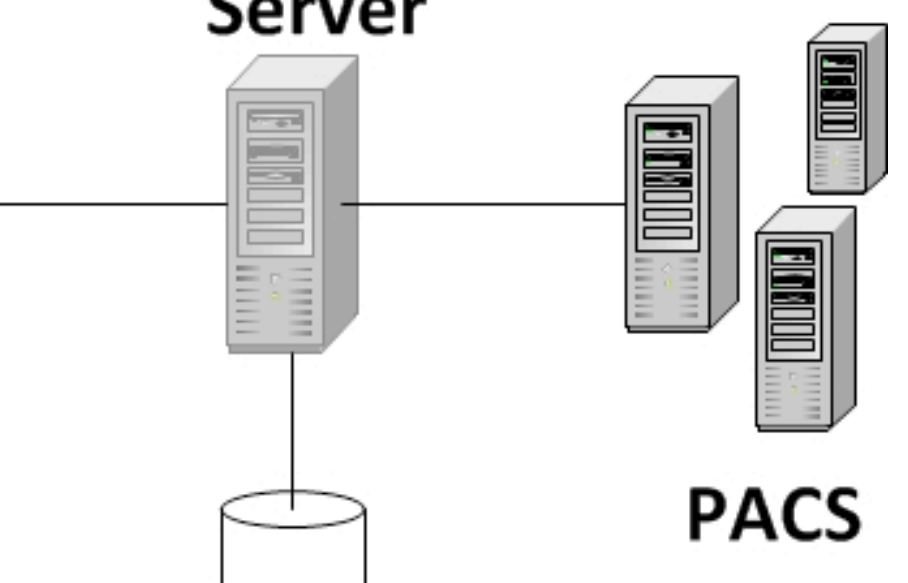

\section{AIM proxy \\ Storage}

Figura 16 - Arquitetura geral do ePAD.

A parte servidora é composta do Proxy e dos serviços Web de comunicação com a parte cliente. A função do Proxy é de se comunicar diretamente com os servidores PACS para recuperar as informações. O Proxy criar um cache das imagens para facilitar o tratamento e a transferência das mesmas entre a parte servidora (Proxy Server) para a parte cliente (Web Client) do ePAD.

Por sua vez, o Web Client foi desenvolvido em grande parte utilizando o GWT. As series de imagens, anotações e demais informações são recuperadas através de requisições HTTP feitas aos serviços Web do Proxy Server. 


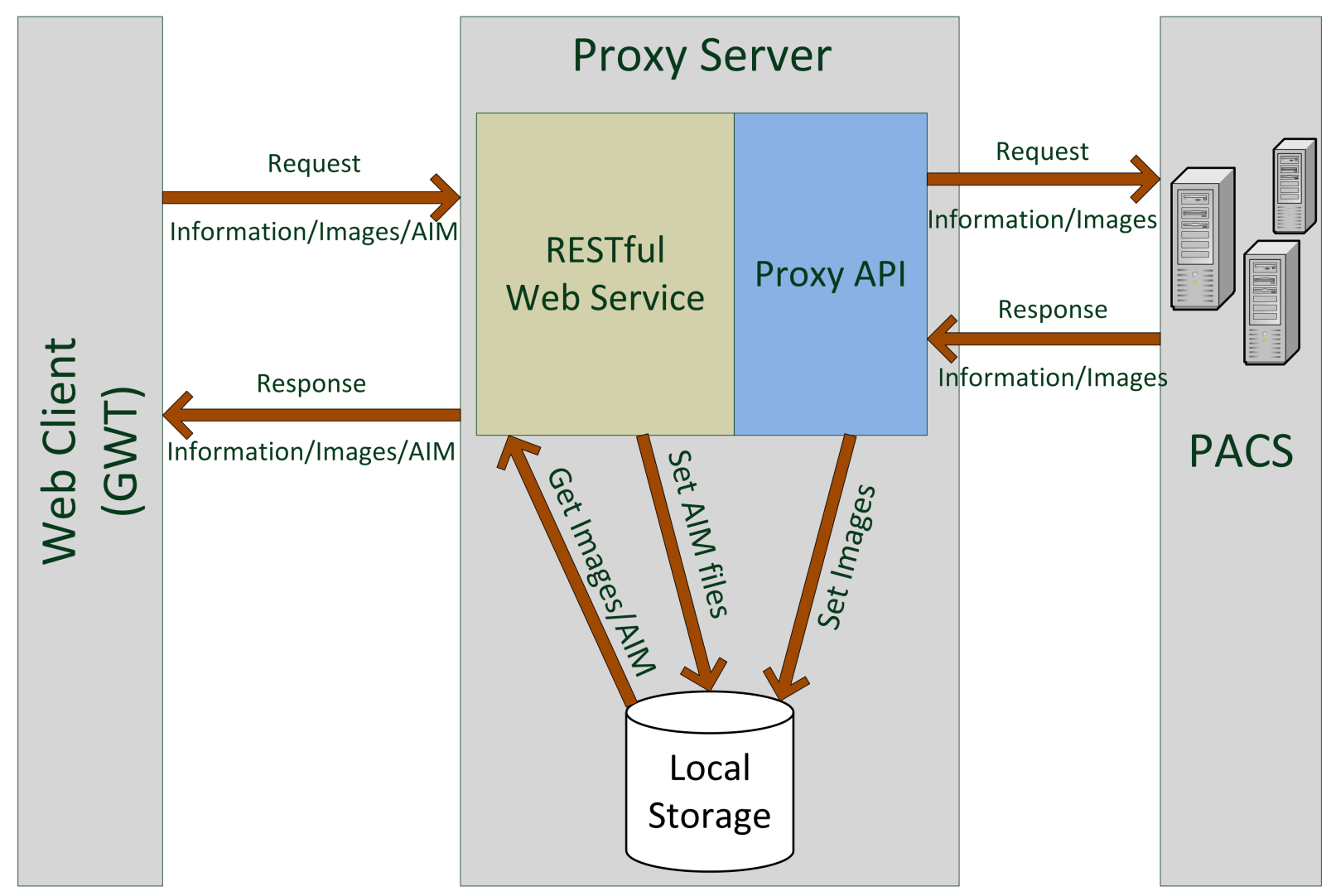

Figura 17 - Arquitetura do servidor Proxy Server do ePAD.

\subsubsection{Proxy Server}

A Figura 17 apresenta a arquitetura de funcionamento da parte servidora do ePAD (Proxy Server). Esta camada se comunica com os PACS através dos protocolos WADO ou HL7, dependendo de qual deles esteja implementado no PACS. Os clientes se comunicam com o Proxy Server através de serviços RESTful implementados por servlets. As servlets podem recuperar imagens/anotações armazenadas localmente ou trabalhar diretamente com a Proxy API para recuperar essas informações nos PACS. Os protocolos e as formas de comunicação entre o Proxy Server e os PACs são encapsuladas na Proxy API, que está sendo desenvolvida pela equipe do LII - Stanford.

A parte servidora também conta com um Local Storage que serve para armazenar os arquivos AIM e as imagens provenientes dos PACS. Estas imagens são passadas para a parte cliente através de chamadas RESTful. 


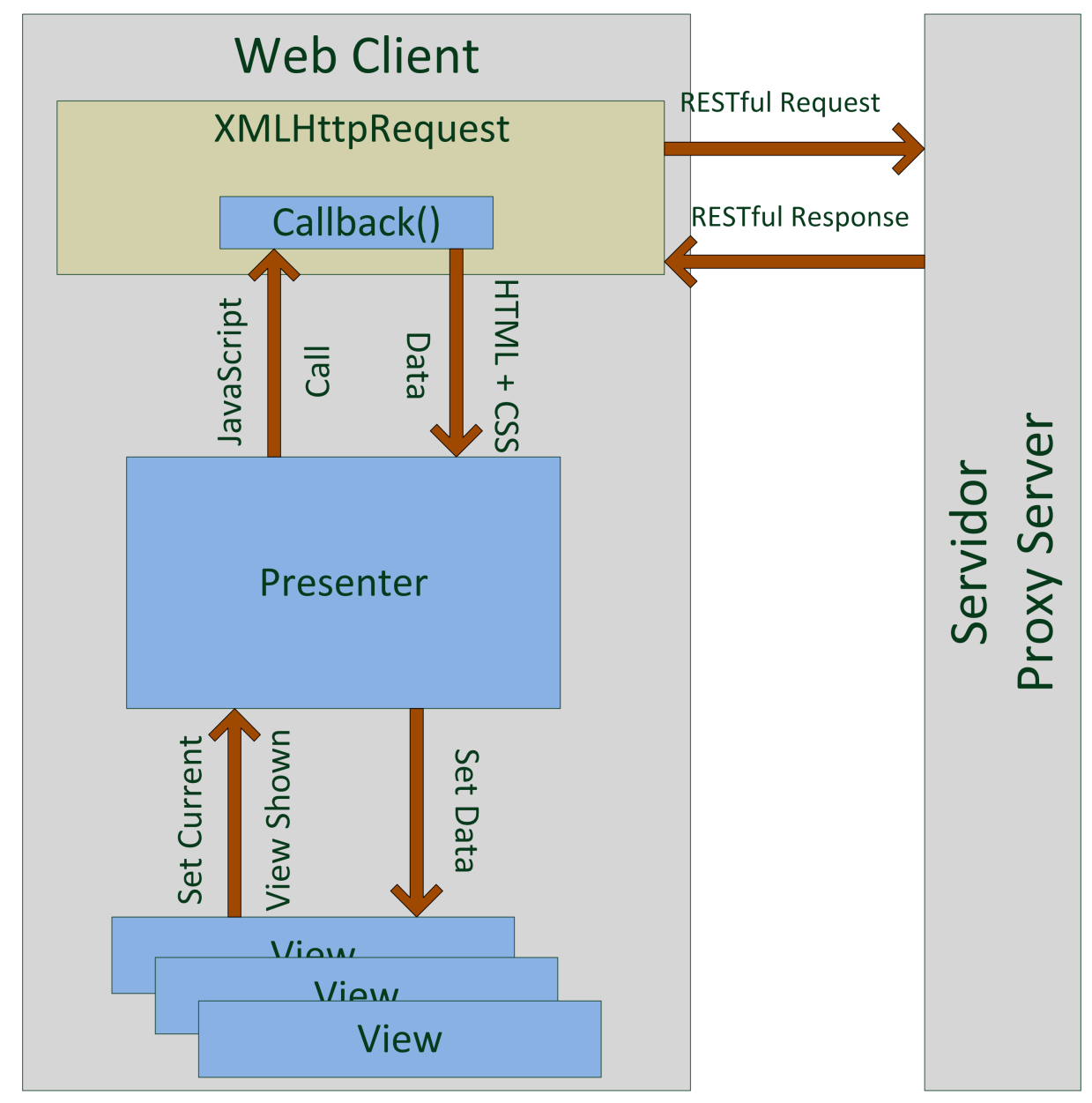

Figura 18 - Arquitetura do cliente ePAD.

\subsubsection{Web Client}

A Figura 18 apresenta a arquitetura de funcionamento do cliente do ePAD. Esse cliente se conecta ao lado servidor através de requisições RESTful. O aplicativo, desenvolvido com GWT, implementa a arquitetura MVP. A camada de apresentação é o coração do sistema. É através dela que os eventos das interações do usuário, capturados pelas views, são tratados na camada de apresentação, que se comunica com a parte servidora através de requisições Ajax com o servidor.

As imagens médicas são recuperadas através das requisições RESTful. A vantagem dessa implementação é a possibilidade de o próprio browser realizar o cache das imagens. $\mathrm{O}$ que aumenta muito a velocidade com que elas podem ser mostradas, já que na segunda vez que as imagens forem carregadas, elas não serão transferidas pela rede e sim carregadas rapidamente do cache do navegador.

A versão cliente deste protótipo pode realizar:

- Visualização dos slices das imagens DICOM (axial)

- Alterar o window/level das imagens no lado do cliente 
- Zoom, girar e mover as imagens visualizadas

- Visualizar anotações existentes

- Criar e editar regiões de interesse (ROI) utilizando formas geométricas

- Criar e associar anotações AIM para estes ROIs

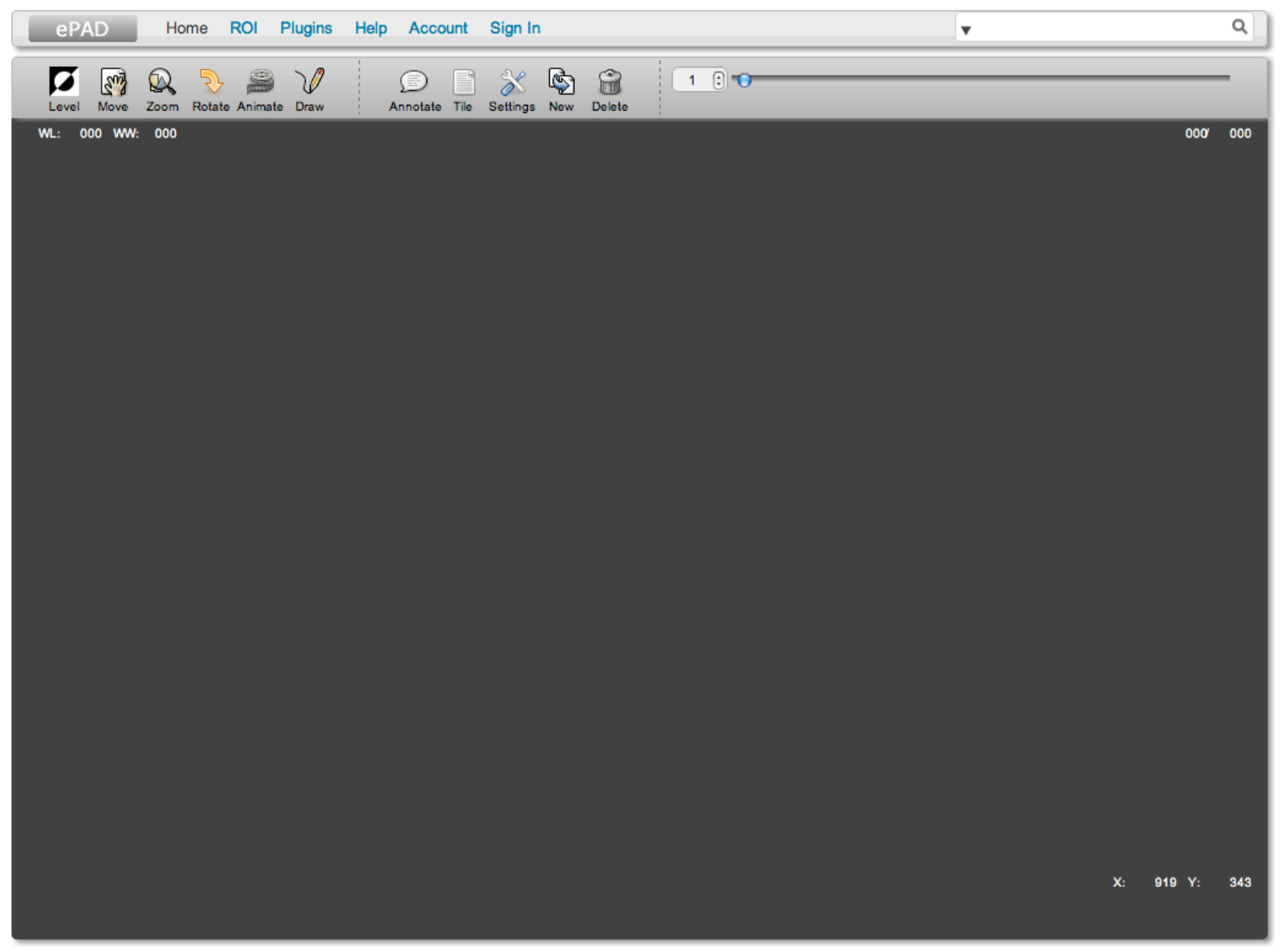

Help Center About Blog Connect Academic Solutions Tools Mobile Developers Publishers My Account

Figura 19 - Tela principal do protótipo (ePAD)

A Figura 19 mostra a tela principal do protótipo. Na base temos a barra de menus e no canto esquerdo (superior) temos a barra de pesquisa. A próxima barra horizontal possui os controles da visualização das imagens. A grande região cinza corresponde a área onde as imagens irão ser posicionadas para visualização. Por fim, na parte inferior temos a barra de links, para o site do projeto, ajuda e atalhos para outros sites e sistemas.

\begin{tabular}{|l|l|l|l|}
\hline ePAD Home ROI Plugins Help Account Sign In & Q \\
\hline & & Patient Name \\
\hline
\end{tabular}

Figura 20 - Barra superior de menu e pesquisa 
A barra superior do sistema, mostrada na Figura 20, é composta, da esquerda para direita, pelo logo do sistema (ePAD), em seguida temos o conjunto de menus do sistema e no canto esquerdo é localizado a barra de busca. O usuário pode buscar as imagens através de um menu de opções, que é mostrado na Figura 20.

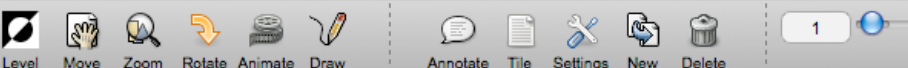

Figura 21 - Barra de ferramentas do ePAD.

A Figura 21 mostra a barra de ferramentas do sistema. Nela o usuário pode alterar as opções de visualização das imagens, como apresentado na Tabela 3:

\section{Tabela 3 - Lista de funcionalidades da barra de ferramentas}

\begin{tabular}{|c|c|c|}
\hline Ícone & Função/Descrição & Implementado \\
\hline Level & $\begin{array}{l}\text { Level: permite a mudança de Window/Level da imagem. O usuário } \\
\text { deve pressionar o botão direito do mouse e arrastar na horizontal e } \\
\text { vertical, trocando os valores de Window/Level da imagem. }\end{array}$ & Sim \\
\hline $\begin{array}{l}\text { Move } \\
\text { Move }\end{array}$ & $\begin{array}{l}\text { Move: permite a movimentação da imagem na tela do sistema. O } \\
\text { usuário deve pressionar o botão direito do mouse e arrastar para a } \\
\text { posição desejada. }\end{array}$ & Não \\
\hline Zoom & $\begin{array}{l}\text { Zoom: permite o aumento ou diminuição da imagem. O usuário deve } \\
\text { clicar na imagem para aumentar ou diminuir o tamanho da mesma. }\end{array}$ & Não \\
\hline Rotate & $\begin{array}{l}\text { Rotate: permite rotacionar a imagem. O usuário deve clicar no botão } \\
\text { para acrescentar } 90^{\circ} \text { de rotação a imagem. }\end{array}$ & Não \\
\hline Animate & $\begin{array}{l}\text { Animate: permite visualizar uma animação das imagens. Quando o } \\
\text { usuário clica opção, as imagens são passadas, intercalando um curto } \\
\text { período de tempo, dando assim um efeito de filme pelas camadas da } \\
\text { serie de imagens. }\end{array}$ & Não \\
\hline Draw & $\begin{array}{l}\text { Draw: permite o desenho de ROI através de formatos geográficos. O } \\
\text { sistema permite o desenho de retas, retângulos, polígonos fechado, } \\
\text { polígonos aberto e elipse. }\end{array}$ & Sim \\
\hline Annotate & $\begin{array}{l}\text { Annotate: permite a criação e visualização das anotações AIM. O } \\
\text { sistema apresenta o formulário de criação de anotações AIM para os } \\
\text { ROI desenhados pelo usuário. }\end{array}$ & Sim \\
\hline Settings & Settings: permite a mudança de configurações do sistema. & Sim \\
\hline
\end{tabular}




\begin{tabular}{|l|l|l|}
\hline \begin{tabular}{l|l} 
New \\
New
\end{tabular} & $\begin{array}{l}\text { New: permite a criação de uma nova anotação. (ira remover os ROI e } \\
\text { anotaçes abertas) }\end{array}$ & Não \\
\hline \begin{tabular}{l} 
Delete \\
\hline
\end{tabular} & $\begin{array}{l}\text { Delete: permite apagar de forma permanente a anotação que esta aberta } \\
\text { pelo usuário. }\end{array}$ & Sim \\
\hline
\end{tabular}

O primeiro passo de um usuário no ePAD seria localizar e abrir uma série de imagens. A Figura 22 apresenta a Tela de resultado do ePAD. O Widget de resultado do ePAD é divido em 3 colunas. A primeira, da esquerda para a direita, apresenta o nome dos pacientes encontrados, no caso visto na figura os nomes dos pacientes foram trocados por códigos. $\mathrm{Na}$ segunda coluna, é mostra um lista com os códigos (UID DICOM) dos estudos encontrados do paciente selecionado na primeira coluna. A última coluna mostra uma miniatura para cada serie encontrada em um estudo selecionado na coluna central.

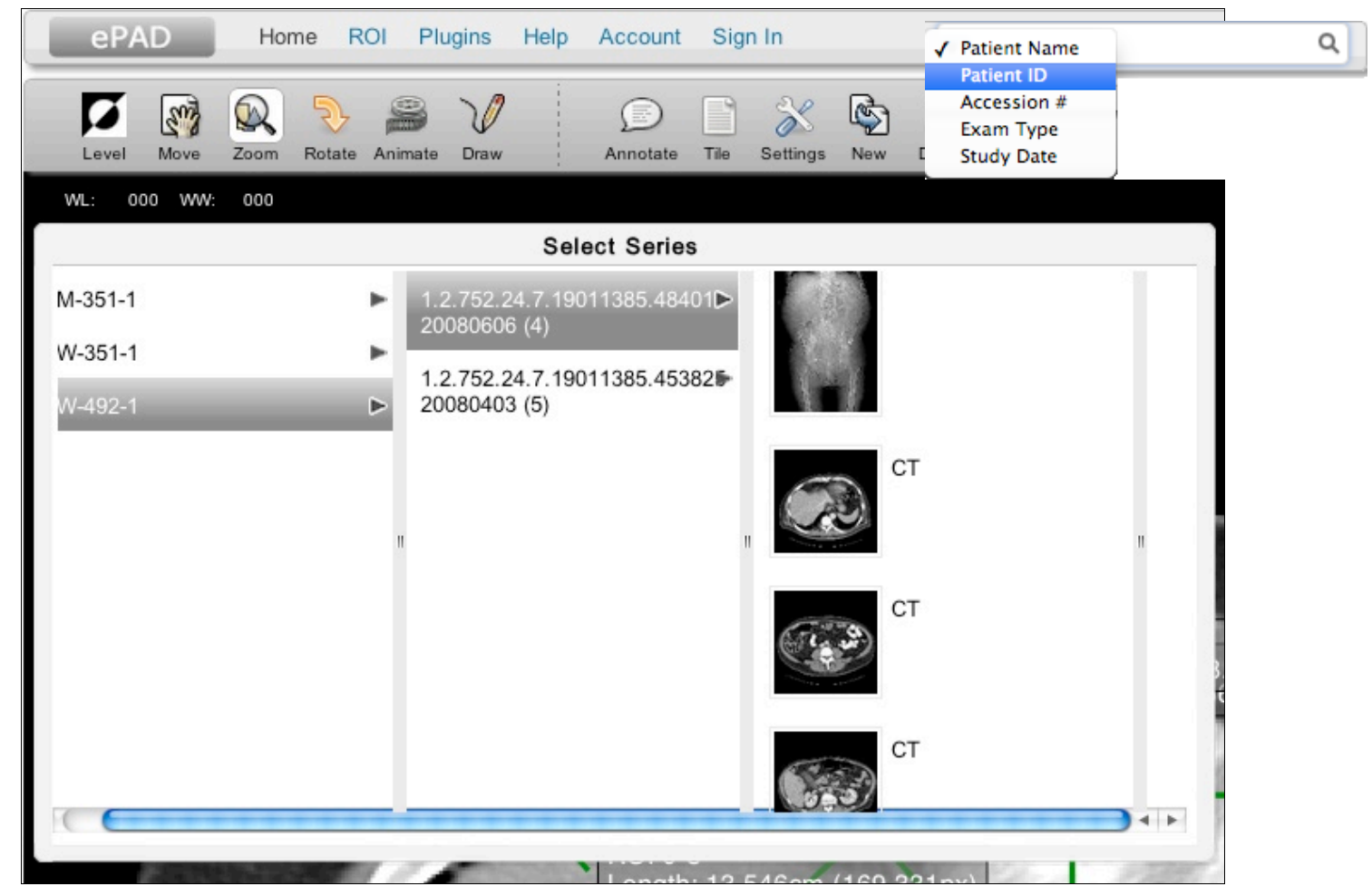

Figura 22 - Tela com Widget de resultado de busca do ePAD

Ao encontrar a serie certa, o usuário clicará na miniatura correspondente da serie para abrila e visualizá-la. Então, o usuário começará a procurar e demarcar as lesões através de ROIs, como mostrado na Figura 23. Ele pode utilizar as ferramentas de visualização de imagem para melhorar sua compreensão sobre as mesmas, como a mudança de window/level, zoom ou movê-las. Essas opções estão marcadas com uma retângulo em vermelho na Figura 23. 


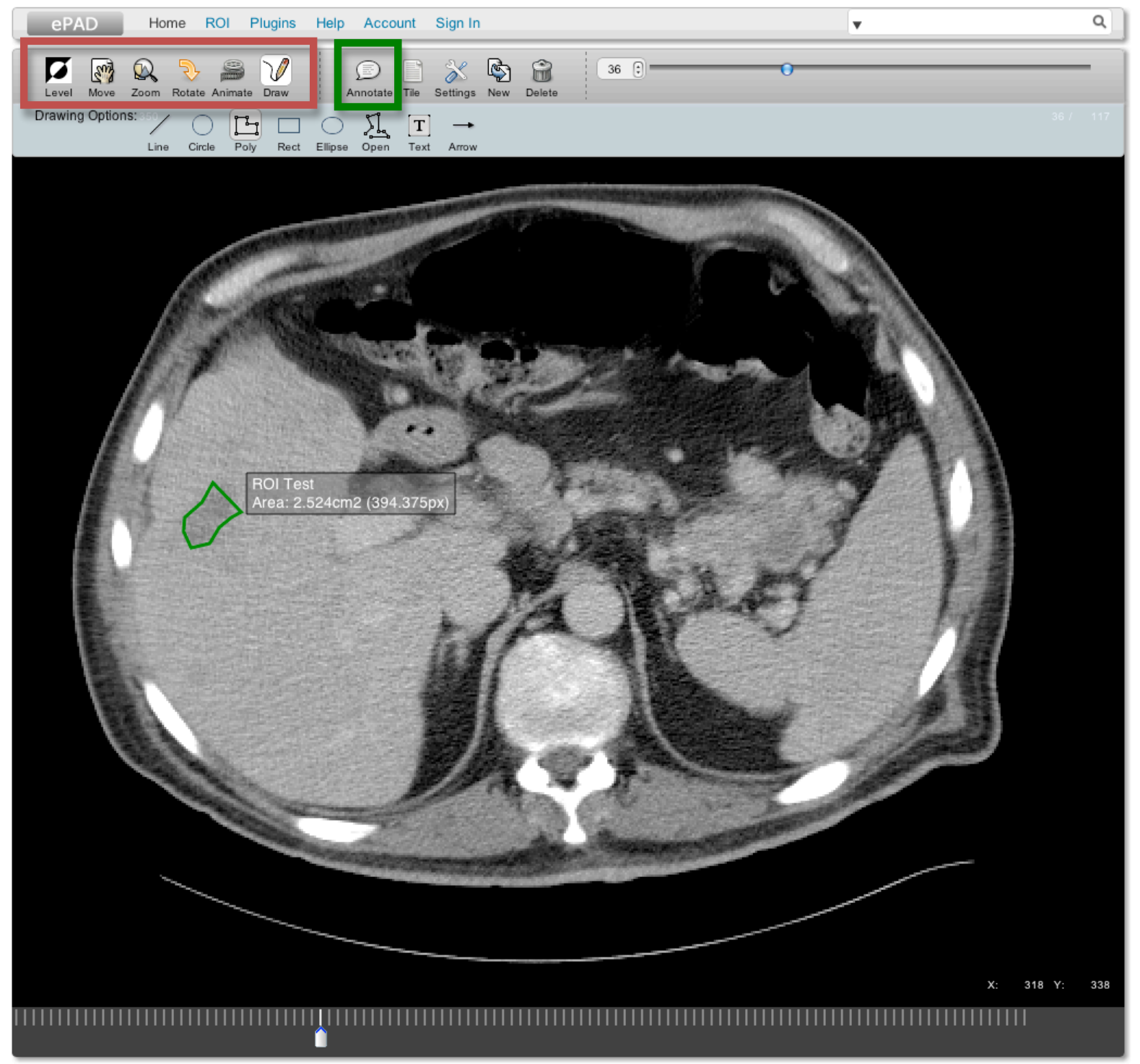

Help Center About Blog Connect Academic Solutions Tools Mobile Developers Publishers My Account

Figura 23 - Tela com o Widget de visualização de imagem do ePAD

Depois de localizar e marcar a lesão (ou lesões) como um ROI, o usuário iniciará a criação de suas anotações através do botão Annotate, marcado com um retângulo verde na Figura 23. Ao clicar em um determinado ROI, o sistema mostrará o pop-up de anotação, apresentado na Figura 24. 


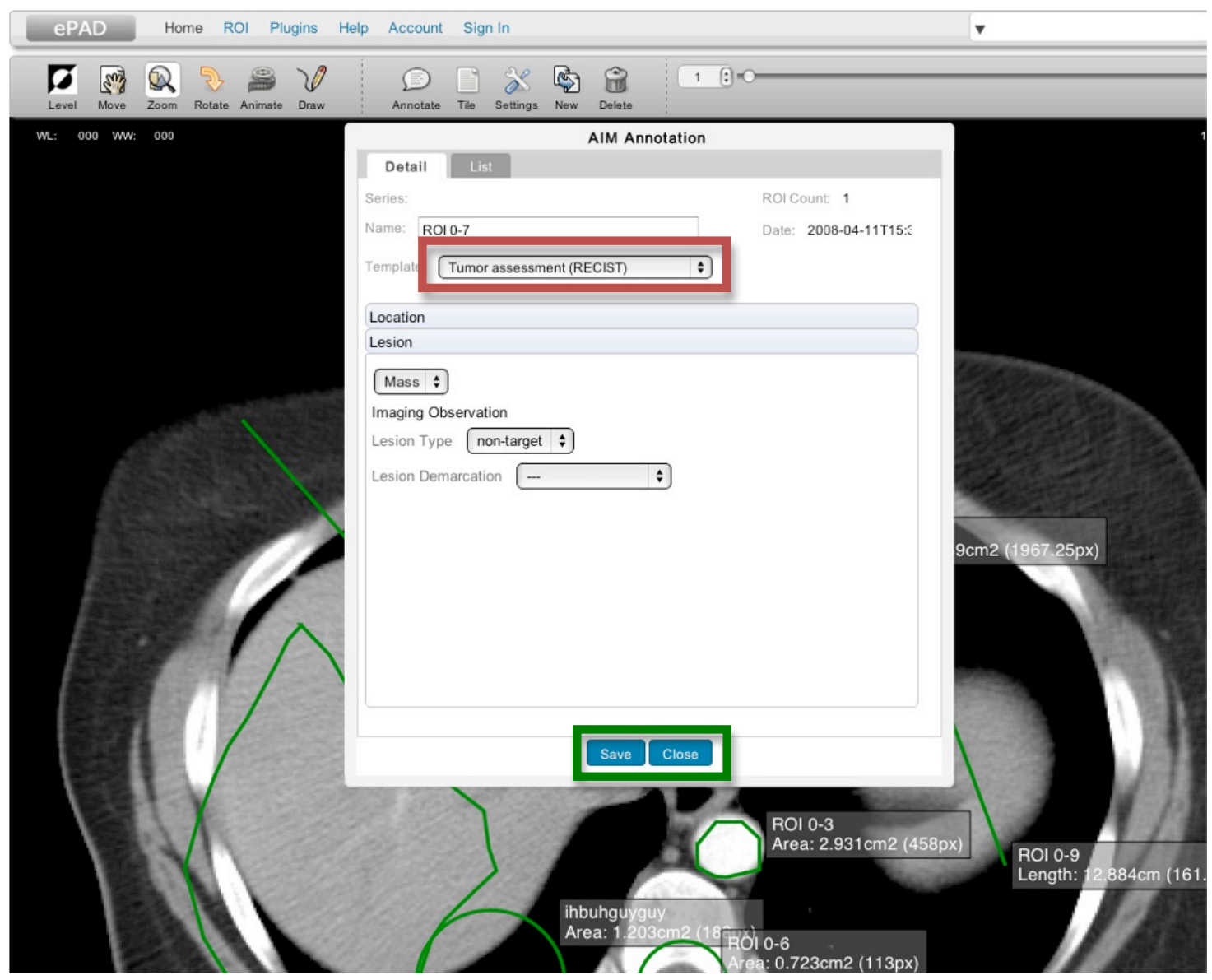

Figura 24 - Tela principal do protótipo (ePAD)

O pop-up apresentado na Figura 24 mostra os campos da template AIM RECIST. No ePAD, os arquivos XML dos templates AIM são armazenados e recuperados do Proxy. Ao entrar no pop-up de anotação, o usuário deverá selecionar o template que irá usar para realizar a anotação. Na Figura 24 existe um retângulo em vermelho indicando o widget com os templates disponíveis para a criação das anotações. É possível ter apenas um template ou um conjunto de templates.

Depois de completar suas anotações, o usuário salva a anotação através do botão "save" mostrado no retângulo verde da Figura 24. O ePAD enviará a anotação para o Proxy, que irá armazenar o arquivo AIM XML junto com os demais arquivos XML das anotações anteriores. No final do processo, assim nas outras ferramentas (AIM ClearCanvas e AIM iPAD), as imagens permanecem inalteradas e separadas das anotações AIM (que usam os DICOM UIDs das imagens para apontarem de volta para elas).

\subsection{Estudo de caso: RSNA 2011}

A Radiological Society of Noth America (RSNA) é promotora de um encontro anual (97th Scientific Assembly and Anual Meeting of the Radiology Society of North America), em 2011, 
que foi em Chicago, EUA. Nesse evento, nós e a equipe do LII - Stanford criamos uma versão do protótipo do ePAD que foi apresentada num stand da seção de Education Exhibits onde o pessoal do LII - Stanford convidou usuários potenciais finais que estavam no evento a experimentarem o ePAD e realizou entrevistas com eles. Seguem alguns dos feedback mais importantes dessas entrevistas:

- Como os usuário podem definir seus próprios templates (AIM Template Builder)? [a caBIG esta desenvolvendo um ferramenta para criação das templates ${ }^{5}$;

- Como os médicos irão acessar estas informações?;

- Privacidade das anotações, radiologistas podem não querer que outros colegas vejam suas anotações e que controlem o acesso as mesmas;

- Adição de um plugin para calcular a dosagem de medicamentos do paciente. Os radiologistas precisam olhar para a dose cumulativa de um paciente antes de decidir pedir outro exame;

- Acesso livre ao código fonte do ePAD;

- O cachê das imagens localmente pode não funcionar em relação a grande quantidade de imagens cacheadas. O servidor poderia servir as imagens em tempo real e em JPEG.

- Interesse de visualizar imagens de laminas de microscópio. Algumas imagens desta modalidade podem ter até 2 gigabytes de tamanho devido a sua alta resolução;

- Muitos radiologistas ainda não entendem as razoes e benefícios de usar o padrão AIM para realizar as anotações;

- Pesquisadores da Bélgica se interessaram em cooperar com o projeto ePAD;

- Pesquisadores da Yale University se interessaram em adotar a ferramenta, quando concluída, para realizar anotações radiológicas;

- Radiologistas indicaram interesse em ferramentas de auto segmentação da imagem para tornar o ePAD mais atraente para eles;

- Desenvolvedores do Raster Images $^{6}$ se interessaram na ferramenta. Atualmente eles desenvolvem uma ferramenta, Oviyam $^{7}$, que ainda não possui a funcionalidade de anotação radiológica, mas se interessaram no padrão AIM para realizar essas anotações.

\footnotetext{
${ }^{5}$ https://tracker.nci.nih.gov/browse/AIMES/component/10392

${ }^{6} \mathrm{http}: / / \mathrm{www}$. raster.in

${ }^{7}$ http://www.dcm4che.org/confluence/display/OV/Home
} 
Eles também mostraram algumas preocupações:

- Preocupações sobre como se dá a ligação direta do ePAD aos PACS;

- Preocupações sobre o tempo de transferência das imagens dos PACS ao ePAD;

- Preocupações de segurança e acesso aos arquivos contendo as anotações;

- Preocupações sobre a quantidade de clicks de mouse necessários para que os usuários realizarem uma anotação (eles querem minimizar esse esforço ao máximo);

- Preocupações sobre a visualização insegura das imagens DICOM na Web. Os arquivos de imagens médicas no formato JPEG podem não ter resolução para visualizar detalhes das imagens em relação aos arquivos no formato DICOM;

\subsection{Considerações finais}

No decorrer do desenvolvimento dos protótipos do ePAD houveram mudanças e melhorias nas interfaces e funcionalidades do sistema, o que demonstra o quão ativo foi o projeto e as constantes interações com os usuários do ePAD.

O lado do servidor do ePAD, o Proxy API, foi capaz de se conectar ao servidor PACS (dcm4chee) e se comunicar com o lado cliente usando RESTful. Isso permitiu ao lado cliente do ePAD se integrar com o PACS de forma transparente, ou seja, as implementações realizadas no lado do Proxy Serve não se preocupam com as peculiaridades de comunicação que os PACS podem ter, um dos objetivos desse trabalho.

O lado cliente do ePAD tem funcionalidades semelhantes ao OsiriX-iPAD e ClearCanvas para edição de anotações mas sem ter o overhead de ser uma aplicação desktop com vários outras funcionalidades e botões que não tem nada haver com anotações. Também um dos objetivos desse trabalho.

A avaliação com os usuários finais no evento do RNSA foi de muita importância, pois nos ajudou a elaborar o plano de trabalho para a primeira versão do ePAD (1.0), marcada para junho de 2012. 


\section{Conclusões}

As formas tradicionais de elaboração de anotações de imagens médicas não garantem uma anotação completa com dados qualitativos e quantitativos sobre lesões cancerígenas. Padrões de anotação semântica surgiram como resposta a necessidade de criação desse tipo de anotações em imagens médicas. As ferramentas atuais de anotação semântica possuem limitações técnicas, dentre elas a necessidade de sistemas operacionais específicos para executarem. Outro fato importante é a falta de uma integração transparente com os repositórios de anotações, como o BIMM, que depende ainda da intervenção do usuário.

Os radiologistas necessitam de uma ferramenta simples, mas completa, para realizar as anotação semântica de imagens médicas de forma mais eficiente.

O objetivo principal desse trabalho foi desenvolver (e explorar) tecnologias Web interativas para criação de anotações semânticas em imagens médicas numa ferramenta simples e integrada com PACS. Esse objetivo foi atingido através do ePAD. Seu primeiro protótipo funcional (apresentado no congresso da RSNA) (Snyder et al., 2011) demonstrou a sua viabilidade técnica: Ele foi capaz de executar o mesmo trabalho básico de anotação de aplicações desktop, como o OsiriX-iPad, sem o mesmo overhead e utilizando apenas HTML, CSS e JavaScript, provando a viabilidade de uma ferramenta deste porte usando essas tecnologias. É importante lembrar que o ePAD usa tecnologias muito recentes, como o HTML 5 , e a 1 ano e meio atrás uma aplicação como o ele seria impossível. Por isso demonstrar sua viabilidade técnica é muito importante.

Por último, o ePAD também mostrou a sua utilidade a comunidade médica o que gerou o interesse de usuários potenciais. A versão 1.0 do ePAD sairá em julho próximo e conta com a colaboração do ACRIN - American College of Radiology Image Network.

\subsection{Contribuições Específicas}

A seguir são listadas algumas contribuições específicas do ePAD: 


\subsubsection{Visualização de imagens DICOM}

Para anotar imagens médicas foi necessário desenvolver um visualizador de imagens médicas para Web. O nosso visualizador pode carregar imagens médicas no formato DICOM e modifica-las em tempo real o Window/Level. O ePAD permite que o usuário navegue pelas fatias das imagens DICOM, abrindo até grandes série de imagens DICOM de uma só vez.

\subsubsection{Criação e edição de ROIs}

Desenvolvemos uma interface visual em duas dimensões para que o usuário pudesse demarcar seus ROIs. O ePAD permite que o usuário crie formatos simples, como retângulos, elipses e polígonos (aberto e fechado).

\subsubsection{Criação de anotações AIM}

O objetivo principal do sistema foi desenvolver uma ferramenta de anotação no formato AIM. O ePAD suporta os AIM templates para criação de anotações AIM e relaciona os ROI a estas anotações.

\subsection{Publicações e Prêmios relacionados ao trabalho}

Como resultados deste trabalho, foram aceitos para publicação os seguintes trabalhos:

Artigo publicado no RSNA 97th Scientific Assembly \& Annual Meeting, 2011 International Conference on Enterprise Information Systems : "ePAD: A Cross-Platform Semantic Image Annotation Tool for Quantitative Imaging” (SNYDER, A.; WILLRETT, D.; MOREIRA, D. A.; SERIQUE, K. J. A.; MONGKOLWAT, P.; SEMESHKO, V.; RUBIN,D.L., 2011);

Artigo publicado no 5th Web2Touch - Modeling the Collaborative Web Knowledge. WETICE 2012: "Using the Semantic Web and Web Apps to Connect Radiologists and Oncologists" (SERIQUE, K. J. A.; SNYDER, A.; WILLRETT, D.; RUBIN, D. L e MOREIRA D.A., 2012);

Artigo publicado no WebMedia 2011 - Simpósio Brasileiro de Sistemas Multimídia e Web - Workshop de Ferramentas e Aplicações (WFA) : "Ferramenta web para visualização e composição de regras SWRL" (RIVOLLI, A. ; ORLANDO, J. P. ; SERIQUE, K. J. A. ; MOREIRA, D. A., 2011); 
Prêmio de melhor ferramenta do X Workshop de Ferramentas e Aplicações do XVII Simpósio Brasileiro de Sistemas Multimídia e Web : "Ferramenta web para visualização e composição de regras SWRL" (RIVOLLI, A. ; ORLANDO, J. P. ; SERIQUE, K. J. A.; MOREIRA, D. A., 2011);

\subsection{Trabalhos Futuros}

Com a disponibilização de novas tecnologias Web nos navegadores mais populares, através do HTML5, se tornou possível a exploração de novos paradigmas de interação com imagens médicas permitindo, por exemplo, a sua anotação de forma colaborativa. Quais as melhores soluções em HCI para essa nova área ainda é uma questão aberta e importante pois afeta como aplicações na área de informática biomédica serão desenvolvidas no futuro.

Estes trabalhos futuros envolvem a criação de novos algoritmos e interfaces para anotação semântica colaborativa online de imagens médicas. Os objetivos para os trabalhos futuros são divididos em etapas a seguir:

1 - Estudo e desenvolvimento de novas Interfaces de Usuário para imagens médicas na Web (remodelando, quando possível, interfaces já existentes de PACs para as condições online). O contexto Web é relativamente novo para o cumprimento dos requisitos de aplicações radiológicas. Por exemplo, a visualização de imagens médicas na Web, em 2D e 3D, ainda é considerada uma novidade recente devido a novas tecnologias Web, como o HTML5, Canvas e WebGL.

2 - Desenvolver interfaces entre as tecnologias de armazenamento e gerenciamento de imagens (PACS) e padrões médicos (DICOM) para o funcionamento via Web. As séries de imagens, como de Computed Tomography (CT) e Magnetic Resonance Imaging (MRI), possuem um grande volume de dados e a sua transferência do servidor para o cliente pode implicar em longos períodos de espera e consumo de banda na rede, isso prejudica a agilidade e rapidez de um sistema baseado na Web. Estratégias devem ser estudas e elaboradas para amenizar o impacto do carregamento dessas imagens no tempo de resposta das interfaces.

3 - Estudos e desenvolvimento de metáforas de interação Web para o gerenciamento de ROI em contextos 2D e (mais recentemente) 3D, explorando as potencialidades do ambiente de aplicação na Web e contornando suas limitações técnicas. A possibilidade de manipulação de imagens 2D e 3D na Web é algo recente. 
4 - Teste e adaptação dos modelos de interação propostos (passo 3) para que sejam também compatíveis com os mais recentes dispositivos sensíveis ao toque, como tablets PCs (13 polegadas ou mais) e desktops com telas sensíveis ao toque. Eles devem ser testados e a interface ajustada para que não prejudiquem a usabilidade em sistemas sensíveis ao toque, sem comprometer sua usabilidade em ambientes tradicionais. Nesses novos dispositivos, alguns componentes (e tipos de interação) do modelo tradicional de Interface do Usuário para Web não serão apropriados, como, por exemplo, o modelo de menus drop-down e alguns tipos de formulários.

Como objetivo secundário espera-se ajudar a solidificar a integração entre o ICMC-USP e o Lab. of Imaging Informatics (LII) - Stanford University, pois esse trabalho, o ePad, está sendo desenvolvido em conjunto e é financiado (parte americana) pelo U.S. National Institutes of Health (NIH), pela grant do National Cancer Institute (NCI): U01 CA142555 Computerized Quantitative Imaging Assessment of Tumor Burden. O LII está trabalhando na criação da arquitetura geral do ePad, na parte do servidor que se comunica com os PACs comerciais e no backend para armazenar as anotações em AIM. Existem também outros colaboradores: Dr. P. Mongkolwat (Radiology - Northwestern University) trabalhando no desenvolvimento da linguagem AIM e o ACRIN (American College of Radiology) na avaliação da ferramenta. Existe muita comunicação entre os grupos, por exemplo, nós estamos colaborando com sugestões (derivadas da interação dos usuários "beta" com nossa interface) para a próxima versão da AIM (versão 4). Essa integração também abre a possibilidade de um doutorado sanduíche na Stanford University. 


\section{Referências}

Almeida, AGC; Bortolon, S; Berger, M e Seibel Junior, H. 2008. Integração de pacs software livre em aplicações médicas: Gerenciamento de pesquisas clínicas multicêntricas e de prontuários digitalizados. In: Sociedade Brasileira de Computação. WIM - Workshop de Informática Médica. Belém, PA, Brazil: SBC2008 - XVIII Congresso da SBC. p. 235-238.

Almeida, M. B. e Bax, M. P. 2003. Uma visão geral sobre ontologias: pesquisa sobre definições, tipos, aplicações, métodos de avaliação e de construção. Ci. Inf., Brasília, v. 32, n. 3, 7-20. DOI $=10.1590 / \mathrm{S} 0100-19652003000300002$.

Barra FR, Barra RR e Sobrinho AB. 2010. Visualizadores de imagens médicas gratuitos: é possível trabalhar apenas com eles?. Radiol Bras. Vol. 43 n 5 - Set. / Out. de 2010. Páginas 313 a 318.

Berners-Lee, T., Hendler, J. e Lassila, O. 2001. The Semantic Web. Scientific American, 34 43, http://www.scientificamerican.com/article.cfm?id=the-semantic-web, acesso em Jan. 2011.

Bernstam, EV, Smith JW e Johnson TR. 2010. What is biomedical informatics?. Journal of Biomedical Informatics, Volume 43, Issue 1, February 2010, Paginas 104-110.

Breitman, K.K.. 2005. Web Semântica: a internet do futuro. LTC, Rio de Janeiro. ISBN 85216-1466-7

Bui AAT e Morioka C. 2010. Information Systems \& Architectures. Chapter 3. Medical Imaging Informatics. 1 Edição, Springer. Paginas 115-170. Hardcover ISBN: 978-1-44190384-6.

Bui AAT e Taira, RK, (Editors). 2010. Medical Imaging Informatics. 1 Edição, Springer, 446p., Hardcover ISBN: 978-1-4419-0384-6. 
Cooper R e Collins C. 2008. GWT in Practice. Manning Publications Co. 376 pages. ISBN: 1933988-29-0.

DICOM. 2009. The DICOM Standard. Technical report. ftp://medical.nema.org/medical/dicom/2009/, acesso em Jan. 2011.

Eisenhauer EA, Therasse P, Bogaerts J, Schwartz LH, Sargent, D, Ford R, Dancey J, (...), Verweij J. 2009. New response evaluation criteria in solid tumours: Revised RECIST guideline (version 1.1). European Journal of Cancer. Volume 45, Issue 2, January 2009, Pages $228-247$.

Gibaud B. 2011. The quest for standards in medical imaging. European Journal of Radiology. Pages 190-198.

Grau, B C, Horrocks, I, Motik, B, Parsia, B; Patel-Schneider, P e Sttaler, U. 2008. OWL2: The Next Step for OWL. Web Semantics: Science, Services and Agents on the World Wide Web. Volume 6, Issue 4, November 2008, Pages 309-322. Semantic Web Challenge 2006/2007. doi:10.1016/j.websem.2008.05.001.

Gruber, T. R. 1993. A translation approach to portable ontology specifications. Knowl. Acquis. 5(2), 199-220. DOI= http://dx.doi.org/10.1006/knac.1993.1008.

Guizzardi, G. . Theoretical foundations and engineering tools for building ontologies as reference conceptual models. Semantic Web Journal, v. 1, p. 3-10, 2010.

Horridge, M., Knublauch, H., Rector, A., Stevens, R. e Wroe, C. 2004. A practical guide to building OWL ontologies using the protégé-OWL plugin and CO-ODE tools edition 1.0. Technical report, University OfManchester. http://www.co-ode.org/resources/, acesso em Dez. 2010.

Horrocks, I. P., Patel-Schneider F. e Van Harmelen F.. 2003. From SHIQ and RDF to OWL: The Making of a Web Ontology Language, Journal of Web Semantics 1 (1) 7-26. 
Huang HK. 2010. PACS and Imaging Informatics: Basic Principles and Applications. 2 edição revisada. ISBN: 978-0-470-37372-9.

Huang, HK. Pacs and Imaging Informatics: Basics Principles and Applications. John Wiley and Sons, Inc., Hoboken, New Jersey, 2004.

Institute of Medicine (2003) Key capabilities of an electronic health record system. The National Academies Press. http://www.nap.edu/catalog.php?record_id=10781. Acessado em 3 março de 2011.

Jaffe TA, Wickersham NW, Sullivan DC. Quantitative imaging in oncology patients: Part 1. Radiology practice patterns at major U.S. cancer centers. AJR Am J Roentgenol. 2010;195:101Y106.

James Philbin, Fred Prior and Paul Nagy. 2011. Will the Next Generation of PACS Be Sitting on a Cloud?. Journal of Digital Imaging, 2011, Volume 24, Number 2, Pages 179-183

Kereki F. 2011. Building for the Web with Google Web Toolkit 2. Pearson Education. ISBN13: $978-0-321-70514-3$.

Kereki, F. 2011. Essential GWT: Buinding for the Web with Google Web Toolkit 2. AddisonWesley, Pearson Education. Boston, USA, ISBN-13 9878-0-321-70514-3.

Koutelakis GV e Lymperopoulos DK. 2006. Pacs through web compatible with dicom standard and wado service: Ad- vantages and implementation. Proceedings of the 28th IEEE EMBS Annual Inter- national Conference, p. 2601-2605, Sept 2006. New York City, USA.

Kundu S, Itkin M, Gervais DA, Krishnamurthy VN, Wallace MJ, Cardella JF, Rubin DL and Langlotz CP, 2009. The IR RadLex project: an interventional radiology lexicon--a collaborative project of the Radiological Society of North America and the Society of Interventional Radiology. J Vasc Interv Radiol 20(4): 433-5.

Langlotz, CP. 2006. RadLex: A New Method for Indexing Online Educational Materials. RadioGraphics 2006; 26:1595-1597. doi: 10.1148/rg.266065168 November 2006. 
Levy MA and Rubin DL, Computational approaches to assist in the evaluation of cancer treatment response. Imaging in Medicine 3(2): 233-246, 2011.

Maedche A e Staab S. 2001. Ontology Learning for the Semantic Web. Journal IEEE Intelligent Systems archive. Volume 16 Issue 2, March 2001. Doi 10.1109/5254.920602.

Mejino JLV, Rubin DL, Brinkley JF. 2008. FMA RadLex: An Application Ontology of Radiological Anatomy derived from the Foundational Model of Anatomy Reference Ontology. Proc. AMIA Symp. Washington DC pp465-469.

Moreira DA e Musen MA. 2007. OBO to OWL: a Protégé OWL tab to read/save OBO $\begin{array}{lllllll}\text { ontologies. } & \text { Bioinformatics (Oxford), } & \text { v. 23, p. 1868-1870, }\end{array}$ http://dx.doi.org/10.1093/bioinformatics/btm258.

Moreira DA, Mungall C, Nigam S, Stuart A, Richter JD, Redmond, T e Musen, M. 2009. The $\mathrm{NCBO}$ OBOF to OWL Mapping. Available from Nature Precedings $<$ http://hdl.handle.net/10101/npre.2009.3938.1>

Motik B, Grau BC, Horrocks I, et al. 2009. OWL 2 web ontology language: Profiles. W3C working draft, W3C, http://www.w3.org/TR/ow12-profiles/, acesso em Dez 2010.

Noy, N. F. e McGuinness, D. L. 2001. Ontology Development 101: A Guide to Creating Your First Ontology. Stanford Knowledge Systems Laboratory Technical Report KSL-01-05.

OBO. 2008. About the OBO Foundry. Disponível http://obofoundry.org/about.shtml. Acessado maio de 2010.

Patel-Schneider, P. F., Hayes, P. e Horrocks, I.. 2004. OWL Web Ontology Language Semantics and Abstract Syntax, W3C Recommendation (10 February 2004).

Pollock, J. 2009. Web Semantic for Dummies. Wiley Publishing. Indianápolis, USA. ISBN: 978-0-470-39679-7 
Potel M. 1996. MVP: Model-View-Presenter The Taligent Programming Model for C++ and Java. Taligent. Relatório técnico. Disponível em: http://www.wildcrest.com/Potel/Portfolio/mvp.pdf. Acessado fev de 2012.

Prior FW, Erickson BJ e Tarbox L. 2007. Open Source Software Projects of the caBIG ${ }^{\mathrm{TM}}$ In Vivo Imaging Workspace Software Special Interest Group. J Digit Imaging. 2007 November; 20(Suppl 1): 94-100. doi: 10.1007/s10278-007-9061-4

Ramsdale C. 2010. Large scale application development and MVP. Disponível em: https://developers.google.com/web-toolkit/articles/mvp-architecture. Ultimo acesso maio de 2011.

RNSA. 2012. What is RadLex? Technical report. http://www.rsna.org/Informatics/radlex.cfm, acesso em Fev. de 2011.

Rosse, C e Mejino, JLV (2007) The Foundational Model of Anatomy Ontology. Capitulo 4. Anatomy Ontologies for Bioinformatics Anatomy Ontologies for Bioinformatics. ISBN 978$1-84628-884-5$.

Rosset, A; Spadola, L e Ratib, O. 2004. OsiriX: An Open-Source Software for Navigating in Multidimensional DICOM Images. Journal of Digital Imaging. Volume 17, Number 3, $205-$ 216, DOI: $10.1007 / \mathrm{s} 10278-004-1014-6$

Rubin DL, Mongkolwat P, Kleper V, Supekar K and Channin DS. 2008a. Medical Imaging on the Semantic Web: Annotation and Image Markup. In: 2008 AAAI Spring Symposium Series, Semantic Scientific Knowledge Integration, Stanford University.

Rubin DL, Rodriguez C, Shah P, Beaulieu C. 2008b. iPad: Semantic Annotation and Markup of Radiological Images. AMIA Annu Symp Proc. 2008: 626-30.7. http://protege.cim3.net/cgibin/wiki.pl?XMLMasterPlugin.

Rubin DL, Shah NH e Noy NF. 2008c. Biomedical ontologies: a functional perspective. Brief Bioinform 9(1): 75-90. 
Shah, N. H. e Musen, M. A. 2007. Which Annotation did you mean? Technical report, Stanford Center for Biomedical Informatics Research. http://bmir.stanford.edu/publications/view.php/which_annotation_did_you_mean, acesso em Dez. 2010.

Shah, S. 2008. Web 2.0 Security: Defending Ajax, RIA and SOA. Course Technology, Boston, USA. ISBN-13: 978-1-58450-550-1.

Silva LB, Costa C e Oliveira JL. 2011. A PACS archive architecture supported on Cloud services. International Journal of Computer Assisted Radiology and Surgery, June.

Snyder, A.; Willrett, D.; Moreira, D. A.; Serique, K. J. A.; Mongkolwat, P.; Semeshko, V.; Rubin,D.L., 2011. ePAD: A Cross-Platform Semantic Image Annotation Tool for Quantitative Imaging. RSNA 97th Scientific Assembly \& Annual Meeting, 2011.

Smith B, Ashburner M, Rosse C, Bard J, Bug W, Ceusters W, Goldberg LJ, Eilbeck K, Ireland A, Mungall CJ, The OBI Consortium, Neocles Leontis, Rocca-Serra, P., Ruttenberg, A., Sansone, S. A., Scheuermann, R. H., Shah, N., Whetzel , P. L. e Lewis, S. 2007. The OBO Foundry: coordinated evolution of ontologies to support biomedical data integration. Nature Biotechnology, 25, 1251-1255.

W3C. 2003. Resource Description Framework (RDF). Disponível http://www.w3.org/RDF/. Acessado maio de 2011. 


\section{Apêndice A - Questionário aplicado com usuários}

\section{Knowing your users}

What is your age range?

Until 20 years

21 - 25 years

26 - 30 years

31 - 35 years

36 - 40 years

46 - 50 years

Above 51 years

What is your area of expertise / knowledge?

Radiology

Oncology

computation

What is your background?

Undergraduate

MSc

Doctoral

Master

Doctor

Post Doctor

What is the Operating System of your

computer? (To use to annotate images)

Windows

Mac OS

Linux

I do not know inform

Other

What is your availability for internet access?

Home

Work
Mobile (use mobile networks)

Other

What is your daily time available to record medical images?

Less than 1 hour

1 - 2 hours

2 - 3 hours

3 - 4 hours

5 - 6 hours

Full-time

What is your experience with the standard Annotation and Image Markup (AIM)?

I know, but little used

Know and use a lot

Know little

Unknown

I will use in future works

What is your experience with the thermology RadLex?

I know, but little used

Know and use a lot

Know little

Unknown

I will use in future works

Which is the image annotation tool that you've used?

iPad

ClearCanvas

XIP

What are their difficulties in interacting with the interfaces of such tools as ipad? 


\section{Apêndice B - Resultados do questionário aplicado com usuários}

\section{Knowing your users}

What is your age range?

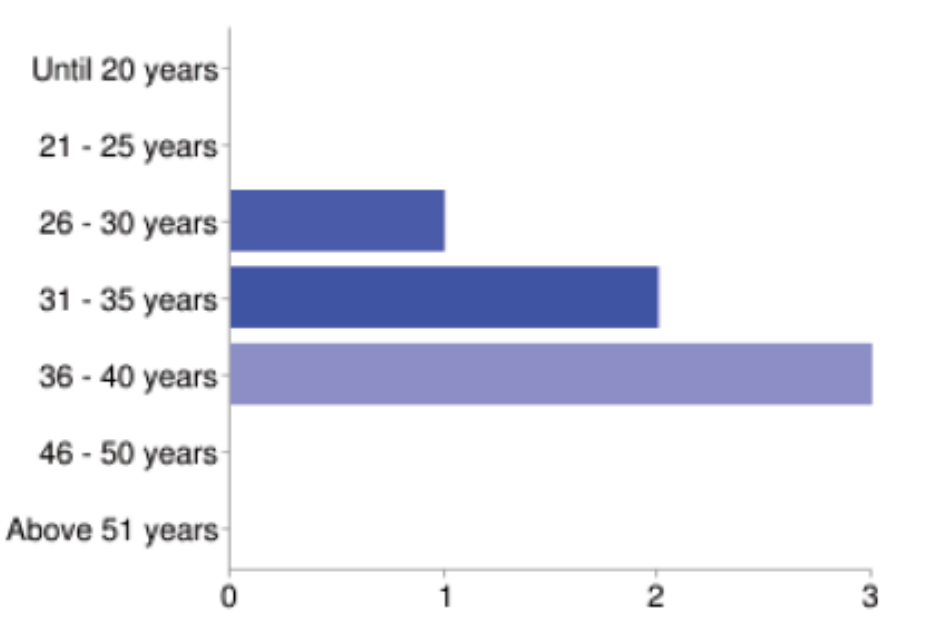

$\begin{array}{llr}\text { Until } 20 \text { years } & \mathbf{0} & 0 \% \\ 21-25 \text { years } & \mathbf{0} & 0 \% \\ 26-30 \text { years } & \mathbf{1} & 17 \% \\ 31-35 \text { years } & \mathbf{2} & 33 \% \\ 36-40 \text { years } & \mathbf{3} & 50 \% \\ 46-50 \text { years } & \mathbf{0} & 0 \% \\ \text { Above } 51 \text { years } & \mathbf{0} & 0 \%\end{array}$

What is your area of expertise / knowledge?

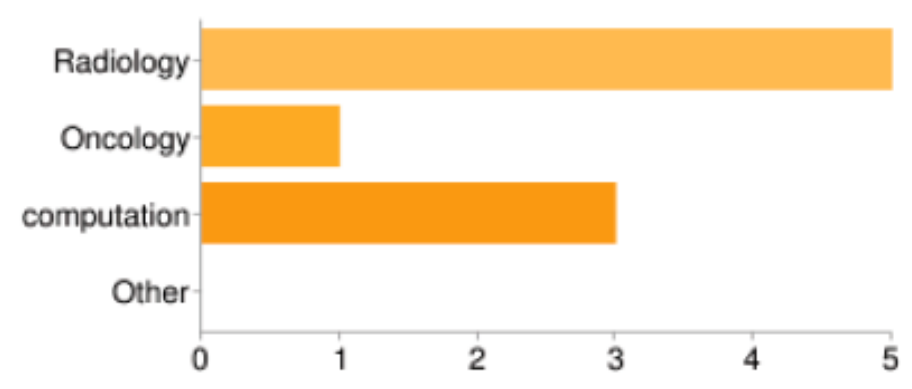

$\begin{array}{llr}\text { Radiology } & \mathbf{5} & 83 \% \\ \text { Oncology } & \mathbf{1} & 17 \% \\ \text { computation } & \mathbf{3} & 50 \% \\ \text { Other } & \mathbf{0} & 0 \%\end{array}$

As pessoas podem marcar mais de uma caixa de seleção, então a soma das percentagens pode ultrapassar $100 \%$.

What is your background?

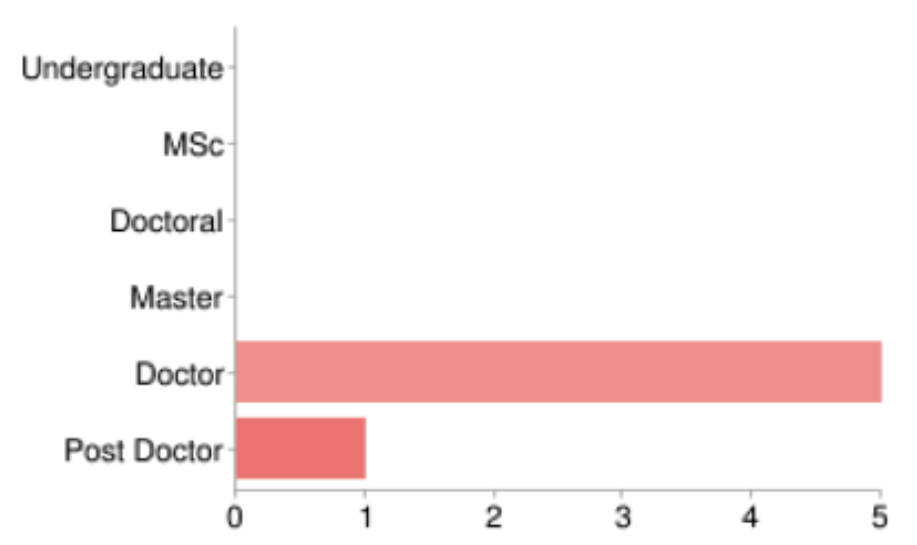

$\begin{array}{llr}\text { Undergraduate } & \mathbf{0} & 0 \% \\ \text { MSc } & \mathbf{0} & 0 \% \\ \text { Doctoral } & \mathbf{0} & 0 \% \\ \text { Master } & \mathbf{0} & 0 \% \\ \text { Doctor } & \mathbf{5} & 83 \% \\ \text { Post Doctor } & \mathbf{1} & 17 \%\end{array}$


What is the Operating System of your computer? (To use to annotate images)

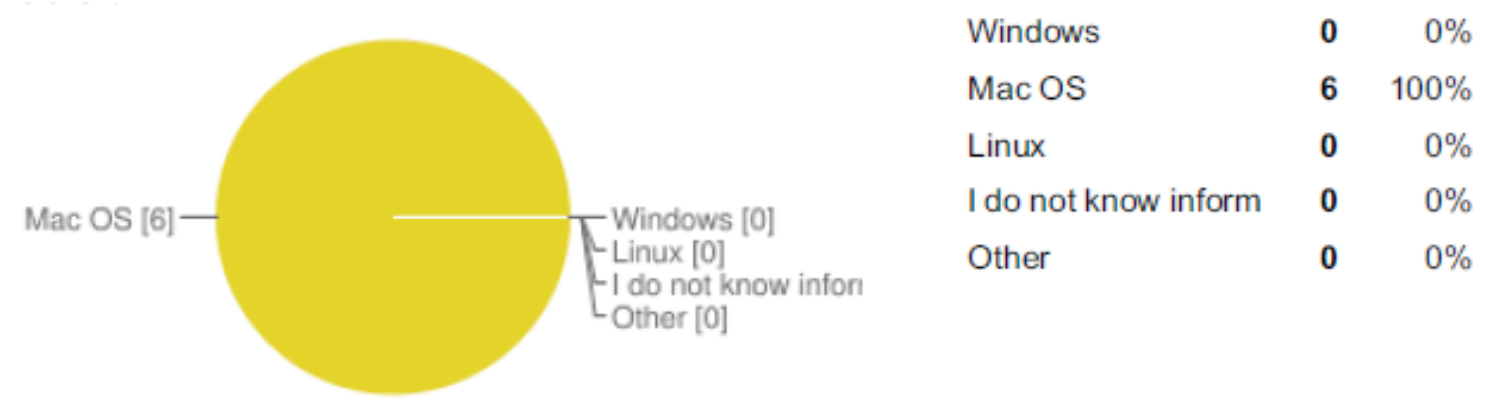

What is your availability for internet access?

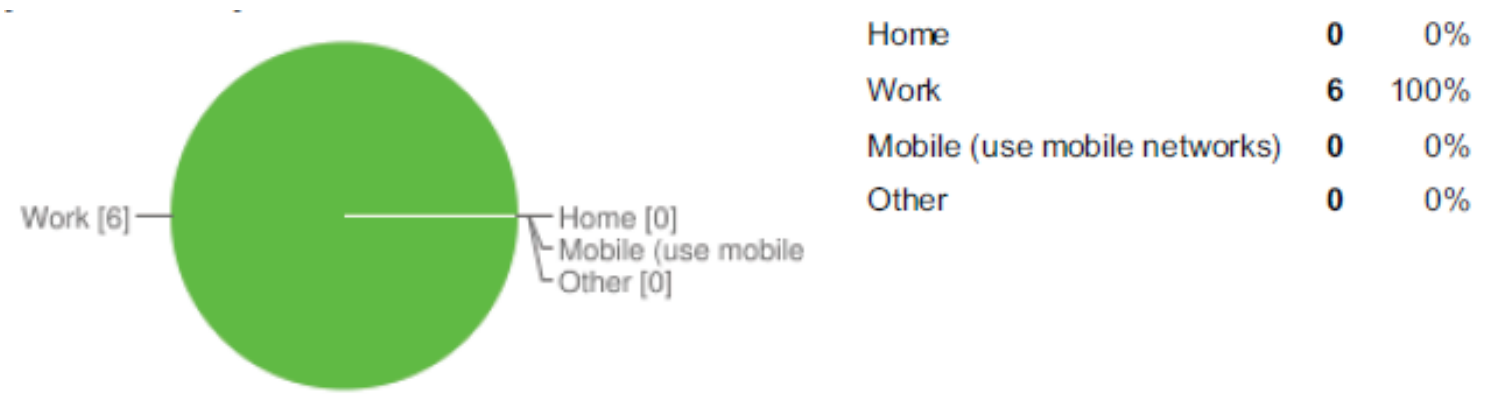

What is your daily time available to record medical images?

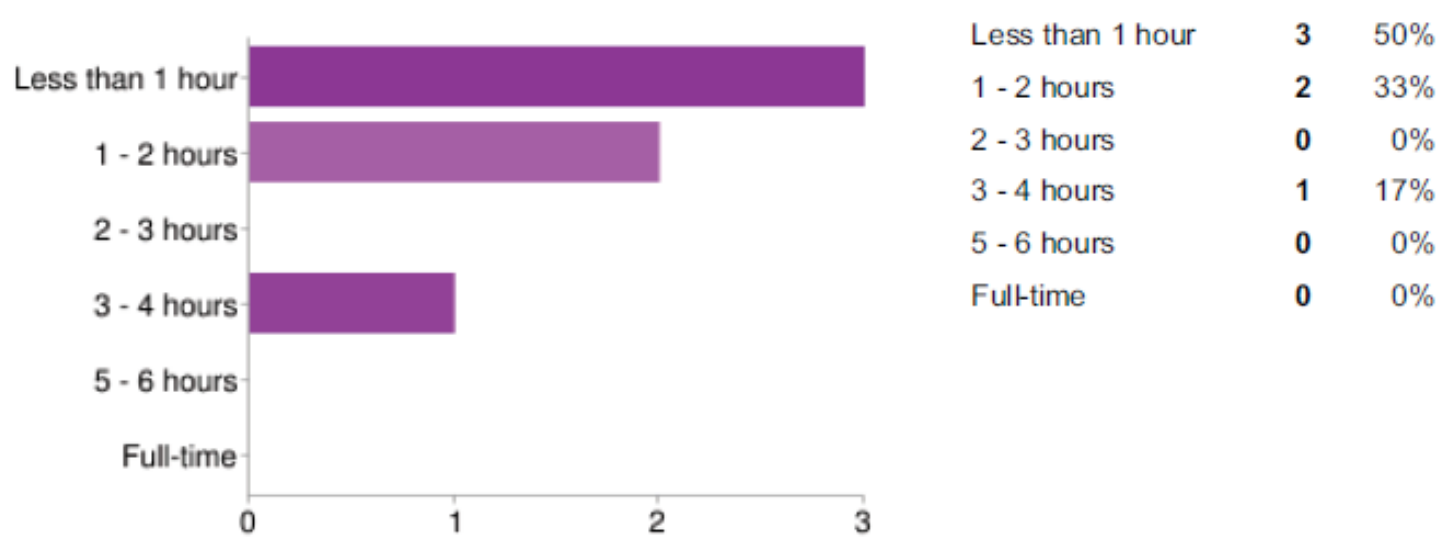

What is your experience with the standard Annotation and Image Markup (AIM)?

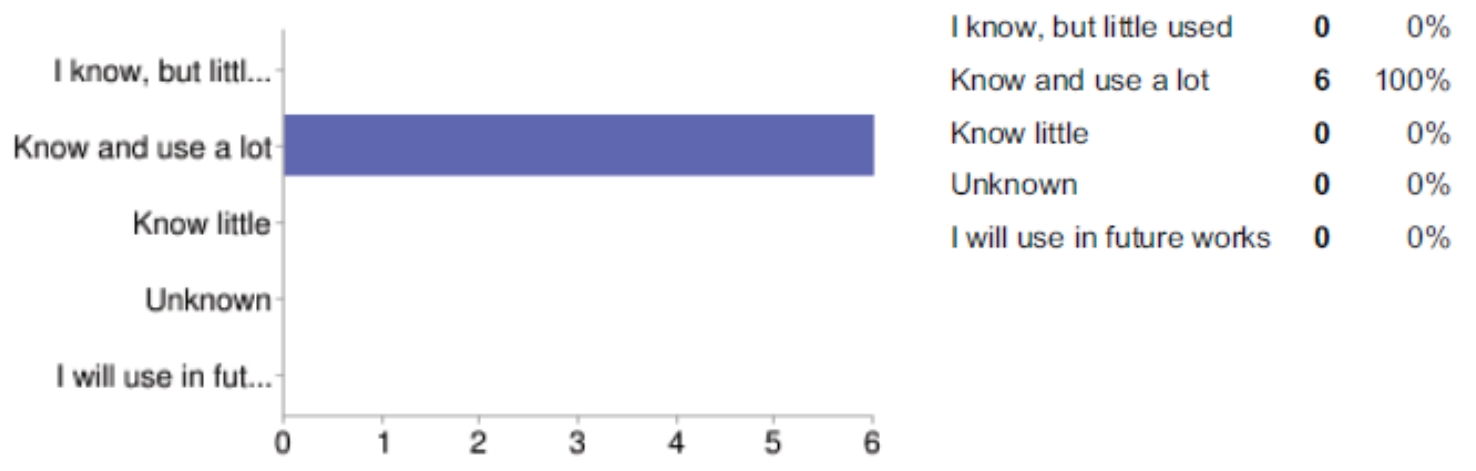


What is your experience with the thermology RadLex?

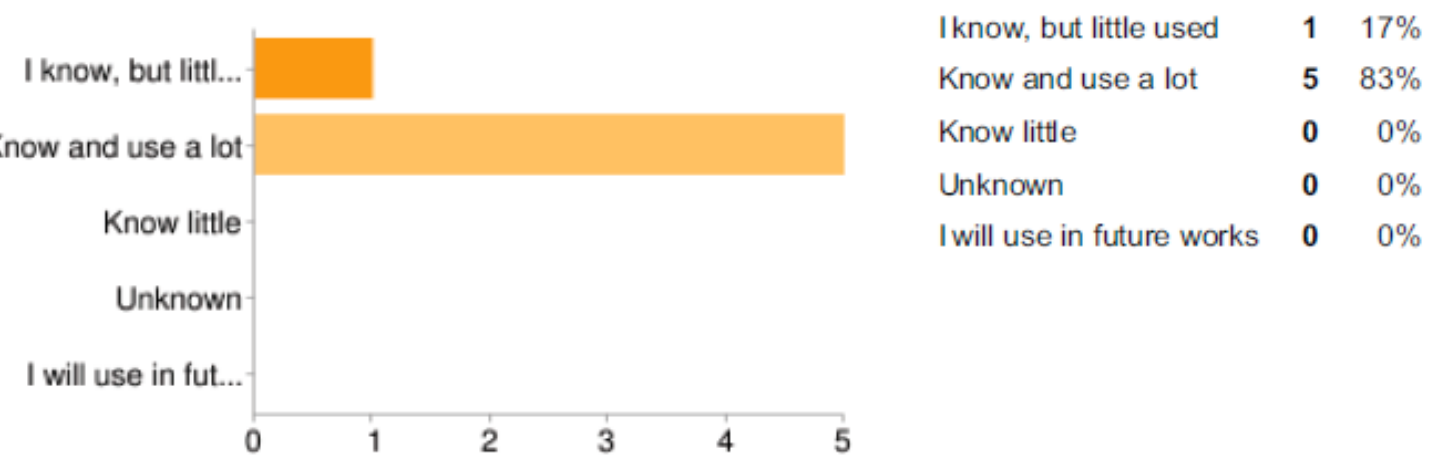

Which is the image annotation tool that you've used?

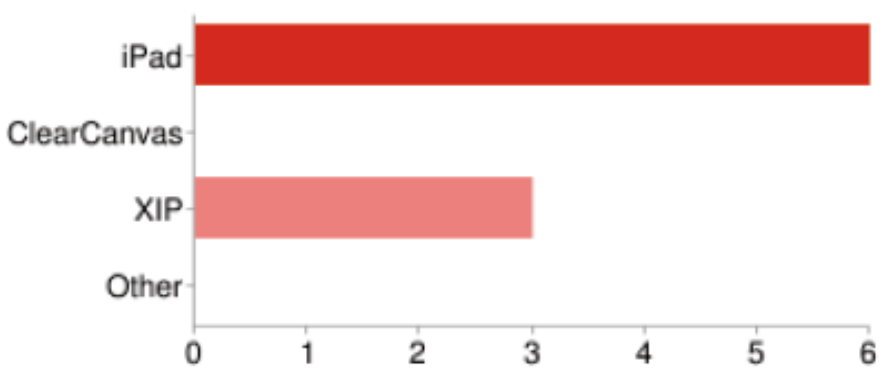

$\begin{array}{llr}\text { iPad } & \mathbf{6} & 100 \% \\ \text { ClearCanvas } & \mathbf{0} & 0 \% \\ \text { XIP } & \mathbf{3} & 50 \% \\ \text { Other } & \mathbf{0} & 0 \%\end{array}$

As pessoas podem marcar mais de uma caixa de seleção, então a soma das percentagens pode ultrapassar $100 \%$. 